\title{
DE TO THE MIGROSGOPIC
}

IMINATION OF THE EYE

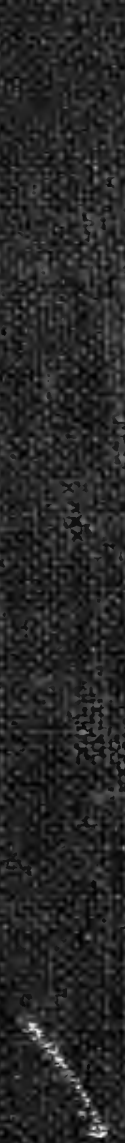

TRANSLATED BX

\section{HUGH WATKDR}




\section{Digitized by the Internet Archive in 2007 with funding from Microsoft Corporation}




GUIDE TO THE MICROSCOPIC EXAMINATION OF THE EYE. 

MEye
G

\title{
GUIDE
}

TO THE

\section{MICROSCOPIC EXAMINATION \\ OF THE EYE}

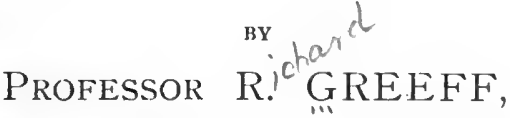

Director of the University Ophthalmic Clinique, in the Royal Charity Hospital, Berlin,

WITH THE CO-OPERATION OF

Professor STOCK and Professor WINTERSTEINER (FREIBUKG)

(VIENNA)

Translated from the Third German Edition

BY

HUGH WALKER, M.A., M.B., C.M., Ophthalmic Surgeon to the Victoria Infirmary, Glasgow.

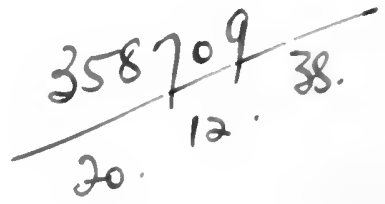

LONDON :

The Ophthalmoscope Press, Thayer Street, IV.

NEW YORK:

PAUL B. HOEBER, 69, EAST 59TH STREET. 



\section{PREFACE TO THE FIRST EDITION.}

I have published this work in response to oft-repeated demands.

It contains the essence of the instruction which I have been accustomed to give in my Microscopic Course, and an account of the methods which I have found to be most generally useful.

Every ophthalmologist who uses the microscope knows that the eye, in virtue of its peculiar form and composition, demands treatment differing in many respects from that sufficient for organs which are more consistent and uniform in structure, and the precise relation of whose parts it is less important to preserve. There are, more. over, certain processes which are adapted for the demonstration of ocular structures solely. Further, the technique involved in the division of the bulb calls for special consideration. Many important points are not discussed in the various excellent handbooks on microscopic work, and, although much may be learned from these regarding general methods, the eye, as a rule, is treated briefly. Here, for the first time, an attempt has been made to collect such matter as may prove specially useful to the ophthalmologist. I am well aware that many workers possess valuable information on certain points, which it has not been my fortune to acquire. Perhaps this book may contribute to a general knowledge of what is most serviceable. Any suggestion will be gratefully received.

At all events, this work is not a mere compilation; the methods described have in almost every instance been tested by myself.

Since the work is intended for students, I have purposely omitted many modifications of methods; it is sufficient to know a few processes thoroughly.

R. GREEFF.

BerLin,

August, I898. 



\section{PREFACE TO THE SECOND EDITION.}

THE early demand for a second edition shows that this modest work has served its purpose, and been accorded a kindly reception. I welcome, therefore, the opportunity I am afforded of making certain alterations and additions which have been suggested by my friends. For these suggestions I am grateful, and I shall still be pleased to receive such.

In other countries also my efforts appear to have been appreciated. The book has been translated into Japanese and English.

In its second edition the work is considerably larger. This increase in size was unavoidable, but I have striven to be brief, and to maintain the simple character of the book. The critics will bear in mind that $I$ have made no attempt at a complete treatment of the subject.

R. GREEFF.

BERLIN,

Oclober, 1900. 



\section{PREFACE TO THE THIRD EDITION.}

In this edition the contents of the book have been revised and brought up to date.

In order to utilise the experience of other cliniques the author has secured the services of Professor Stock, of Freiburg, and Professor Wintersteiner, of Vienna. He is indebted to these gentlemen for their suggestions and improvements, and he ventures to consider them as his collaborators in the new edition.

R. GREEFF.

BERLIN,

Deiember, 1910. 

xi.

\section{TRANSLATOR'S PREFACE.}

I venture to hope that this translation of Professor Greeff's "Guide" will be as well received as was that of the second edition. The work has appeared in serial form in the pages of The Ophthalmoscope, and I am indebted to Mr. Sydney Stephenson, the editor of that journal, for the interest he has taken in it and for the suggestions which he has made.

HUGH WALKER.

GLASGOW,

June, 1913. 



\section{CONTENTS.}

Preface to the First Edition

Preface to the Second Edition...

Preface to the Third Edition

Translator's Note

\begin{tabular}{cccccr} 
& & & & \multicolumn{2}{r}{ PAGE. } \\
$\ldots$ & $\ldots$ & $\ldots$ & $\ldots$ & $\ldots$ & v \\
$\ldots$ & $\ldots$ & $\ldots$ & $\ldots$ & $\ldots$ & in \\
$\ldots$ & $\ldots$ & $\ldots$ & $\ldots$ & $\ldots$ & ix \\
$\ldots$ & $\ldots$ & $\ldots$ & $\ldots$ & $\ldots$ & xi
\end{tabular}

\section{GENERAL PART.}

Equipment ...

On Procuring Material

Orientation of the Eyeball

Examination of Fresh Tissues...

Freezing Microtome ...

Methods of Fixing and Hardening

1. Hardening in Alcohol

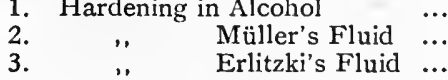

4. ", Corrosive Sublimate

5. " Zenker's Fluid

6. $\quad$ Picric Acid

7. " " $\quad$ Picric Acid Sublimate

8. Formalin

9. ", Osmic Acid

10. ", Nitric Acid (Benda's Method)

11. ". Platinum Chloride

12. " " Hermann's Solution 13. .. Merkel's Fluid

Washing

Completion of the Hardening Process in Alcohol

Division of the Hardened Eyeball

Imbedding Processes ..

1. The Celloidin Process

\section{... $\quad$...}

$\begin{array}{lllll}\cdots & \cdots & \cdots & \cdots & 1 \\ \cdots & \cdots & \cdots & \cdots & 3\end{array}$

$\cdots \quad 4$

... 5

... 6

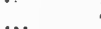

... 8

... 10

... 10

... 10

... 11

... 11

... 11

... 12

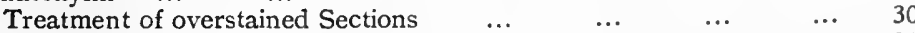

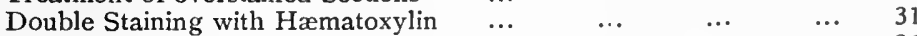

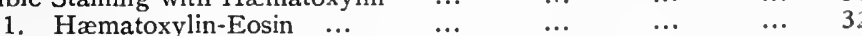

$\begin{array}{llllllll}2 . & \text { Orange G. } \\ \text {. } & \ldots & \ldots & \ldots & \ldots & \ldots & \ldots & 32\end{array}$

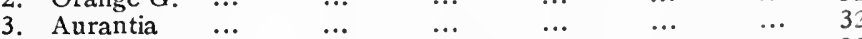

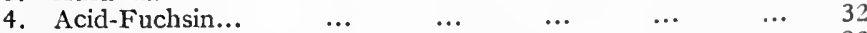

$\begin{array}{lllllll}\text { Triple Staining } & \ldots & \ldots & \ldots & \ldots & \ldots & \ldots\end{array}$

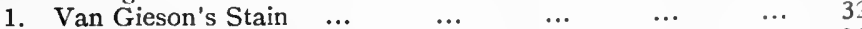

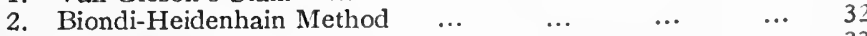

Carmine

Double Staining with $\ddot{\text { Carmine }}$

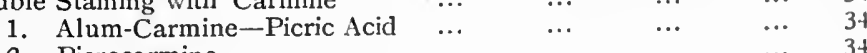

Safranin

2. Picrocarmine..

Specific Methods of Staining ...

1. Weigert's Stain for the Medullary Sheaths

2. Pal's Stain for the Medullary Sheaths...

3. Marchi's Method ...

5. Weigert's Stain for Neurolgia... $\quad \ldots$

6. Stains for Elastic Fibres $\ldots$... $\ldots$

8. Mallory's Connective Tissue Stain

9. Epithelial Cell Boundaries

$\ldots$


xiv.

Demonstration of Definite Substances and Tissue Elements

PAGE

1. Fat and Fatty Degeneration

2. Calcareous Degeneration

3. Cholestearin

4. Mucoid Degeneration

5. Hyaline Degeneration

6. Amyloid Degeneration

7. Fibrin

8. Iron in the Interior of the Eye

9. Copper

10. Mercury

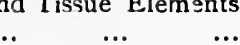

$\begin{array}{lll}\ldots & \ldots & 43 \\ \ldots & \ldots & 43 \\ \ldots & \ldots & 45 \\ \ldots & \ldots & 46 \\ \ldots & \ldots & 46 \\ \ldots & \ldots & 47 \\ \ldots & \ldots & 48 \\ \ldots & \ldots & 50 \\ \ldots & \ldots & 51 \\ \ldots & \ldots & 52 \\ \ldots & \ldots & 53 \\ \ldots & \ldots & 53 \\ \ldots & \ldots & 54 \\ \ldots & \ldots & 54 \\ \ldots & \ldots . & 55 \\ \ldots & \ldots & 57 \\ \ldots & \ldots & 58 \\ \ldots & \ldots & 58 \\ \ldots & \ldots & 59 \\ \ldots & \ldots & 59 \\ \ldots & \ldots & 60 \\ \ldots & \ldots & 61 \\ \ldots & \ldots & 61 \\ \ldots & \ldots & 63 \\ \ldots & \ldots & 63\end{array}$

Injection of Tissue

which do not act similarly in all Cell

1. Golgi's Method

Rapid or Chrome-Osmium-Silver Method

2. Ehrlich's Intra Vitam Methylen Blue Method Dogiel's Process

1. Blood Vessels

2. Injections by Puncture

Decalcification

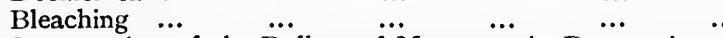

Preservation of the Bulbs and Macroscopic Preparations

1. Gelatine Method of Priestley Smith

2. Dry Method

3. Preservation in Formalin

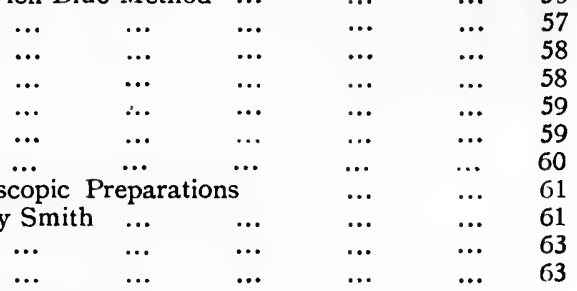

\section{SPECIAL PART.}

Cornea

Layers of the Cornea

Gold Chloride Methods

Silvering of the Cornea

Inflammation

Incised Wounds ...

Iris and Choroid

Dilatator Pupillæ

Nerves.

Pigment Cells .

Blood Vessels

Lens

Hardening ...

Lens Capsule $\quad \cdots$

Endothelium $\quad \ldots \quad \ldots$.

Lens Substance ...

Zonula Cilıaris

Method of Demonstration...

Corpus Vitreum ...

Retina

Visual Purple $\cdots \quad \ldots$

Coloured Globules

Layers of the Retina

Ora Serrata

Comparative Anatomy

Optic Nerve

Divisions of the Nerve

Neuroglia Mantle

Chiasma

Comparative Anatomy

Corpora Amylacea

Appendix $\quad \ldots \quad \quad \ldots$

Examination of Secretions and Bacteria...

Procuring the Secretion

Staining

Description of the Commoner Micro-organisms

Gram-positive Micro-organisms $\quad \ldots \quad \ldots$

Gram-negative ,

Staining of Gram-positive Micro-organisms in Sections Gram-negative

Staining of Spirochæta Pallida"

Trachoma Corpuscles 


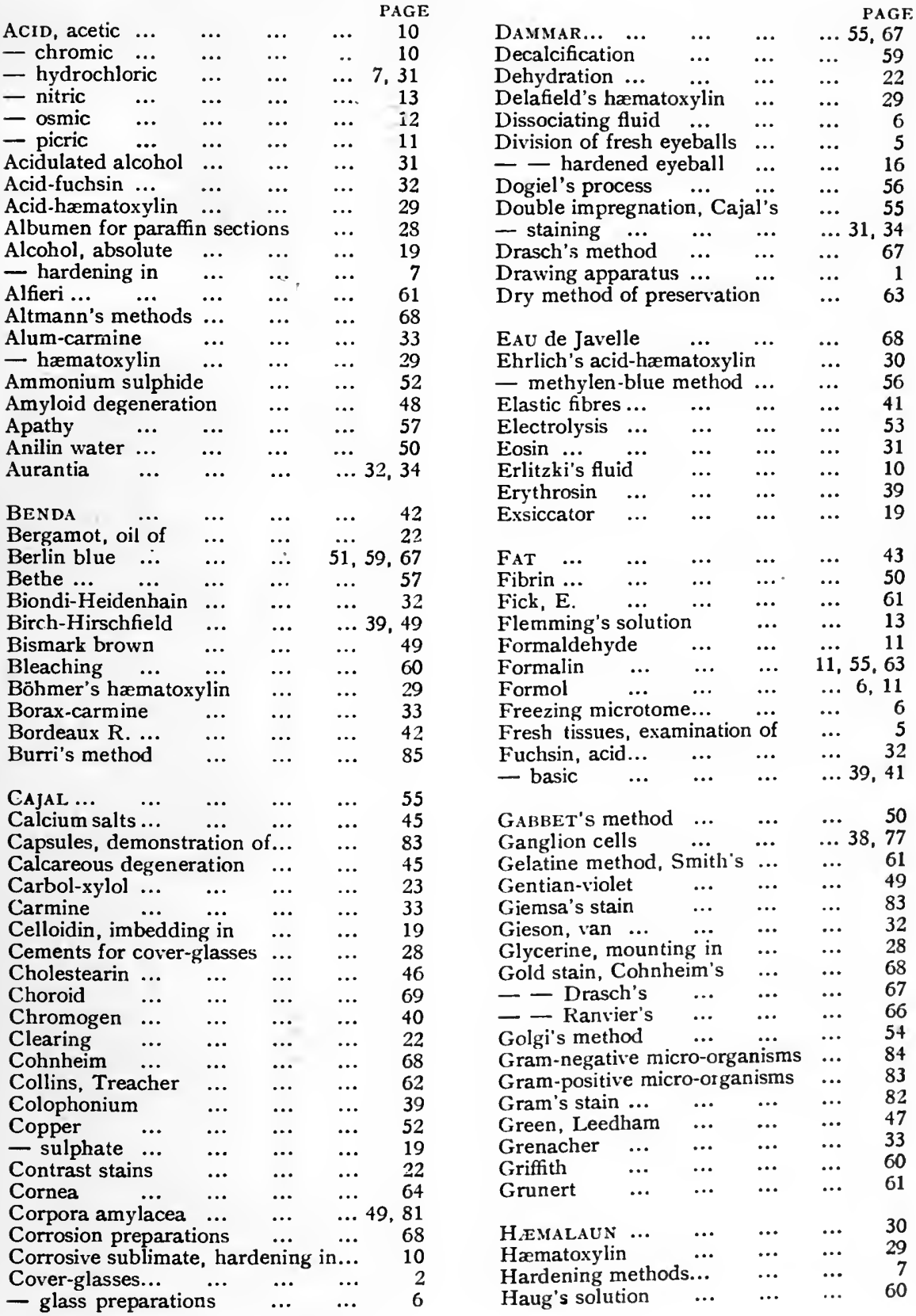


xvi.

\begin{tabular}{|c|c|c|c|c|c|c|c|}
\hline & & & PAGE & & & & PAGI \\
\hline Heidenhain $\ldots$ & $\cdots$ & $\cdots$ & 42 & Origanum, oil of & 列 & $\cdots$ & $\cdots$ \\
\hline Held's stain ... & ... & $\cdots$ & $\cdots$ & Orth's mixture & $\cdots$ & $\cdots$ & $\cdots$ \\
\hline Hermann's solution & $\cdots$ & $\cdots$ & $\ldots$ & Osmic acid $\quad \ldots$ & $\cdots$ & $\cdots$ & $\ldots$ \\
\hline Hoyer's stain... & $\ldots$ & $\cdots$ & $\ldots$ & Ossification $\ldots$ & $\ldots$ & $\ldots$ & $\ldots$ \\
\hline Hyaline degeneratio & & $\ldots$ & $\ldots$ & Overstained sections & s... & $\ldots$ & ... \\
\hline Hydrogen, peroxide & of & $\cdots$ & $\cdots$ & & & & \\
\hline Hyrtl's method & $\cdots$ & $\cdots$ & $\cdots$ & PAL's stain & $\because \cdot$ & $\cdots$ & $\cdots$ \\
\hline & & & & Paraffin, imbedding & in & $\ldots$ & ... \\
\hline IMBEDDING process & & $\ldots$ & $\ldots$ & Perl's reaction & $\ldots$ & $\ldots$ & $\cdots$ \\
\hline Incubator & $\ldots$ & $\ldots$ & $\ldots$ & Photoxylin & $\ldots$ & $\ldots$ & $\ldots$ \\
\hline Indifferent medium & ... & $\cdots$ & ... & Picric acid & $\ldots$ & $\ldots$ & ... \\
\hline Injection processes & $\ldots$ & $\ldots$ & $\ldots$ & - - sublimate & $\ldots$ & $\ldots$ & $\ldots$ \\
\hline Intermediate fluid & $\ldots$ & $\ldots$ & $\ldots$ & Picrocarmine & $\ldots$ & $\ldots$ & $\ldots 7,34$ \\
\hline Intra vitam methyl & len-blue & e meth & sod & Pigment cells & $\ldots$ & $\ldots$ & $\ldots 70,75$ \\
\hline Iodine-green ... & $\cdots$ & $\cdots$ & $\cdots$ & Platinum chloride & $\ldots$ & $\cdots$ & $\cdots$ \\
\hline — serum & ... & $\cdots$ & $\ldots$ & Priestley Smith & $\ldots$ & $\ldots$ & ... \\
\hline- reaction $\ldots$ & $\cdots$ & ... & $\cdots$ & Puncture, injection & by & $\ldots$ & $\ldots$ \\
\hline Iron $\quad \ldots$ & $\cdots$ & $\cdots$ & $\cdots$ & & & & \\
\hline - hæmatoxylin & $\cdots$ & $\cdots$ & $\cdots$ & QUINCKE'S reaction & a... & $\cdots$ & $\cdots$ \\
\hline Iris & $\cdots$ & $\cdots$ & $\cdots$ & & & & \\
\hline ALLIUS & & & & RANVIER & $\cdots$ & $\cdots$ & $\cdots$ \\
\hline aryomitotic $\dddot{\text { figures }}$ & $\cdots$ & $\cdots$ & $\cdots$ & Retina... & $\cdots$ & $\cdots$ & $\cdots$ \\
\hline 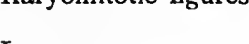 & & $\cdots$ & $\cdots$ & SAFRANIN & & .. & $\ldots 13$ \\
\hline ANGHANS $\ldots$ & ... & $\cdots$ & 48 & Salt solution ... & $\ldots$ & $\ldots$ & $\ldots$ \\
\hline Leber ... & $\ldots$ & $\ldots$ & $\ldots 65,67$ & Sattler... & $\ldots$ & $\ldots$ & $\ldots$ \\
\hline Lens $\ldots$ & $\ldots$ & $\ldots$ & $\ldots$ & Schultze & $\ldots$ & ... & $\ldots$ \\
\hline Leutert & $\ldots$ & $\ldots$ & $\ldots$ & Secretions, procurin & ig of & $\ldots$ & $\ldots$ \\
\hline Levaditi's method & ... & $\ldots$ & $\ldots$ & Serial sections, cello & oidin & ... & $\ldots$ \\
\hline Liquids, examinatior & $\mathrm{n}$ of & $\ldots$ & $\ldots$ & Siderosis & $\ldots$ & $\ldots$ & $\ldots$ \\
\hline Liquor ferri sesquich & hlorati & $\ldots$ & $\ldots 32,41$ & Silver methods & $\cdots$ & $\cdots$ & 65,67 \\
\hline - - sulfurici oxyd & & $\ldots$ & $\ldots$ & Slides ... & $\ldots$ & ... & ... \\
\hline Lithia-carmine & $\ldots$ & $\ldots$ & $\ldots$ & Spirochæta Pallida & $\ldots$ & ... & ... \\
\hline Löffer's methylen-b & olue & $\ldots$ & $\ldots$ & Stabilit... & $\ldots$ & $\ldots$ & $\ldots$ \\
\hline Lugol's solution & $\cdots$ & $\cdots$ & $\cdots$ & $\begin{array}{l}\text { Staining en masse } \\
\text { - of fresh tissue }\end{array}$ & $\ldots$ & $\cdots$ & $\begin{array}{l}\ldots \\
\ldots\end{array}$ \\
\hline MACERATING media & & $\cdots$ & 6 & Stains, nuclear and & double & $\cdots$ & $\ldots$ \\
\hline Macula lutea ... & $\cdots$ & ... & $\ldots 74,78$ & Straub... & ... & ... & $\ldots$ \\
\hline Mallory's connective & e tissue & e stain & $\ldots \quad 43$ & Stricker & $\cdots$ & $\ldots$ & $\ldots$ \\
\hline Marchi's method & $\ldots$ & $\ldots$ & $\ldots$ & Sublimate, hardenin & $\mathrm{g}$ in & $\ldots$ & $\ldots$ \\
\hline$r, P$. & $\cdots$ & $\cdots$ & $\ldots$ & & & & \\
\hline Medullary sheaths, & stains & for & $\ldots$ & TEASED preparation & & ... & $\ldots$ \\
\hline Mercury & $\ldots$ & $\ldots$ & $\ldots$ & Thionin & $\ldots$ & ... & $38,47,49$ \\
\hline l's fluid & ... & $\ldots$ & $\ldots$ & Trachoma corpuscle & & $\ldots$ & $\ldots$ \\
\hline en-blue & $\cdots$ & $\cdots$ & $7,39,56$ & Triple-staining & $\ldots$ & $\ldots$ & $\ldots$ \\
\hline Methyl-green... & $\cdots$ & $\cdots$ & $\ldots$ & le bacilli, sta & ins for & ... & $\ldots$ \\
\hline - violet & $\cdots$ & $\cdots$ & $\ldots$ & Turpentine & $\cdots$ & $\ldots$ & 22,63 \\
\hline Microscopes ... & $\ldots$ & $\ldots$ & $\ldots$ & & & & \\
\hline Microtomes ... & $\cdots$ & $\ldots$ & $\ldots$ & UNNA-TENZER & $\ldots$ & $\ldots$ & $\cdots$ \\
\hline Mucoid degeneratior & & $\ldots$ & $\ldots$ & & & & \\
\hline Müller's fluid... & $\cdots$ & $\cdots$ & $\cdots$ & VISUAL cells ... & $\cdots$ & $\cdots$ & $\cdots$ \\
\hline IP... & & & & $\cdots$ & $\cdots$ & $\cdots$ & $\cdots$ \\
\hline Weigert' & & for & $\begin{array}{l}62 \\
40\end{array}$ & Vitreous & $\cdots$ & $\cdots$ & $\cdots$ \\
\hline Nissl's method & $\ldots$ & $\ldots$ & $\cdots$ & WA & & ... & \\
\hline & & & & & & & $\ldots$ \\
\hline EGIA & $\cdots$ & $\cdots$ & $23^{\circ}$ & - stain for fibrin & $\ldots$ & $\ldots$ & $\ldots$ \\
\hline Oils & $\ldots$ & $\ldots$ & $\ldots$ & - - - medullary & sheath & & ... \\
\hline Oil-cast method & ... & $\ldots$ & $\ldots$ & - - neuroglia & $\ldots$ & ... & $\cdots$ \\
\hline Openshaw $\quad .$. & ... & $\ldots$ & $\ldots$ & Wintersteiner... & $\ldots$ & ... & ... \\
\hline Optic-nerve $\ldots$ & $\ldots$ & $\ldots$ & $\ldots 18,78$ & & & & \\
\hline Orange $\mathrm{G}$. & $\ldots$ & $\ldots$ & $\ldots 32,34$ & XYLoL & $\cdots$ & $\cdots$ & $\cdots$ \\
\hline Ora serrata $\quad .$. & $\ldots$ & $\ldots$ & $\ldots$ & & & & \\
\hline Orcein... & $\ldots$ & ... & 41 & ER's fluid & $\cdots$ & $\cdots$ & $\cdots$ \\
\hline Orientation of the & yeball & $\ldots$ & $\ldots$ & Zonule of Zinn & $\cdots$ & $\cdots$ & $\ldots$ \\
\hline
\end{tabular}




\section{GUIDE TO THE MICROSCOPIC EXAMINATION OF THE EYE.}

\section{General Part.}

\section{EQUIPMENT.}

THE equipment of a small laboratory suitable for the microscopic examination of the eye does not, as is often supposed, involve great trouble or expense. The oculist finds his chief work in the practice of his profession, but it is a matter for regret if he confines his attention to this solely. The organ with which he deals is so small that he ought to embrace every opportunity of becoming acquainted with its finer microscopic structure, and thus be able by anatomical examination to demonstrate the necessity for the operative treatment he may have undertaken.

It is impossible for every one to become an expert in staining methods, and in many cases the results attained must fall short of those of the professional pathologist. The aim of this work, however, is to show that a satisfactory examination of an eye can be made without elaborate instruments or numerous re-agents. On the other hand, slavish adherence to a single method is reprehensible. The greatest sinners in this respect are our supermodern confrères, who rush to what is newest, who recognise nothing but this, and who scoff to-day at what a year ago they were wont to laud as best. It is much better to learn a few methods of staining thoroughly, and then to study the tissues themselves rather than waste time over non-essential details. Each works best with the agents most familiar to him. This is a secret which, if known, would settle many a dispute.

Microscope.-In the first place a trustworthy microscope is essential, and in the choice of this excessive economy as well as excessive extravagance should be avoided. It may not be convenient to purchase everything at once, but a good stand should in any case be chosen-one capable of having fitted to it all that is eventually necessary. Good work can be done without an oilimmersion lens, and this can be procured subsequently. The favourite instruments (in Germany) are those of Zeiss and Leitz. The Zeiss microscopes are the more expensive; the author has found those of Lcitz equally satisfactory if the lenses are carefully selected. When expense is a consideration, Leitz's stand IIb may be procured. This stand can be inclined at different angles, and is provided with an Abbé condenser, an iris diaphragm, and a nose-piece for three objectives. The most suitable eye pieces are No. I (40 mm.) and No. III (30 mm.); the most suitable objectives, No. 3 (I $3 \mathrm{~mm}$.) and No. $6(4.4 \mathrm{~mm}$.). Such an instrument costs $£ 7$ or $£ 8$. A good oil-immersion lens, $T_{2}^{-1}(2.1 \mathrm{~mm}$.), costs $£ 5$ more. A 
micrometer cye-picce is useful for the exact measurement of objects. Excellent instruments are sold by Beck, Swift, Watson, and Powell and Leland, of London.

Microtomes.-A microtome is also necessary, and this should be simple in construction. Complicated instruments are cxpensive, and are more difficult to kecp clean. A good knife and careful imbedding are the main requisites for the production of thin sections. Microtomes, of which there are numerous models, are usually so constructed that the knife is moved horizontally on a slide backwards and forwards, the object being fixed during cutting, and being elevated after cach stroke through a distance which corresponds to the thickness of the section desired. The clevation of the specimen is accomplished in one of two fashions. Either the object-holder is raised by being advanced along an inclined plane, or, and this is, in the opinion of the author, preferable, the holder is directly elevated by means of a micrometer-screw. The simple microtome manufactured by Schanze of Leipzig can be recommended. It costs about $£ 5$.

If examinations have to be undertaken with the object of establishing an immediate diagnosis, a freezing apparatus is indispensable, and every microtome should admit of being fitted with this.

The ordinary slide is too narrow. A convenient size is that measuring 32 by $62 \mathrm{~mm}$. Cover-glasses, $20 \mathrm{sq}$. $\mathrm{mm}$., are cmployed for smaller sections ; and those, 25 sq. mm., for sections of the complete bulb.

The mounted specimens should be kept in simple cardboard cases, and should be placed horizontally to prevent the Canada balsam from running.

With the aid of a set of scales the commoner staining solutions can be produced at small cost. A milligramme of error is of no consequence. Reliable stains can be obtained in powder from the laboratory of Dr. G. Grübler, Lcipzig. Solutions which are difficult to prepare should be procured ready for use.

When the tissue is to be imbedded in paraffin an incubator is required, and this, as will be shown hercafter, can be utilised for other purposes.

Lastly, there should be provided a broad section-lifter, scissors, two teasingneedles, a platinum needle, a graduated cylinder for measuring liquids, and several shallow vessels of different sizes. These last ought to have flat bottoms, so that they are not easily upset.

Drawing Apparatus. - Some form of drawing apparatus is useful, not only for those who have no talent for drawing, since by means of it errors in shape and relative size are avoided. Till lately Abbé's drawing camera was the best device. The drawing-surface, which is placed at the level of the stage, is reflected by a mirror and double prism situated above the eye-piece. The image formed by the objective is seen through an aperture in the silvering of the prism. Still more convenient is Leitz's drawing eye-piece. This consists of a prism attached to an eye-picce. The upper part of the microscope is inclined $45^{\circ}$, and the surface of the table behind the microscope is reflected to the eye by two total reflections at the surfaces of the prism. A special drawing table is thus unnecessary.

The two instruments just mentioned are adapted for the drawing of microscopic sections. For projection and for the drawing of large specimens, such as sections of the complete bulb, Edinger's apparatus can be highly recommended. It projects the image of the preparation directly on to the drawing-surface, so that it is visible to the by-standers. The apparatus is, therefore, suitable for the demonstration of specimens.

Edinger's instrument has been adapted for photographic purposes by Nieser. The maker is E. Leitz. 


\section{On Procuring Material.}

Difficulty is often experienced in procuring material. Eyes removed from the living subject furnish the most suitable tissues for anatomical and pathological research. It is important when the topographical relations of the parts are to be studied that the eyc be hardened, and it should be transferred at once to the hardening medium, since a few seconds after removal diffusion of the intraocular fluids sets in, and the corneal epithelium begins to dry. The diseases to which the eye is subject do not, as a rule, necessitate enucleation; and, moreover, in these times treatment is becoming more and more conservative. Further, eye diseases rarely prove directly fatal. As a consequence, many diseases escape pathological examination ; indeed, there are numerous affections which are well known clinically, but which have never been submitted to anatomical investigation.

Still greater difficulties are experienced in procuring normal specimens of the human eyeball. Eyes taken from the dead body have undergone changes which render them unsuited for minute cxamination. The most valuable material for this purpose has hitherto been furnished by eyes enucleated on account of small tumours, for in these the greater portion of the globe may be quite normal. Occasionally, a healthy bulb is removed by the surgeon in resection of the upper jaw.

Both opportunity and resource are required in obtaining from the dead body organs exhibiting pathological processes; and these, when procured, are more serviceable for the study of pathological changes than for that of normal histology. Pathologists, unfortunately, do not always take into account the disadvantages un ler which ophthalmologists rest, and often give with a grudge material which is of little value to themselves. Those anxious to obtain such specimens should be constant in attendance in wards devoted to general diseases and to affections of the nervous system; and should there examine the patients, and study the ophthalmoscopic appearances of the eyes. Special attention should be paid to cases which are likely to have a fatal termination. In this way changes are often discovered in the eye which are the result of the general disease and also accidental conditions, such as anomalies of refraction, which are of interest and value when so studied.

But even after such discoveries are made, it is difficult to obtain the organs at the conclusion of the post-mortem examination. The removal of the eye produces disfigurement which should be avoided. There are several ways of averting this.

When as is often the case, only the posterior portion of the globe is desired for examination, the following procedure is adoptcd.-The brain having been removed, access to the eye is obtained by breaking in the roof of the orbit in front of the optic foramen. The splinters of bone are picked away, and one blade of the scissors is pushed into the bulb, which is then completely divided along its equator, the optic nerve being meanwhile held by mcans of forceps. The scissors should cut deeply, so as to include and to sever the retina, and not tear it from its attachment at the optic papilla, an accident which may occur in unskilful hands. The anterior portion of the globe thus remains in situ, and if, after removal of the posterior hemisphere, the cavity of the orbit is stuffed with cotton wool, inspection from the front fails to disclose the slightest disfigurement.

When the brain has not been examined, the removal of the fundus is somewhat more difficult. The method then employed is as follows:- The eye is enucleated in toto, divided in the manner just described, and the space behind 
the lens having heen firmly packed with wool, the anterior segment is replaced. From without the wool is invisible, and the reposition can be effected so as to leave no trace of disturbance.

Should the entire bulb be required, one of two devices may be adopted. After enuclcation, the orbit is packed and the eyelids are closed by a stitch inserted at the inner canthus; or, preferably, an artificial eye is introduced. Artificial eyes should form part of the equipment of every post-mortem theatre.

The bulb having been procured, a thread is passed through the end of the optic nerve or through the stump of a muscle, and the specimen is suspended in a vessel containing a plentiful supply of Müller's or other suitable hardening fluid. The liquid is absorbed and the globe quickly resumes its spherical shape. Or, otherwise, the floor of the vessel is covered with cotton wool to prevent flattening when the eye is soft. It is a good rule to suspend the eyeball by a thread passed through the tendon of the superior oblique muscle. Blood, pus, and matter capable of sedimentation are then found in their proper topographical positions.

When it is of importance to retain the shape of the eyeball, the fixing fluid is injected into the vitreous. The necdle of the syringe should be very sharp, and should penetrate the sclera obliquely. The syringe is then elevated, and the fluid injected into the centre of the vitreous. The retina and choroid are thus preserved in their normal position. Zenker's fluid is recommended for this purpose.

If Merkel's fluid is employed, it is unnecessary to resort to injection. In this, even collapsed (e.g., highly myopic) bulbs removed from the dead body recover their normal shape; but the sclera of such eyeballs should be incised before they are subjected to treatment with Müller's fluid, formalin, or alcohol. Otherwise, the diffusion currents are apt to lead to a second collapse, and to disturbance of the parts.

\section{Orientation of the Eyeball.}

It has become customary, for purposes of description, to compare the bulb with the earth, and it would be well if this convention were generally adopted. References based on this comparison exclude those misunderstandings which are apt to arise in anatomical accounts of the direction of planes, etc. The eye is considered to possess an anterior and a posterior pole, and to be divided by the equator into an anterior and a posterior hemisphere. Sections made parallel to the plane of the equator are styled "Equatorial Sections"; those parallel to the plane of a meridian, "Meridional Sections." In the case of the latter, it is necessary to specify the meridian concerned. When it is stated that horizontal meridional sections are to be made, or that the eye is to be divided into sections parallel to the horizontal meridian, there can be no mistake. To express the same meaning, others employ the term "Horizontal Axial Sections." Vague terms such as "radial" afford no definite information. This word is unnecessary even in descriptions of the iris (cf. Kallius, Ergebnisse der Anatomie und Entwicklungsgeschichte, $\mathrm{Bd}$. VIII, 1898$)$.

It is of advantage to know the position the bulb occupied in the orbit before proceeding to divide it. Sections can then be made parallel to the horizontal meridian or in any other direction desired. It is also of importance to know to what part of the eycball a section belongs, and what part of it is superior, inferior, temporal, and nasal.

It will be shown that it is possible to determine the different planes and 
axes, even after the eye has been enucleated and hardened. It is, however, preferable to mark the position of the eye in the orbit before enucleation. This can be done simply by touching the upper border of the cornea with nitrate of silver previous to the operation. Or, immediately after the eye has been removed, a thread may be passed through the tendon of the superior rectus muscle.

\section{Examination of Fresh Tissues.}

The examination of tissues in the fresh state is at present too little practised. In the case of the eye, more often than in that of any other organ, there is a tendency to omit this examination, and first to harden the healthy or diseased globe ; because attempts to divide it previous to hardening are apt to disturb the topographical relations of the parts and to spoil the specimen. Nevertheless, something must be said in favour of examining certain tissues while fresh. The excellent words of Virchow, H. Müller, Sattler, and many others, show how much instruction can be derived from the study of fresh specimens. Many advantages are lost by hardening. A glioma retine presents in the hardened and stained preparation a picture quite different from that which it affords in the fresh condition. Every intraocular tumour should be examined in its natural state. Only then can a proper conception of its appearance in the living subject be gained. The individual cells, moreover, reveal their structure better in the recent condition than when hardened, shrunken, and closely packed together. Finally, as in the case of tumours, it is often important to establish a diagnosis immediately after the extirpation or exploratory puncture. The examination must then be made while the tissue is fresh, since the hardening process, even under the most favourable circumstances, occupies several days.

Fresh tissues require some preparation before they can be submitted to microscopic examination.

Division of Fresh Eyeballs. - If internal structures are to be examined in the fresh condition the eyeball must be opened at once. In practice this is by no means easy, since the globe collapses immediately an incision is made. The most suitable method of procedure is as follows :- The eyeball is held between the fingers of the left hand, and a sharp knife is applied to it in the equatorial region, so as to cut through its membranes for a short distance. The globe is now quite soft, and, having been carefully taken up with forceps, it should be placed in a vessel three to four $\mathrm{cm}$. deep containing physiological salt solution, 0.6 per cent. Here it is held with the forceps applied to the margin of the incision, and the division is completed by snipping it with sharp scissors around the equator. If it is undesirable that the freshly opened eye come into contact with liquids, it may be held in a towel during the process. Division of the eye along the equator into an anterior and a posterior half is preferable, because by this method dislocation of the lens and destruction of the specimen are avoided. If, however, it is desired to cut the bulb along a meridian (into an upper and a lower half), the division should be commenced at the posterior pole, the scissors and forceps carried forward on either side, and the anterior structures (lens, iris, cornea) finally severed by one strong snip. After the removal of the portions required (usually small particles), the hemispheres can be hardened.

Examination of Liquids.-It may be desirable, especially when pathological changes are present, to examine liquids removed from the interior of the eye, e.g., subretinal exudations. These contain an abundance of cells, elements which have suffered fatty degeneration, and often cholestearin crystals. The 
last can be scen well only in the fresh specimen, since they are dissolved by the hardening solutions. Further, it may be necessary to examine subchoroidal exudations, the vitreous, and vitreous opacities. These are removed from the eye by means of a platinum loop, and a drop of the fluid is transferred to a slide, protected with a cover-glass, and placed under the microscope.

These liquids can also be put up in the form of cover-glass preparations, such as are used in bacteriological examinations.

When the fluid removed from the interior of the cyeball is to be examined for micro-organisms, the spot at which the needle is inserted or the opening incision is made, should be smeared with the galvano-cautery. Otherwise, the specimen is likely to be infected by the xerosis bacillus.

Cover-glass l'reparations.-A thin layer of the liquid is taken up and smeared on a cover-glass by means of a platinum loop. After being allowed to dry thoroughly, the glass is drawn slowly three times through the flame of a spirit lamp. Some drops of a staining solution are then transferred to the cover-glass by means of a glass rod, and left there for I to 5 minutes. The preparation is next washed in water, and dried on a thick pad of blottingpaper. It is then placed aside until the water has evaporated, and, finally, the cover-glass is mounted on a slide with Canada balsam.

Examination of Tissues. - In the case of soft tissues, e.g., gliomata, it is sufficient to draw the blade of a scalpel over the surface of the tumour, or, still better, over the surface of a section, and to cxamine what adheres to the blade in some "indifferent" medium. For this purpose there is nothing better than the liquid of the eye itself, aqueous or vitreous. Failing these, 0.6 per cent. salt solution may be employed. The more widely the cell mass is spread out, and the less of it taken, the more instructive is the specimen. Only a drop of the medium should be added; otherwise, the cover-glass does not remain fixed, and the cells exhibit continuous movement.

Teased Preparations. - Tissues of firmer consistence, e.g., sarcomata of the choroid, have generally to be teased before they can be examined microscopically. A very small piece of the tissue should be removed with forceps and scissors, placed on a slide in a drop of an indifferent liquid, and teased into fine shreds by means of two strong needles.

Sometimes the tissue is so resistant that it can be resolved into its constituent elements only after treatment with a Macerating or Dissociating Medium. To this end the pieces are laid for $2+$ hours in 30 per cent. alcohol, or for two or three days in a small quantity of Müller's fluid.

Sections.-Hard tissues in the fresh condition may be cut with a sharp knife while held between two pieces of hardened liver. Those accustomed to a double-bladed knife may prefer to employ this. The freezing microtome gives very beautiful and very thin sections of tissucs which do not fall to pieces when thaw ed. The tunics of the eye unfortunately do not belong to this class.

The piece to be sectioned must not be more than $2 \mathrm{~mm}$. to $4 \mathrm{~mm}$. in thickness, or it does not frecze uniformly. It is placed with as smooth a surface as possible upon a metal plate, against the under surface of which an ether spray play's. 'The spray should not be worked strongly or continuously, but intermittently, so as to give the ether time to evaporate. It is well to keep the preparation pressed lightly against the metal plate by means of a scalpel until it is frozen hard, and the plate should be moistened with water before the tissue is placed on it. The sections are examined in water.

Quite fresh tissues suffer considerably in the freezing and thawing. On the other hand, the freezing microtome produces very beautiful sections of tissues which have been slightly hardened. For this purpose formalin is now re- 
commended. Collen (Centralblatt für allgem. Pathol. und. puth. Anatomie, I 895, S. 449) advises that the pieces ( $1 \times 0.5 \times 0.2 \mathrm{~cm}$. in size) be placed in a Io per cent. aqueous solution of formalin for two hours before being cut. This method possesses the advantage that the red bleod corpuscles are not disintegrated by the freezing and thawing.

The following are the stages in the process:-

I. Sections are made from the frozen tissue.

2. These are placed in $5^{\circ}$ per cent. alcohol for thrce minutes.

3. They are transferred to absolute alcohol for one minute.

4. They are immersed in water for a minute.

5. They are stained in hæmatoxylin for two minutes.

6. They are treated with alcolol (containing, if nccessary, $1 \cdot 5$ per cent. hydrochloric acid).

7. They are counter-stained with cosin.

8. They are dehydrated in 95 per cent. alcohol, and then in absolute alcohol.

9. They are cleared in oil, and mounted in Canada balsam.

Tissues removed from Müller's fluid may, after bcing washed for a short time in water, be cut with the freezing microtome, without being imbedded.

Specimens which have been hardened in spirit must be thoroughly saturated with water. It is well to leave them in water for twenty-four hours, since the tissue does not adhere to the metal plate unless every trace of alcohol has been removed.

The staining of fresh preparations is accomplished by placing a drop of the staining solution on the slide at the edge of the cover-glass, the stain being drawn under the glass by means of a piece of blotting-paper applied at the margin opposite the drop.

Hæmatoxylin is not suited for this purpose, and Löffler's methylen blue, or picrocarmine, should be employed.

\section{Methods of Hardening and Fixing.}

\section{Hardening in Alcohol.}

The essence of the hardening process consists in the extraction of water from the tissucs, and in the coagulation of the albumen they contain. These changes are brought about with remarkable rapidity by means of alcohol. Hence it follows that loose tissues which contain much water and little albumen shrink greatly in alcohol. The eye is a tissue of this nature. The vitreous, even in a normal eye, contains only a small quantity of albumen, and after the most careful hardening shrinks to a thin layer behind the lens. If, therefore, strong alcohol be employed, the shrinkage is intense; and not only docs the vitrcous shrink, but also the entire bulb with its protective membranes. Consequently, entire eyeballs should not be brought directly into alcohol. It is preferable to " fix" the tissues in solutions of certain salts in a manner explained hereafter, and to complete the hardening with alcohol. In cases of tuberculosis and in those where this is suspected, the rule does not apply. The bacilli of tuberculosis and similar diseases (anthrax, leprosy, etc.) stain better when the hardening is accomplished by alcohol from the first. At all events, it should be borne in mind that the staining of tubercle bacilli may not be successful if the tissues have been treated with Müller's fluid. 
If, then, alcohol be chosen as the hardening medium it should be employed first in a dilute form, and only gradually be increased in strength. In this method the following is the procedure:-

I. The eye is placed in

Alcohol, 50 per cent., for 24 hours.

2. Section of the cyeball.

$\begin{array}{lllll} & 60 & , & " & " \\ " & 70 & " & " & " \\ " & 75 & " & " & " \\ " & 80 & " & " & " \\ " & 90 & " & " & " \\ " & 95 & \text { absolute } & " & "\end{array}$

3. The parts are again placed in absolute alcohol for one day.

4. They are imbedded in celloidin.

An eyeball, however, that has been so treated is usually considerably distorted.

Alcohol, when employed directly, possesses the further disadvantage of removing the colouring matter of the red blond corpuscles, so that only the "shadows" of these are left.

Small pieces of firm tissue, $e g$., portions of a tumour or segments of the optic nerve, may be hardened without injury in alcohol.

Complete cyeballs can be fixed in absolute alcohol if the following device is adopted. - A narrow tube, about 10 inches long, has one end attached to a glass funnel, and its other end to the needle of a hypodermic syringe. The funnel and tube are then filled with absolute alcohol, and the needle is pushed through the sclera to the centre of the vitreous. The funnel is now fixed to a stand at a level which allows the bulb just to touch the bottom of the vessel in which it lies. This vessel is covered as closely as possible. After the alcohol has been allowed to flow into the eyeball for a half to one hour, the vessel is filled with alcohol, and 24 hours later, the preparation is ready to be imbedded.

Greatly shrunken eyeballs, which contain no cavity, and those which cannot shrink owing to the presence of ossification of the choroid, may be placed at once in 95 per cent., not absolute, alcohol. The calcareous plates can easily be felt through the sclera.

\section{HARDENING in MüLlER'S Fluid.}

Müller's fluid is much used for fixing the tissues of the eyeball, and is, in many cases, a most suitable medium. It is a $f_{d}$ vourite practice to place specimens in it which do not require to be examined at once, and which are not to be treated by any special method. It possesses the advantage that tissues hardened in it are adapted for taking up most nerve-stains; it should be used if it is intended to demonstrate the medullary nerve sheaths (Weigert, Pal). On the contrary, it should not be employed for tuberculous tissues, since, after being exposed to it, bacilli do not stain well.

Müller's fluid, by destroying the structure of the nucleus, prevents the demonstration of karyomitosis; and the almost universal use of this agent hitherto may explain the lack of attention paid to nuclear division in the past. On the other hand, it preserves the colour of the red corpuscles, so that blood in the vessels and extravasations are rendered prominent by their yellow appearance.

Müller's fluid penetrates the tissues deeply. The external form of the bulb is therefore maintained. Still, even when it is used, there is great shrinking of the vitrcous, and almost always artificial detachment of the retina. 
The practice of incising the bulb before placing it in the fixing fluid is bad, for it causes mutilation of the eye and offers no advantage. This applies in the case of Müller's and almost every other fixing fluid, with the exception, perhaps, of osmic acid. which possesses only slight penetrating power. Clinicai experience shows how easily the cornea and sclera are permeated by chemical substances (e.g., atropin); experiments teach the same lesson. An eyeball which has lain for even a few minutes in Müller's fluid shows, when cut, that all its membranes have been permeated. The vitreous alone presents difficulty. Incision of the membranes, however, is equally ineffective in producing uniform saturation, and is likely to do more harm than good. Eyes taken from the dead body show how permeable their tunics are, for although greatly collapsed, when placed in Miiller's fluid or when suspended in it by a thread, they quickly absorb the liquid and become tense.

The following rules must be observed to obtain thorough fixation of the tissues :-

The eyeball should be placed in the fixing fluid immediately after enucleation, otherwise diffusion outward of its contents begins, rendering it flaccid and destroying its original form (cf. Helmholz Physiologische Optik., ist edition, p. 6.) The cornea also, being no longer moistened, begins to dry. During fixation an exchange of fluids takes place, those of the eye passing out and Müller's passing in. To accelerate the process and to obtain a satisfactory result an abundance of the hardening medium must be employed. The vessels used should be of such a size as to contain a quantity of liquid equal to at least six or eight times the volume of the eyeball.

For the first four or five days the liquid should be changed daily, in fact till it no longer becomes turbid. Then the specimens can be left undisturbed for a considerable time.

Müller's fluid is easily prepared. It consists of :-

$\begin{array}{lcccc}\text { Bichromate of potash } & \ldots & \ldots & \text { IO to } 12 \cdot 5 \\ \text { Sulphate of soda } & \ldots & \ldots & \ldots & 5 \\ \text { Distilled water } & \ldots & \ldots & \ldots & 500\end{array}$

Albuminate of chromium is formed.

The minimum time for hardening an eyeball is six weeks at ordinary temperatures, or fourteen days in an incubator at a temperature of $36^{\circ}$ to $40^{\circ} \mathrm{C}$.

The vessel containing the eyc should be kept in the dark, to prevent the deposition of chromic salts in the tissues.

After fixation is complete the eyeball must lie for several days in running water or in water which is frequently changed. This removes any excess of chromium, which would be injurious to the staining process. But see "Staining of Medullary Sheaths."

The hardening is completed in alcohol gradually increased in strength.

The process is as follows:-

I. Müller's fluid, 6 weeks or longer.

2. Washing in running water, I-2 days.

3. Hardening in alcohol.

Alcohol, 70 per cent., for 24 hours.

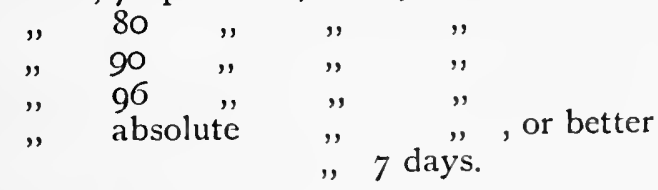

4. The eyeball is now divided. 
5. The pieces are again placed in absolute alcohol for 24 hours.

6. Imbedding, etc.

Hardened in pure chromic acid ( $\frac{1}{3}$ to $\frac{1}{2}$ per cent. aqueous solution) is less to be recommended, since it renders the tissues, especially the retina, very brittle.

\section{Hardening in Erlitzki's Fluid.}

Erlitzki's fluid acts in the same way as Müller's. It is composed of :-

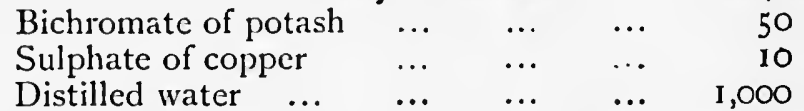

This rcagent unfortunately tends to produce shrinkage and to cause deposits and is, therefore, not very suitable for minute examinations. It possesses the advantage, however, of fixing much more quickly than Müller's fluid. About 10 days suffice for a complete eyeball at ordinary tempcratures, or 4 days in the incubator $\left(40^{\circ} \mathrm{C}\right)$. Then follow thorough washing in water and further hardening in alcohol.

The author has often employed this fluid, and the results have usually been satisfactory.

\section{Hardening in Corrosive Sublimate.}

Corrosive sublimate is in many cases an admirable hardening medium. It fixes nuclei and karyokinetic figures excellently. There is no better method for the demonstration of these (Sec "Heidenhain's Method"). The nuclei stain particularly well, while the cell bodies are usually feebly brought out.

Corrosive sublimate possesses slight penetrating power. It is employed as a concentrated aqueous solution of abuut $\mathbf{I}$ in 20 . Boiling water dissolves $\mathbf{I}$ part of sublimate in 7.5 . Some authors employ a 0.5 per cent salt solution instead of water. Others add acctic acid to the mixture.

N.B.-Acetic acid, on account of its penetrating power, is recommended as an addition to almost all preserving media, espccially to the chromic salts.

The unopened eyeball remains in the fluid for $12-24$ hours, or, if placed in the incubator, for 2-3 hours. Longer immersion renders the tissues too hard.

It is then washed in running water for 24 hours, in order to remove the sublimate.

The hardening is completed in alcohol gradually increased in strength.

Thorough removal of the sublimate is most important, because mercurial precipitates appear black, and may casily be confused with the pigmented structures of the eye. It is wcll, therefore, to divide the bulb while it lies in alcohol, and to add to the alcohol a few drops of tincture of iodine, or of a solution of iodine and iodide of potassium, until a wine-red colour results. Should there still be any mercury in the preparation it is extracted, and forms iodide of mercury, so that after some hours the solution becomes colourless. The alcohol is renewed, more tincture of iodine added, and so on until a wine-red colour remains permanently. Pure alcohol is then cmployed, and this is gradually increased in strength until the stage of absolute alcohol is reached. Now follow im bedding, etc.

\section{HARDENING in ZENKER'S Fluid.}

Corrosive sublimate $\quad \ldots \quad \ldots \quad \ldots$

$\begin{array}{llll}\text { Bichromate of potash } & \ldots & \ldots & 2.5\end{array}$

$\begin{array}{llll}\text { Sulphate of soda ... } & \ldots & \ldots & \text { 10 }\end{array}$

Distilled water $\quad \ldots \quad \ldots \quad \ldots \quad \ldots \quad 100$ 
Before the solution is used, five parts of acetic acid are added. The eyeball should remain only six hours in the fixing medium. It should then be thoroughly washed, and treated with alcohol and tincture of iodine to ensure the removal of the mercury.

Zenker's fluid is the best hardening medium, because in it the choroid retains its normal thickness. Formalin causes the vitreous to swell up and to compress the choroid.

\section{Hardening in Picric Acid.}

For small and delicate specimens, and, in particular, for embryonic tissues, picric acid is employed in the form of a concentrated aqueous solution. In this the pieces remain for $24-48$ hours, and are then transferred, without being washed in water, to 70 or 80 per cent. alcohol. The next stage is the extraction with alcohol of the picric acid, since it interferes with the staining. To attain this object, the alcohol is renewed until it no longer shows a yellow tinge. This may take a considerable time.

\section{Hardening in Picric Acid Sublimate.}

Preferable to purc picric acid for fixing delicate tissues is a mixture of picric acid and corrosive sublimate. Equal parts of saturated aqueous solutions are taken. Although more suitable for small pieces, entire cycballs can be hardened in it.

Eyeballs are placed in the mixture for 24-30 hours.

Small pieces are placed in the mixture for 10-20 hours.

Thorough washing in running water for I day.

Alcohol, 70 per cent., etc.

The mercury must be removed by means of iodine in the manner explained in section 4. This is accomplished in a comparatively short time. To get rid of the picric acid, which is a much more tedious process, it is necessary to change the alcohol several times.

\section{Hardening in Formalin.}

Formalin (Schering) or Formol (Höchster Farbwerke) is an aqueous solution containing about 40 per cent. of the gas formaldehyde ( $\mathrm{HCHO})$. Blum was the first to use it for microscopic work. It is a clear liquid with a pungent odour. Although allied to alcohol, formalin is remarkable not so much for its power of extracting water as for the rapidity with which it fixes the tissues without destroying the form of the globc. In this respect it is one of the most excellent hardening media at our disposal. The eycballs should not, however, lie too long in formalin if it is intended to prepare microscopic sections, for in no other fluid do sclera and lens become so hard. It must, therefore, be avoided if the lens is to be cxamined. On the other hand, since formalin possesses the property of maintaining the shape of the bulb, it is an excellent fluid to use when specimens are being mounted for the muscum. Further, formalin preserves the transparency of the cornea ; this is of importance when the preparation is intended to be used for macroscopic demonstrations. The lens, however, becomes very opaque in formalin. Its action on cornea and lens is the reverse of that of other hardening media. When treated with formalin, the tissues retain their colour, and take up most stains well. Weigert's stain for the medullary sheaths can be applied to nerves hardened in formalin, if the preparations are immersed in a chromium or iron 
solution for a few weeks before being placed in alcohol. Further, formalin has been recommended in recent times as a substitute for osmic acid in Golgi's method.

A ro per cent. aqueous solution of formalin is used, i.e., a mixture consisting of one part of the commercial liquid and nine of water. Formalin fixes still better when diluted with salt solution instead of water. The formula is :-

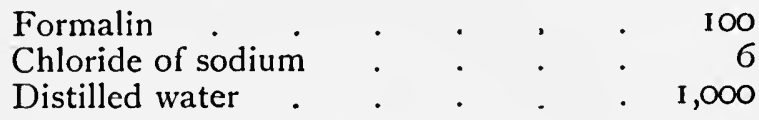

In this the eyeball remains 12 , or, at most, 24 hours. Washing in water is unnecessary, the subsequent hardening in alcohol following immediately. The strength of the alcohol must be increased very gradually, as otherwise shrinking is apt to take place.

Another advantage attached to the use of formalin is its rapid action.

Its chief disadvantage is that the choroid is compressed owing to the swelling of the vitreous which occurs in formalin solutions.

Formalin, again, should not be employed if it is desired to study the ocular pigment; for it extracts from the blood, and deposits in and betwcen the cells, a granular pigment which rescmbles melanin. This cannot be removed, and may lead to grave errors.

Orth's Formalin-Müller Mixture.-Orth has suggested a mixture of formalin and Müller's fluid, which can be highly recommended. The following is the procedure :-

The eyeball is laid for 2 or 3 days in a mixture of Müller's fluid (4 parts) and pure formalin ( $I$ part), plenty of the reagent being taken. Fixation is carried out in the dark, since formalin undergoes chemical changes when exposed to light and air.

Thorough washing, I 2-1 4 hours, in running water.

Completion of the hardening process in alcohol gradually increased in strength.

If it is desired to stain the medullary nerve sheaths, the tissue is not washed, but is transferred to pure Muiller's fluid for a few days, and is then treated with alcohol of gradually increasing concentration.

\section{Hardening in Osmic ACid.}

Osmic acid was first employed by Max Schultze in the form of a I-2 per cent. solution; by means of it he made his classical investigations into the retina. At present osmic acid is either used alone, or as an ingredient of many mixtures required for special methods, e.g., those of Marchi, Golgi, ctc., which will be described later. Osmic acid can also be used in the form of vapour for fixing purposes.

The following rules should be observed when osmic acid is employed :-

Osmic acid is decomposed by light; it should, therefore, be preserved in dark glass bottles, and, since it is very volatile, these must be securely stoppered. In any case, however, it does not kcep well, and solutions should be freshly made. The vessels used should be absolutely clean. The solutions must not be brought into contact with iron; platinum needles are employed. Long exposure in osmic acid renders the tissues brittle. It is the most rapid fixing medium, but, since it has little penetrating power, the pieces to be tieated are chosen as small as possible. Dimmer has succeeded in hardening complete bulbs in Flemming's solution, and has secured specimens exhibiting the retina fixed in its position and free from folds. To obtain this result, large 
incisions, extending into the vitreous, are made along the equator of the eyeball.

Osmic acid exhibits the body of the cell well, but the nuclear stain is sometimes defective. The karyomitotic figures, which stain more intensely than the nuclei, are very prominent.

Finally, osmic acid renders fat globules very dark, a property which is of value in the study of albuminuric retinitis, etc.

It should be noted that tissues hardened in osmic or other acids do not stain well with hrmatoxylin.

A suitable stain is a I per cent. watery solution of safranin ( $\frac{1}{2}-24$ hours).

\section{Methods of USING OSMIC ACID.}

(a) Pure Osmic Acid.-The solution does not kcep well, and so should be prepared freshly by the worker himself. The acid occurs in commerce in the form of yellow crystals sold in sealed glass tubes, each containing $\frac{1}{2}$ or I gramme. One of these tubes is placed in a clean bottle provided with a glass stopper. The tube is then broken, and the required quantity of distilled water is poured over the crystals. Care should be taken to avoid the vapour, which is very poisonous.

Pure osmic acid is usually employed for fixing the retinal elements, especially the rods and cones.

Fixation in $1-2$ per cent. solution. Small globes are treated as a whole; larger ones are bisected through the equator. The process lasts 6-24 hours. Washing in distilled water, which should be frequently changed, for several days.

Teasing.

Staining is usually unnecessary.

Mounting in glycerine.

(See "Examination of Retina.")

(b) Mixtures containing Osmic Acid.-Osmid acid is emplayed most frequently as a fixing medium in the form of Flemming's Solution. This consists of :-

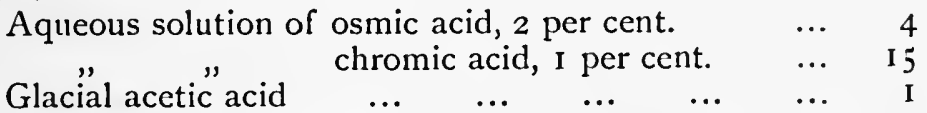

The tissues remain in this for I-3 days, not longer, or they become brittle. Washing for 3-6 hours in distilled water.

Further hardening in alcohol, 50, 60, 80, 96 per cent., in each 24 hours.

Absolute alcohol, 2 days.

Celloidin.

Staining with I per cent. solution of safranin.

For Hermann's solution, a mixture of osmic acid and chloride of platinum, and for the use of osmic acid in the Methods of Cajal, Marchi, ctc., see later.

(c) Osmic Acid in Vapour Form.-The zoologist frequently cmploy's the vapour of osmic acid to fix delicate tissues rapidly and safely. Ramvicr recommends it for fixing the retina.

\section{io. Hardening in Nitric ACid.}

Benda proceeds as follows :-

I. Nitric acid, Io per cent. solution, 24 hours.

2. Without being washed, the tissue is placed in

$\left.\begin{array}{l}\text { Müller's fluid, I part } \\ \text { Distilled water, } 2 \text { parts }\end{array}\right\} 4_{4} 8$ hours. 
$\left.\begin{array}{l}\text { 3. Müller's fluid } \\ \text { Distilled water }\end{array}\right\}$ equal parts, 48 hours.

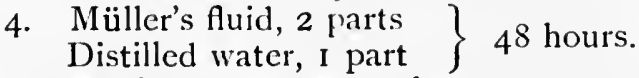

5. Washing in water, 24 hours.

$6 . \quad F u r t h e r$ hardening in alcolool.

The ordinary nuclear stains are not suited for tissues so treated.

The stains of Heidenhain or Benda should be used. By these the nuclei and karyokinetic figures are particularly well displayed. Benda's method of hardening renders the tissues very brittle, and is not suitable for large specimens. Benda stamps out small pieces of the ocular tunics with an iron punch.

Nitric acid is, after osmic acid, the best medium for the demonstration and isolation of the retinal elements. It possesses this advantage over osmic acid, that it preserves the natural colour of the retinal pigments, the yellow pigment of the macula lutea and the coloured globules found in the cones of many animals, etc.

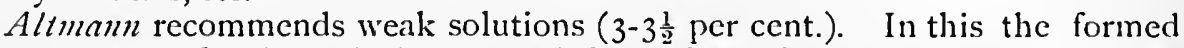
clements are fixed, and demarcated from the soluble albuminates which surround them.

The fixing process lasts 6-Io hours.

Rapid, but thorough, rinsing.

Alcohol, 80 per cent., for a short time.

Sections are made, or the tissue is teased in glycerine (See "Retina").

\section{iI. Hardening in Chloride of Platinum.}

I. Aqueous solution of platinum chloride, I per cent. $\begin{array}{llllll}\text { (Mcrkel) } \quad \ldots & \ldots & \ldots & \ldots & \ldots & 50\end{array}$ Aqucous solution of chromic acid, I per cent. ... $\quad \ldots .50$

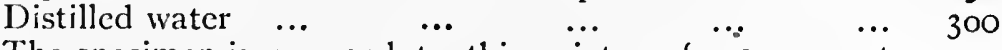

The specimen is exposed to this mixture for 24 , or, at most, 48 hours.

2. Washing in running water, 24 hours. in concentration.

3. Completion of the hardening process in alcohol gradually increased

This solution fixes and hardens quickly, and preserves the topograplical relations of the parts. Hæmatoxylin is the best stain.

\section{Hardening in Hermann's Solution.}

Hermann's solution is a mixture of platinum chloride and osmic acid. It consists of-

Solution of platinum chloride, I per cent. $\quad \ldots \quad$ I 5

Solution of osmic acid, 2 per cent. $\quad \ldots \quad$... 4

Glacial acetic acid $\quad \ldots \quad \ldots . \quad \ldots \quad \ldots \quad$ I

Small objects are fixed for $\mathrm{I}-\mathrm{f}$ days, and then thoroughly washed in running water.

Further hardening in alcohol, etc.

Hermann's solution preserves the nuclear and protoplasmic structures excellently.

Staining with safranin or gentian-violet. 


\section{I3. Hardening in Merkel's Fluid.}

The fluid consists of :-

$\begin{array}{llllllr}\text { Chloride of platinum } & \ldots & \ldots & \ldots & \ldots & \text { I } \\ \text { Distilled water } & \ldots & \ldots & \ldots & \ldots & \ldots & 400 \\ & & & & & & \\ \text { Chromic acid } & \ldots & \ldots & \ldots & \ldots & \ldots & \text { I } \\ \text { Distilled water } & \ldots & \ldots & \ldots & \ldots & \ldots & 400\end{array}$

These solutions are kept separate, and equal parts are mixed before use. The fluid is not concentrated, and so, while possessing considerable penetrating power, it is slow in its fixing and hardening action. Since it produces great swelling of the vitreous, it is, as has been said, suitable for hardening collapsed eyeballs or thin-walled staphylomata. It is not adapted for the lens.

The tissues remain in Merkel's fluid for 3-4 days, and undergo further hardening in another fluid (Müller's fluid, formalin, alcohol).

Hæmatoxylin stains the sections very slowly.

\section{Washing.}

The eyeballs or pieces of tissue must be thoroughly washed after most of the fixing processes, and this is best accomplished in running water. Only in the case of a few reagents, e.g., formalin and, under certain circumstances, picric acid, is this unnecessary.

The eyeball is placed in a tall vessel under a water tap. A piece of rubber tubing is led from the tap to the bottom of the vessel. The stream must not fall simply on the surface of the water, but must be so directed that the whole of the water is constantly renewed. Nor must the stream be too violent, else the preparation is washed away. If the specimen is light and floats, it is well to cover the mouth of the vessel with gauze.

When several specimens have to be washed simultaneously, the vessels may be placed close together, and the water led from one to another by means of small glass siphon-tubes. There are several forms of washing apparatus on the market : some are simple, others complicated.

\section{Completion of the Hardening Process in Alcohol.}

After the eyeballs or pieces of tissue have been fixed and washed, they should always undergo further hardening in alcohol. To prevent shrinking, they are not placed in pure alcohol at once, but are transferred to weak alcohol, the strength of which is gradually increased. According to the result desired, this process is conducted more or less slowly. In general, the bulbs are placed in :-

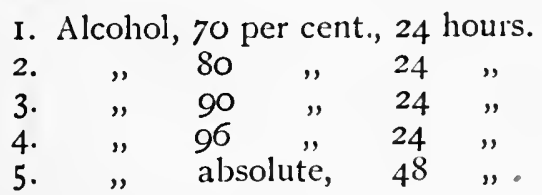

The last stage is carried out in the exsiccator. See "Celloidin Process."

The bulb may remain in any of these alcohols as long as is desired, the alcohol acting as a preserving medium. 


\section{Division of the Hardened Eyeball.}

It has been said that the eyeball is placed unopened in the fixing medium, unless this is osmic acid. It must, however, be cut into pieces before being imbedded. This operation is best performed when the eye has attained its maximum degree of firmness, viz., after it has lain in absolute alcohol for one day. The lines of section depend on the position which the segments are intended to occupy in the celloidin block. At the outset it may be remarked that no method is less practical than that of bisecting the bulb along the horizontal meridian. Every one possessed of even slight experience, knows that, especially in the case of large specimens, the first few and the last few sections are lost. Consequently, if the bulb be bisected horizontally, in whatever way it is mounted, whether with the cut surface above or below, many of the most valuable sections, those which pass through the papilla, macula, and pupillary area, are inevitably lost. Moreover, if this method be adopted, since the vitreous sinks towards the sclera, sections affording a complete view of the centre of the eycball cannot be obtained. It is best, therefore, to cut the bulb into three, or in some cases into five, discs : Innless in special circumstances the lines of the section should be horizontal.

Orientation of the Bulb.-The horizontal mcridian is casily recognized from the form of the cornea, which is ovcr-lapped by the limbus conjunctive to a greater extent above and below than laterally. This diameter of the cornea is, therefore, somewhat longer than the vertical, the circumference forming an ellipse with its major axis placed horizontally.

A further indication of the position of the eye is gained by noting that the entrance of the optic nerve lies almost in the horizontal meridian and slightly internal to the posterior pole.

There only remains the determination of the superior and inferior aspects. If the cornea has not been marked, a piece of thread may be tied to the tendon of the Rectus Superior muscle after enucleation; or, simpler still, the side to which the eye belongs is noted. The eycball must then be held so that the optic nerve lies internal to the posterior pole, in order to indicate which is the superior aspect.

When the cyeball is cut into horizontal discs, the papilla, macula and pupil are found in the middle segment in the same plane. This plane should be carefully guarded in opening the eye, and gradually cut down upon with the microtome.

The hard lens occasions some difficulty during the division, since the almost empty cavity of the vitreous affords it no support, and the easily ruptured zonula alcne holds it in position. Hence, if the section is made from the corneal aspect, it usually happens that the lens, instead of being cut, recedes before the linife and is dislocated into the cavity of the vitrcous. It is therefore important, in performing the section, to place the cornea firmly on the table, and to cut from above. In this way the lens is supported by the iris, and it in its turn by the cornea. It is stili better to make the upper and lower domes to be removed from the eyeball so small that the knife does not require to traverse the lens.

The division is carried out with a thin sharp knife applied in steady and continuous sweeps to the eye. To avoid cutting in to the table, the section of the cornea should be completed with scissors, or the eyeball may be rested on a piece of soap or on a cork.

The middle segment (2) is examined first. It is mounted horizontally. The upper and lower segments may be arranged similarly, but in this case the 
microscopic sections become more and more tangential as they approach the poles. This is sometimes confusing to the beginner, especially if little folds are present. It is better, therefore, to remove the two corners (6) of these segments, and to mount the central portions vertically. Sections are thus obtained perpendicular to the tunics of the eye.
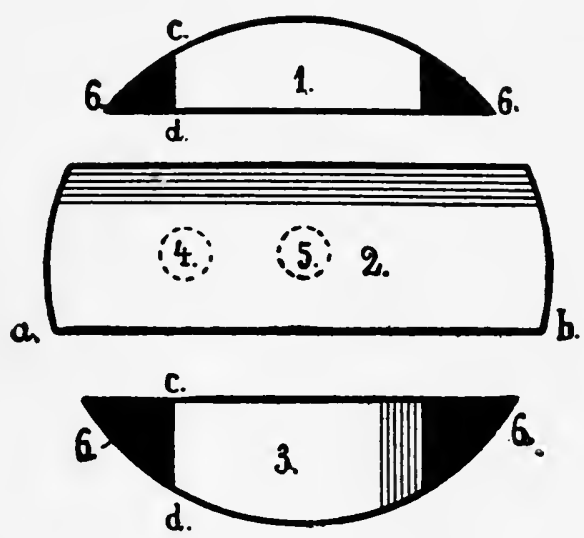

Right Eyeball.

FIG. I.-Method of dividing the Eyeball.

I, Upper ; 2, Middle ; 3, Lower segment ; 4, Papilla : 5, Macula ; 6, Discarded corners. $a b$, Surface by which the middle segment is fixed to the block. cd, Surfaces by which the upper and lower segments are fixed. The thin lines indicate the direction of the microtome cuts.

In special cases, e.g., where there is a fungiform tumour of the choroid, it may be necessary to divide the bulb in a different manner. If it is cut in such a way that incisions are made across the head of the tumour, the origin of the growth is not demonstrated, and isolated portions are shown lying in the cavity of the vitreous.

Thus, the section should not be made, as in Fig. 2, vertically along $a b$, nor yet in the direction $c d$, for in both of these cases it would cross the summit of the tumour. It should be made in the plane of the diagram, that is, perpendicularly to the base of the tumour If the exact site of the tumour has not been noted by means of the ophthalmoscope, it is still possible to discover this in the hardened eye, palpation of the walls of the globe revealing increased resistance over the seat of the tumour.

In other cases, again, the method must be modified to suit the circumstances.

The eyeball, either fresh or hardened, is often frozen before being divided Such a procedure is advocated by Priestley Smith (Ophthalmic Review, March, 1883). The eye, previously hardened in Müller's fluid, is placed in a guttapercha bag, the surface of which has been smeared with oil to prevent adhesion, and frozen solid by immersion in a vessel containing a mixture of two-thirds pounded ice and one-third salt. The vessel should have an opening in its bottom to allow the water to drain away; a small flower-pot is suitable. The eye remains in the freezing mixture for at least half an hour. It is then cut with a sharp table-knife in the desired direction. It is more difficult to perform the section with a thick-backed blade, like that of a razor. If necessary, the lines of the incisions can be marked out in ink.

Leber has devised a very useful instrument in the shape of a guillotine, with which the bulb can be divided in any direction, e.g., through the centre of the 
cornea and the middle of the optic nerve. The only objection to the apparatus is its high price (Report of the 22nd Ophthalmological Congress, I 892, p. 2 I I ).

Method of Dividing the Optic Nerve. - In conclusion, a few words must be said regarding the method of section to be followed in examination of the optic nerve. The intraocular end of the nerve is usually cut longitudinally. Farther back in the nerve cross-sections are made. If the case is one of

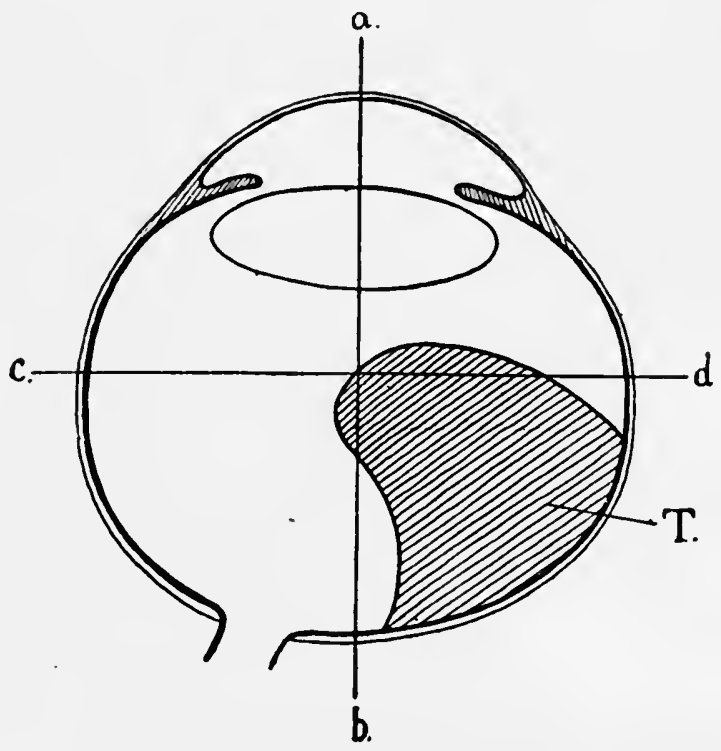

FIG. 2. - Method of dividing the Eyeball to exhibit origin of tumour.

partial atrophy, for instance, atrophy of the papillo-macular bundle, it is important to trace the course of the fibres. These, as is well known, change their position as they pass along the nerve. A guide is then necessary to show how the individual sections were situated in the nerve. If a considerable

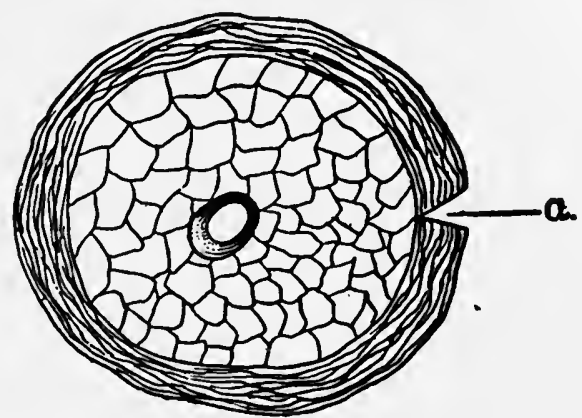

FIG. 3.-Method of marking the Outer Aspect of the Optic Nerve.

length of the nerve is to be examined, it should, before being placed in the fixing fluid, or, at all events, before being severed from the globe be incised with a sharp knife along its outer aspect. The outer margin of every section can now be recognised by the gap in its dural sheath (Fig. 3, a).

Further, it is necessary to divide the nerve into pieces $5-7 \mathrm{~mm}$. long, and this should be done before it is placed in Müller's fluid, because small pieces 
harden better and are more suitable for mounting. To prevent confusion, the author does not sever the nerve completely. A small bridge of dura is left undivided so that the segments remain connected. The whole is then hardened and placed in celloidin, and the connecting links are not divided till the pieces are ready to be placed in the block. In this they are inserted in order, the most anterior being taken first. The anterior end of each segment should be placed uppermost. Thus, the fibres can be traced along the whole course of the nerve without difficulty.

When it is desired to examine the contents of the intervaginal lymph space, e.g., in cases of cerebral tumor and choked-disc, the nerve inust be ligatured before being divided.

\section{Imbedding Processes.}

There are two methods of imbedding, each of which has its advantages and disadvantages: I. Imbedding in celloidin (or photoxylin); 2. Imbedding in paraffin.

For various reasons the celloidin method is preferred for the eye. Sections, so large as those of an entire human bulb, can hardly be cut in paraffin. Further, the appearances characteristic of many pathological changes are destroyed by the high temperature involved in the paraffin process. On the other hand, when paraffin is used, much thinner sections can be obtained, and it is easier to get these in series. Paraffin is therefore employed for small pieces of delicate tissue.

\section{The Celloidin Process.}

The pieces of the eyeball must be thoroughly dehydrated before they can be imbedded in celloidin. Herein lies the secret of good imbedding. If this is properly performed, better results are obtained with the simplest cutting apparatus than with the most complicated and expensive microtome when the imbedding is defective. A sharp knife is also essential.

Dehydration is carried out in absolute alcohol. This, however, takes up water from the atmosphere, and after a time loses in concentration. To get over this difficulty, Exsiccators have been devised. Of these there are various forms, but the simplest and most convenient is, in the opinion of the author, constructed as follows.-A wide glass vessel, provided with a ground-glass stopper, is taken, and in it there is placed a wire support on which the tissue to be dehydrated rests. A layer of roasted copper sulphate is spread on the floor of the vessel, so as to form a layer under the alcohol. Any water present in the alcohol sinks, owing to its higher specific gravity, and unites with the powder which has a great affinity for it. Thus, the tissue, which lies in the upper layers of the alcohol, escapes contact with the water. The copper sulphate when exhausted becomes green in colour, and must then be dried and roasted afresh.

The eyeball remains in the exsiccator for $24-28$ hours, and is then divided into pieces suitable for imbedding. During the process it is exposed to the air and is touched with moist hands, and, consequently, after bcing divided, it must be replaced for one day in the exsiccator. The pieces are then taken up with forceps and transferred to a thin solution of celloidin.

CElloidin is manufactured by Schering, of Berlin, and sold in the form of soft semi-transparent tablets or shavings. It is advisable to cut up the whole tablet into small pieces, while it is still soft. These pieces are dried in the 
incubator, till they assume an amber colour. They can then be preserved in a wide-necked bottle with a well-fitting cork. A tablet weighs 40 grammes. Thin celloidin is prepared by adding to Io grammes of dried celloidin 120 $\mathrm{ccm}$. of ether and $\mathrm{r} 20 \mathrm{ccm}$. of absolute alcohol. For thick celloidin we take $60 \mathrm{ccm}$. of ether, $60 \mathrm{ccm}$. of absolute alcohol and 10 grammes of celloidin. The celloidin is dropped into the solvents. The bottle should be well shaken and laid on its side, to prevent the celloidin from sticking to the bottom; after a few hours, the bottle should be shaken again and laid on its other side. An excellent plan for securing a pure solution is to place the celloidin chips in a muslin bag, and to suspend this in the centre of the solvent, where its contents dissolve most readily. Any foreign matter in the celloidin (e.g., when celloidin is used for a second time) is retained in the bag.

It is of the utmost importance that the celloidin solution should be free from water ; therefore we must take care that the alcohol and ether employed as solvents contain none. Ordinary ether frequently contains as much as 10 per cent. of water. This must be extracted by means of roasted copper sulphate, or by the addition of anhydrous phosphoric acid.

Wintersteiner's method is as follows. - The tissue to be hardened rests on a small glass ring which is supported by three glass legs. This support is placed in a wide-necked preparation jar provided with a ground glass stopper, and capable of holding $30 \mathrm{ccm}$. The bottom of the jar is covered with roasted copper sulphate over which the absolute alcohol is poured. If the pieces of tissue are so small that they would fall through the ring, which was primarily intended to carry the half of the eyeball, the ring may be covered with a piece of filter paper.

After being hardened, the pieces remain for I-IO days (according to their size) in a mixture of equal proportions of absolute alcohol and ether ; then for 8-I4 days in thin celloidin; and for a similar period in thick celloidin. The ether should be allowed to evaporate very slowly in a well-covered vessel, until the celloidin attains the consistence of soft wax. A preparation of some size is therefore left in the celloidin solutions for a month.

Photoxylin.- This new substance is used for imbedding in exactly the same manner as celloidin. It occurs in commerce in the form of wool, which, being very explosive, is scheduled under the Dynamite Act. It can be obtained also in the form of a syrup.

It possesses certain advantages over celloidin : (I) it dissolves immediately ; (2) it is more transparent, so that the preparation is better seen when mounted ; (3) it is less deeply stained by hæmatoxylin.

Since the wool takes up water from the air, it must be dried for a time in the incubator. It dissolves readily in a mixture of alcohol and ether, and should be added to this gradually, until the solution is of the desired consistence. A thin and a thick solution are prepared, as in the case of celloidin.

The pieces of the eyeball remain four days or longer in thin celloidin, and for the same time in thick celloidin.

Now they are ready to be mounted.

\section{Preparation of the Celloidin Block.}

The tissue having been saturated with celloidin must be set upon a firm support. Wood is unsuitable, as it contains colouring matter which finds its way into the preparation and has a deleterious influence on the nuclear and diffuse stains. Nor is cork to be recommended, since it contains an acid which is injurious to the tissues. It is better to employ "Stabilit," a material which 
may be procured from the electrical depots. It can be trimmed to the proper shape with a saw. There are two methods of procedure:-

I. A strip of paper is fastened round the piece of "Stabilit" by means of thin celloidin, thus forming a small box. The upper edge of the paper should be a little higher than the surface of the specimen when this is in position. Some thick celloidin is then poured into the receptacle, so as to close all chinks and to form a viscous layer on the floor. The preparation having been placed in the box by means of a lifter, adjusted suitably for cutting, and pressed firmly into the layer on the floor, the receptacle is completely filled with thick celloidin. The ether must now be allowed to evaporate until the celloidin attains the consistence of soft wax. If this takes place quickly, the surface of the mass becomes hard and evaporation from the deeper parts is hindered. The ether should consequently be allowed to evaporate slowly. This is effected by "partial covering," the preparation being placed under a bell-glass slightly raised at one side from the table on which it rests by means of the handle of a teasing needle. As soon as the celloidin has attained the requisite consistence, which may be judged by finding if it no longer takes on the impress of the finger point, the block is transferred to 70 per cent. alcohol. The evaporating stage lasts from four to twelve hours, the time required depending on the quantity and thickness of the celloidin and on the extent to which air is admitted. In the alcohol the celloidin becomes milky and attains the consistence suitable for cutting. After a few hours the paper is removed and the superfluous celloidin cut off. Henceforth the preparation must not be allowed to dry, but must be preserved in 70 per cent. alcohol.

2. The tissue is placed in a shallow vessel and thick celloidin is poured over it. The vessel is partially covered, and the ether allowed to evaporate very slowly, the process lasting, if necessary, even for several days. The more gradual the evaporation, the finer the preparation. In Greeff's laboratory the evaporating process sometimes lasts from two to three weeks. The vessel containing the specimen must not be disturbed till the celloidin is firm, or air bubbles may be produced. As soon as the celloidin has attained the consistence of soft wax, the tissue is cut out and placed on a piece of "Stabilit" which has been smeared with thick celloidin. The joint is allowed to harden in the air for about five minutes, and the block is then transferred to 70 per cent. alcohol. Sections may be made after a few days.

\section{On Cutting Celloidin Sections.}

Preparations imbedded in celloidin are cut with the microtome. The knife should be tightly screwed to its carriage. Whereas in cutting paraffin sections the blade is placed at right angles to the tissue, in cutting celloidin sections it should be adjusted obliquely, so as to pass with its whole length through the block. The more perfect the imbedding, the more obliquely should the knife be set. The object must be firmly secured in the holder of the microtome, and levelled so that its surface lies in the plane of the knife, and all the screws must be tight. After each section is cut, the knife and the tissue are moistened with a brush dipped in 70 or 80 per cent. alcohol. The sections should, in fact, swim on to the knife. They are preserved till stained in 70 or 80 per cent. alcohol.

Wintersteiner recommends that the sections be cut under alcohol, but places each section as it is removed from the knife in a large staining dish containing water. Here it swims about, and becomes perfectly flat. In this way curling and wrinkling of the section are avoided during the subsequent processes. 
The thickness of the sections depends on their size, but in no case should this exceed $25 \mu$, even when complete or distended myopic eyeballs are being cut.

\section{Staining.}

Hardencd preparations require to be stained. Stains are selected which affect the different elements of a cell in a different degree, and render one clement more prominent than the rest. The oldest and still the most important stains are those which exhibit a special affinity for the nuclei of all cells present in the section. Hence their name-nuclear stains. Of these hæmatoxylin and carmine are the chief. The nucleus having been stained, the protoplasm can, if desired, be brought into relief by means of another, the so-called contrast stain. Stains which have a diffuse action are selected for the latter purpose. Since the nuclear stains are mostly employed in the form of aqueous solutions, the sections are immersed in water for a short time before being placed in them. If, however, alcoholic staining solutions be employed, this is unnecessary. After being removed from the staining solution, the sections are washed thoroughly in water to get rid of any superfluous colouring matter. (See "Nuclear Stains and Double Stains.")

Having been stained and washed, the section is then cleared, and mounted on a slide. It must, however, be thoroughly dehydrated before being treated with the clearing agents, as these are not miscible with water.

\section{Dehydration.}

Dehydration is carried out by means of alcohol. Since the section is apt to become wrinkled when transferred directly from water into strong alcohol, it should first be immersed in weaker spirit, 80 to 90 per cent. It is next placed upon the slide by means of the section lifter, and dried with blotting-paper. Alcohol, 96 per cent., is then poured over it. It would be preferable to employ absolute alcohol, but this is inadmissible, because it would dissolve the celloidin which holds the parts of the section together.

\section{Clearing in Oil.}

The section is now saturated with an essential oil which clears it. Thereafter it is carefully examined to determine whether it is perfectly transparent. If any water is left, owing to incomplete dehydration, it separates in the form of microscopic drops, which appear like white clouds to the naked eye. Should this occur, the section must be treated with 95 per cent. alcohol once more.

Clove Oil may not be used, since it dissolves celloidin.

Oil of Turpentine possesses the same disadvantage.

Admissible are :-

Oleum Origani Cretici, and

Oil of Bergamot.-This last is the least sensitive to water.

Cedar Oil should be reserved for use with the oil-immersion lens.

All oils are more or less injurious to the staining; the sections, therefore, should be left in them for only a short time, and the oil should be dried off by means of blotting-paper.

The best substitute for the oils is Xylol. It, however, is very sensitive to water, and requires thorough dehydration of the section. If the celloidin is 
to be retained, the dehydration is carried out in 96 per cent. alcohol, and, since xylol does not clear from this grade, the section is first treated with Carbol-Xylol. This consists of :-

Pure carbolic acid crystals

Xylol

It acts rapidly.

Carbol-Xylol should not be used for sections in which bacteria may be found, since carbolic acid removes the anilin dyes. Such sections should be thoroughly dehydrated, and treated in pure xylol or cedar oil.

After being cleared, the section is covered with a drop of Canada balsam, and protected with a cover-glass.

\section{Recapitulation.}

The following is a synopsis of the various stages in the preparation of the stained celloidin section :-

I. Fixing, e.g., in Müller's fluid, 6 weeks.

2. Washing in running water, I day.

3. Completion of the hardening process in alcohol :-

Alcohol, 70 per cent., I day.

4. Division of the bulb.

$\begin{array}{lll}" & 80 & \\ " & 90 & " \\ " & 96 \quad " \\ , & \text { absolute (exsiccator), } 2 \text { days. }\end{array}$

5. Exsiccator, I day.

6. Thin celloidin, 4 days.

7. Thick " 4 ",

8. Mounting on the block; partial covering ; slow evaporation.

9. Alcohol, 70-8o per cent., 6 hours or longer.

I0. Section cutting with the microtome under 70 per cent. alcohol.

I1. Water, 1 minute.

12. Staining (hæmatoxylin, carmine, etc.).

13. Washing in water.

14. Alcohol, 8o per cent., in a staining dish.

15. Drying with blotting paper, on the slide.

16. Alcohol, 96 per cent.

$\left.\begin{array}{l}\text { 17. Carbol-xylol. } \\ \text { I8. Xylol. }\end{array}\right\}$ or oil.

I9. Canada balsam.

\section{Serial Celloidin Sections.}

I. To Weigert belongs the credit of describing a method whereby serial sections can be obtained from material imbedded in celloidin. This method has been modified to advantage by Obregia (Neurol. Centralbl., I 890, No. I 8).

Several strips of toilet paper, slightly broader than the width of the sections, are procured. A flat plate is placed near the microtome, and covered with a thick layer of blotting paper moistened with 80 per cent. alcohol. The paper strips are arranged on the blotting paper, glossy side upwards. Each section, as it is cut, is removed from the knife, on which it lies in spirit, by applying one of the strips of paper to the section and drawing it to the left along the blade. The next section is taken up on the same strip to the right of the 
last, and so on, till the sections extend the length of the slide to be used. While each section is being cut, the strip of paper is laid on the moist plate, the side with the sections being uppermost. In this way a series of strips is prepared and arranged in order on the plate.

Obregia employs two solutions :-

\section{Solution $A$.}

Solution of sugar candy in distilled water, of syrupy consistence (difficult to make)

Alcohol, 90 per cent.

Syrupy solution of dextrin

This mixture is poured over a sheet of glass of suitable size, so as to form a thin film, just as if a photographic plate were being prepared. The film is allowed to dry in the air for about half an hour. The strips carrying the sections are then pressed upon the surface of the film to which they adhere, and the paper is removed. Several strips can be so applied.

There is now poured over the sections, so as to form a uniformly thin layer :

\section{Solution $B$.}

Photoxylin

Absolute alcohol

Ether

This is allowed to settle, and the clear liquid is decanted.

The sheet is placed in a horizontal position, and exposed to the air till the milky appearance around the sections disappears. It is then immersed in water, where the sugar dissolves and the photoxylin film becomes detached. The film can be stained as desired. After this the film is cut into suitable pieces, and mounted in Canada balsam under large cover-glasses or sheets of mica.

2. The simplest, and for most purposes the most convenient, method of obtaining serial sections in celloidin is as follows.-A large circle of blotting paper is placed on a plate, and moistened in the manner just described. The upper margin of the circle is marked (I). Commencing from the mark the strips bearing the sections are arranged on the blotting-paper in the form of a spiral. They may be numbered, although this is unnecessary. When the circle is complete, the paper is transferred to a flat vessel provided with a closely fitting lid. The floor of the vessel is covered with weak alcohol sufficient to keep the blotting-paper moist without, however, allowing the sections to float. A second spiral is similarly prepared, numbered (2), and placed above the first, and so on till the process is completed. The sections are thus arranged in order, and can be stained when convenient.

When this method is adopted it is not compulsory to finish the work at one sitting, and, moreover, every section need not be examined. It is often sufficient to take every fourth or sixth section, and thus to gain a general idea of the object. Afterwards sections can be inserted at any place where this is necessary.

The sections are stained singly in vessels placed in a row. Leber has devised a plate with circular depressions, after the style of an egg-tray, which is very convenient for arranging and staining serial sections, and which can hold as many as 300 of these. (Bericht der Heidelberger Oph. Gesellsch., 1892).

Large sections, such as sections of the complete eyeball, may be removed 
from the knife on separate pieces of blotting paper, and placed one above the other in a tall vessel. The papers can be numbered if this is desired. The subsequent procedure is as detailed above.

Wintersteiner recommends the following simple apparatus, when serial sections have to be made of large objects imbedded in celloidin.-A glass plate is placed in a stout wooden frame $26 \mathrm{~cm}$. long and $22 \mathrm{~cm}$. broad. The box so formed serves to hold 30 glass dishes with overlapping lids. The dishes are $4 \mathrm{~cm}$. in diameter, and have a capacity of $10 \mathrm{c.cm}$. Both dishes and lids are numbered ( $\mathrm{I}$ to 30 ), the pigment being burnt in so that it resists all reagents.

Before use the lids are removed, and the dishes are filled with 60 per cent. alcohol. The sections are lifted from the knife by means of a large soft brush, and placed in the dishes according to their number. When each dish contains a section we begin again with the first, and so on. There is no risk of confusing the sections in any one dish, since, after thirty sections have been made, their macroscopic appearance and outline differ so greatly that they are readily recognised. Of course this applies only to objects like the eye.

If the tissue has been stained in bulk, so that the sections are ready to be placed on the slide, we may examine every fifth section to obtain a rough idea of the series. We take numbers I, 6, I I, etc., or numbers 5, IO, I 5, etc. Of course, in order to avoid confusion, the sections from each dish must be treated separately in the clearing fluid, and the slides carrying the mounted specimens must be numbered.

If the sections are unstained, the covers of the dishes, which, as has becn mentioned, are also numbered, serve to contain the staining fluid. Here, again, we examine every fifth section, in order to determine which part of the series is of importance, and to learn if another staining method is more suitable.

Since the dishes are of considerable capacity, it is not necessary to hurry on with the work. Moreover, before the sections of the first series are mounted, those of a second series, provided they are readily distinguishable, may be distributed among the vessels.

Since the dishes and the bottom of the frame are transparent, this apparatus allows us to select the colour of our background to suit the transparency of the sections. We choose a dark ground for unstained pale sections, and a white one for coloured or pigmented tissues. This advantage is lost if white porcelain dishes are used, as has been suggested by Leber and others. Additional advantages of this apparatus consist in the larger quantity of fluid which the dishes contain, in the ease with which they can be removed from the frame, and in the prevention of evaporation owing to the well-fitting lids. The apparatus can be procured from Dümler, 25 Mariahilferstrasse, Vienna. It costs about fifteen shillings.

\section{Nuclear Stains and Double Stains.}

Every staining solution should be filtered before being used.

\section{The Paraffin Process.}

Imbedding in paraffin possesses two great advantages. In the first place very thin sections can be obtained; and, secondly, continuous serial sections can be produced without difficulty. But it is not without its disadvantages. Most preparations are unable to resist the high temperature involved in this process, so that almost all workers perfer to use celloidin. Further, if paraffin 
is employed, large sections, e.g., sections of the complete bulb, are difficult to cut. Finally, in it the delicate structures of the eye, such as the connective tissue of the optic nerve, are prone to shrink.

At the same time, when it is desired to submit small sections to minute examination, paraffin should be chosen, and beautiful results can be obtained by careful working.

Paraffin penetrates the lens with great difficulty and should not be used for this or for a thick sclera.

Two paraffins of different melting point, a soft and a hard, are used. They are mixed in proportions that depend on the temperature of the laboratory. When this is low, a larger proportion of soft paraffin is taken; when the temperature is high, the hard paraffin should be in excess. In general, equal quantities of the two kinds are used. These are placed in a suitable vessel, and slowly melted in the incubator at a temperature which should not rise higher than a degree or two above the melting-point of the mixture.

The author employs a Soft Paraffin whose melting-point lies between $40^{\circ}$ and $42^{\circ} \mathrm{C}$., and a Hard Paraffin whose melting-point lies between $52^{\circ}$ and $54^{\circ} \mathrm{C}$. The temperature of the incubator should be somewhat higher, $60^{\circ}$ or at most $62^{\circ} \mathrm{C}$., and is kept at this point by means of a Regulator.

The pieces of the hardened bulb must be thoroughly dehydrated in absolute alcohol.

They are now saturated with an Intermediate Fluid. As such xylol may be recommended, and, if this is chosen, the immersion should not be of longer duration than 4-6 hours, or the tissues are rendered too brittle. Chloroform (24 hours) may be used, or turpentine, cedar oil, etc.

When the structures to be treated are very fine, the transition from alcohol to the intermediate fluid should be gradual, so as to avoid violent diffusion currents and shrinking of the tissue. This is prevented by putting the heavy intermediate fluid into a test tube, and carefully pouring a column of absolute alcohol over it. The specimen is then gently lowered into the tube, and lies on the interface between the fluids. When thoroughly impregnated by the heavier fluid it sinks to the bottom. Then the alcohol is poured off, and the tissue left for a few hours in the pure intermediate fluid.

The next step is to pour the fluid and tissue into a staining-glass, and to add some pieces of soft paraffin. The glass is covered and set aside till the paraffin is dissolved. Then the cover is removed, and the glass placed in the incubator, so that the intermediate fluid evaporates. The specimen is next transferred to the mixture of soft and hard paraffin, a few hours' immersion in which suffices to saturate it.

After this the tissue is ready for Imbedaing. An imbedding frame is formed by placing two L-shaped metal bars on a sheet of glass, or a small paper box is made. In either case the surfaces should be brushed with glycerine to prevent the paraffin from adhering. The tissue is placed in the receptacle, its position carefully noted, and the melted paraffin is poured in. The paraffin must be quickly cooled, in order to secure homogeneous consistence. With this end in view it is immersed in water. The paper or frame having been removed, and the block trimmed, the specimen is ready for cutting.

The stages in imbedding a small, 6-9 $\mathrm{mm}$. long, piece of retina are as follows :-

\section{A. Saturation with the Intermediate Fluid.}

The tissue is thoroughly hardened and placed in-

I. Absolute alcohol, Io minutes. This stage is repeated with fresh alcohol. 
2. Absolute alcohol $\frac{2}{3}$ Xylol $\left.\quad \begin{array}{l}\frac{1}{3} \\ \text { A }\end{array}\right\}$ well mixed, 10 minutes.

3. Absolute alcohol Xylol

$\left.\frac{1}{3}\right\}$

well mixed, 10 minutes.

4: Xylol-paraffin mixture with xylol in excess, 15 minutes.

5. Xylol saturated with paraffin, 15 minutes, or a few minutes in the incubator.

These solutions are kept ready for use in well-stoppered vessels. The absolute alcohol should be frequently renewed.

6. Mixture of hard and soft paraffin contained in a small porcelain vessel, I-2 hours in the incubator, at $60^{\circ} \mathrm{C}$.

Larger pieces of tissue, which, however, should not be more than a few millimetres in thickness, are left in each of the first five solutions for 30 minutes, and in paraffin for $12-24-36$ hours.

\section{B. Imbedding.}

The tissue can be imbedded in a staining-dish which has been breathed upon, or one of the receptacles described above may be used.

$\left.\begin{array}{l}\text { Adjustment of the specimen } \\ \text { Covering with paraffin }\end{array}\right\}$ quickly performed.

Solidification, a few minutes.

Trimming the block.

Mounting the specimen on a firm support by heating the under surface of the block with a hot spatula.

\section{On Cutting Paraffin Sections.}

The paraffin block is trimmed into the shape of a cube, and mounted on a piece of wood, or on a metal support, such as is provided with the Schanze microtome. The support is now securely clamped in the object holder. The knife should be fixed at right angles to the paraffin block. The sections are cut dry, and as thin as possible. The knife is adjusted so that only its edge comes into contact with the block, and is carried quickly through the paraffin. If the sections tend to curl up into little rolls, they may be prevented from doing so by gentle pressure of a fine brush held in the left hand, or by breathing on the knife and surface of the block. Much depends on cutting the sections at a proper temperature. If this is too low, the sections crumble ; if it is too high, they are apt to become folded on themselves. In the former case the knife may be warmed or the microtome placed near the fire; in the latter the block may be surrounded with a piece of gauze surrounded by ether. The sections, as cut, are arranged along the back of the knife.

If serial sections are desired, the block should be trimmed to the shape of a triangle, so that the apex of one section adheres to the base of the next. Long ribbons can be obtained in this way.

\section{Fixing to the Slide.}

The sections must now be mounted on slides in order that they may not be injured in the subsequent manipulations. In most cases it is sufficient to spread upon the slide a drop of water containing a trace of alcohol, and to lay the section or sections on this. The slides are then placed in the incubator $\left(30^{\circ}-35^{\circ} \mathrm{C}\right.$.) for $12-24$ hours or warmed (without melting the paraffin) over a flame till the water has evaporated. If the incubator is at too high a temperature, the slides may be laid on the top of it 
for 24 hours. When the tissue has been hardened in chromic acid, Müller's fluid, or osmic acid, the sections require to be fixed to the slide more firmly. For this purpose P. Meyer recommends filtered white of egg mixed with an equal quantity of glycerine; to this may be added a trace of thymol or a few grains of salicylate of soda, to prevent the development of fungi. A small drop is spread in a thin layer on a slide, and on this the section is laid. Thereafter the slide is warmed, etc.

\section{Staining.}

The paraffin requires to be removed before the sections are stained. This is accomplished by immersing the slide in a tube of xylol for one or two minutes. The sections are next treated with-

Absolute alcohol, to remove the xylol.

Alcohol, 90 per cent.

Water (omitted if alcoholic stains are used).

Staining fluid (carmine, hæmatoxylin, etc.)

Water.

Alcohol, 90 per cent.

Absolute alcohol, xylol, Canada balsam.

The re-agents are poured over the section as it lies on the slide.

The process is thus similar to that followed in the case of celloidin, the only difference being that the binding substance, the paraffin, must be removed, and, since the xylol employed for this purpose is not miscible with water, the sections must be treated with absolute alcohol. Further, absolute alcohol, which ought to be avoided in the case of celloidin, may be used to complete the dehydration of the sections. Of course, a counter stain may be employed if desired.

\section{Mounting in Glycerine.}

Glycerine is a clearing agent, and, since it does not evaporate or change its chemical constitution, it is adapted for mounting permanent preparations. It is less suitable for fresh material, as it renders this too transparent. On the other hand, it is a very good medium to adopt for the examination of unstained sections of hardened tissuc. It possesses the advantage of being less highly refracting than Canada balsam. Unstained sections are thus more apparent in glycerine than in balsam. Again, it is chosen for mounting sections which must not come into contact with alcohol after having been stained. Lastly, it is used for mounting very fine tissues or particles, e.g., teased preparations, which cannot undergo the manipulation of staining. dehydration, etc. It is thus adapted for mounting the rods and cones and other retinal elements which have been hardened and isolated in osmic or nitric acid.

The sections may be transferred directly from water or salt solution into glycerine.

The teasing should be performed in glycerine. Pure glycerine is generally employed, more rarely diluted glycerine (Io parts of glycerine to 50 of water). If it is intended to preserve the preparation for any length of time, the coverglass must be securely fixed to the slide so as to exclude the air. This is accomplished by ringing the cover-glass with cement. Any superfluous glycerine about the edge of the glass is removed by means of a rag moistened with absolute alcohol. The margins of the cover may then be sealed by drawing the wick of a newly extinguished wax taper along them. A better 
method, however, is to paint the margins of the cover-glass with a layer of glycerine-jelly, and over this to apply a coat of asphalt varnish or Krönig's cement.

Beale recommends a jelly consisting of equal parts of isinglass and glycerine. The cement may be purchased from the dealers.

\section{Hæmatoxylin.}

Hæmatoxylin, the colouring matter of the Brazilian campeachy wood (logwood), is found commercially in the form of crystals. It is the best and most certain nuclear stain. At the same time its action is slightly diffuse. The nuclei are stained dark blue, the protoplasm pale blue. Hæmatoxylin is very sensitive to acids, and is, therefore, not suited for staining tissues which have been hardened in them. Freshly prepared solutions act slowly; after a few days their power of staining increases, but in course of time again decreases. Solutions of hæmatoxylin do not, as a rule, keep well. Fungi develop and prove troublesome when they come into contact with the sections. Consequently, the staining solution should be filtered before use.

Previous to being transferred to the staining solution the sections are immersed for a short time in water, and after being stained they are thoroughly washed (for a quarter of an hour, or better still for several hours) to prevent subsequent darkening. Beautiful results are obtained by employing a very dilute solution (a few drops of the staining fluid in a glass of water), and leaving the section in it for perhaps 24 hours. The process is as follows :-

I. Immersion in water, for a few minutes.

2. Staining.

3. Washing, best for a considerable time.

4. Alcohol, 80 per cent.

5. Alcohol, 96 per cent.

6. Oil (not clove oil).

7. Canada balsam.

Hæmatoxylin readily overstains, that is to say, sections become too dark if immersed unduly long in the staining solution. They must, therefore, be examined from time to time in water. It is impossible to state how long the staining process should last. This depends not only on the solution employed but also on the method by which the sections have been prepared. An immersion of $\frac{1}{2}$-IO minutes is usually sufficient.

There are many formulæ for hæmatoxylin solutions; only the most common are mentioned here.

I. The simplest hamatoxylin solution is a I per cent. solution of the dye in distilled water. This is bright yellow in colour, and suited for staining sections and also for staining in bulk.

2. Alum-Hamatoxylin (Boehmer).-This is the oldest and most generally used solution. It is prepared in the following manner. Two solutions are kept in stock-

I. A solution of I gramme of hæmatoxylin in $30 \mathrm{c.cm}$. of absolute alcohol.

2. A I per cent. solution of ammonia-alum.

Some days before the stain is required the hæmatoxylin solution is added to the alum solution till a bright violet colour is obtained. The violet colour changes to blue on exposure to the light, and the stain is then ready for use.

3. Delafield's Hamatoxylin.-The following solutions are mixed and 
exposed to the light and air in an unstoppered bottle for four days, and then filtered-

I. A solution of 4 grammes of crystalline hæmatoxylin in $25 \mathrm{c.cm}$. of absolute alcohol.

2. $400 \mathrm{c} . \mathrm{cm}$. of a concentrated solution of ammonia-alum.

To the mixture are added $100 \mathrm{c} . \mathrm{cm}$. of glycerine and $100 \mathrm{c} . \mathrm{cm}$. of methylic alcohol; after two days the whole is filtered.

Delafield's hæmatoxylin stains more intensely and quickly than Boehmer's, and is at present much in favour. It can also be applied in a dilute form with good results. For the rest it behaves like alum-hæmatoxylin.

Hamalaun (P. Mayer). - This stains like hæmatoxylin, and is therefore mentioncd in this place. One gramme of hæmatein is dissolved by heat in $50 \mathrm{c.cm}$. of 90 per cent. alcohol, and mixed with a solution of 50 grammes of alum in I litre of distilled water. A crystal of thymol is added to preserve from fungi.

Hæmalaun possesses some decided advantages. In the first place, it is ready for immediate use; sccondly, it acts very quickly; and, thirdly, overstaining is not apt to occur. Hæmalaun is therefore a favourite stain in some laboratories.

Ehrlich's Acid-Hamatoxylin.-This consists of :-

$\begin{array}{lllr}\text { Water } \ldots & \ldots & \ldots & \text { 100 } \\ \text { Absolute alcohol } & \ldots & \ldots & 100 \\ \text { Glycerine ... } & \ldots & \ldots & 100 \\ \text { Glacial acetic acid } & \ldots & 10 \\ \text { Hæmatoxylin } & \ldots & \ldots & 2\end{array}$

Alum in excess.

The mixture is filtered and ripened by exposure to light until it acquires a dark red colour. It is said to keep for years, if preserved in a well-stoppered bottle.

Heidenhain's Iron Homatoxylin.-Sce " Demonstration of the Karyomitotic Figures."

Benda's Sulphate of Iron Hamatoxylin.-See ditto.

Weigert's Hamatoxylin. - This is not a nuclear stain. It is employed to demonstrate the medullary sheaths.

\section{Treatment of Overstained Sections.}

Sections which have been overstained in hæmatoxylin and become too dark can be cleared up by various methods :-

I. The stain may be partially re-dissolved in a 1 per cent. solution of ammonia-alum. The section remains in this for several hours until the blue colour becomes bright violet, and is then thoroughly washed.

2. The depth of the stain may be reduced by placing the section in one-tenth per cent. solution of hydrochloric acid, and thereafter washing it for twelve hours.

3. The following is an excellent method by means of which a pure nuclear stain is obtained. It is employed by the author when he desires specially fine sections for demonstration, or when it is intended to photograph, or to make drawings of, the specimen. A contrast stain may be added with advantage. In successful cases the nuclei appear blue, while all else is pale (e.g., the celloidin, which is always a disturbing element). The pale elements readily take up a contrast stain such as eosin. The procedure is as follows :-

I. Overstaining with hæmatoxylin for at least half an hour.

2. Washing in water for a short time. 
3. Immersion in weak nitric acid (one drop of strong nitric acid added to a watch-glass of water) until the section becomes red.

4. Immersion in weak liquor potassæ (one drop, etc.) until the section becomes bright blue.

5. Washing in water.

The section must now be examined in order to determine whether it is sufficiently differentiated or not. The celloidin is decolourised first, the protoplasm next, then the nuclei, and, finally, the karyokinetic figures of the nucleus. If the differentiation is not sufficient, the section is placed once more in the nitric acid solution, and the process is repeated until the nuclei alone are prominent. This is conveniently determined by examination under the microscope, but the proper depth can also be estimated by the naked eye. Thus, the celloidin should be decolourised, also the sclera, which contains few nuclei. On the other hand, two distinct blue lines ought to be visible in the retina, corresponding to its stained nuclei. In conclusion, it should be noted that the sections must be thoroughly washed in order to prevent subsequent decolourisation.

A contrast stain may be added if desired.

Differentiation can be performed in the same manner by means of-

Acidulated Spirit.-This consists of :-

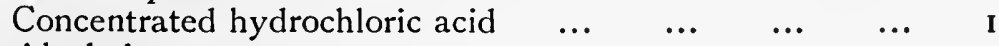

Alcohol, 70 per cent.... $\quad \ldots \quad \ldots . \quad \ldots \quad \ldots \quad \ldots r$

N.B.-The following principles should be adopted, when hæmatoxylin is employed. The author prefers Delafield's solution. The section should be overstained. It should next be washed in water for $\frac{1}{2}-\mathrm{I}$ hour, the water being changed frequently ; then immersed in acidulated spirit until the celloidin is colourless, and the tissue assumes a reddish tinge. Thereafter it should be immersed in a weak solution of ammonia till it regains its blue colour; thoroughly washed in water; and counterstained with eosin.

\section{Double Staining with Hæmatoxylin.}

A double stain consists of a preliminary stain and a secondary or contrast stain. It is important to choose for the former a good nuclear stain, for the latter a diffuse stain which colours the protoplasm and formed tissue elements differently.

1. Hamatoxylin-Eosin.-The preliminary staining is carried out with an ordinary hæmatoxylin solution, and should not be too intense.

The nuclear stain is more precise if the section is overstained and then differentiated in nitric acid and caustic potash in the manner just described.

After being removed from the staining solution (or the liquor potassæ) the sections should be thoroughly washed.

A few drops of concentrated aqueous solution of eosin are added to a watchglass of water. The sections remain in this until they become faint rose-red (I-5 minutes).

They are rinsed in water containing a trace of eosin.

Eosin, unlike hæmatoxylin, is very feebly held by the tissues and is immediately extracted by liquids which do not already contain some of it. Hence a trace of it is added to the water and to the various alcohols with which the sections are treated.

Alcohol (eosin), 8o per cent.

Alcohol (eosin), 96 per cent.

Oil, or carbol-xylol and xylol.

Canada balsam. 
The contrast staining can also be carried out in alcohol. A few drops of the solution of eosin are added to the 80 per cent. alcohol, and the sections are stained in this. Then they are transferred to stronger alcohol, oil, Canada balsam. An aqueous solution should be added to water; an alcoholic solution to alcohol.

Staining with eosin may also be accomplished if a trace of an alcoholic solution is added to the carbol-xylol.

The following stains have been recommended in place of eosin, and yield even more beautiful results:-

2. Orange G.-An anilin dye. A concentrated aqueous solution is prepared, and used diluted with water or alcohol.

3. Aurantia is employed in the same manner.

4. Acid-Fuchsin.-This is used like the others of the series, but, unlike them, is not removed by washing, so that care must be taken not to overstain.

\section{Triple Staining.}

I. Van Gieson's stain:-

I. Hardening in Müller's fluid or otherwise.

2. Imbedding in celloidin. Section-cutting.

3. Preliminary staining in Delafield's or Boehmer's hæmatoxylin. It is better to overstain the sections (half an hour), and not, as was originally recommended, to keep them in the hæmatoxylin for only three to five minutes.

4. Thorough washing in water.

5. Staining for a minute or two in a mixture consisting of a saturated aqueous solution of picric acid to which a few drops of saturated aqueous solution of acid-fuchsin are added before use. The depth of the fuchsin stain may. if necessary, be lessened by immersing the sections in a solution of picric acid.

6. Washing for a minute or two.

7. Alcohol, 80 per cent. and 96 per cent.

8. Oil, Canada balsam.

Van Gieson's method is of the greatest importance. It ought to be employed whenever it is desired to contrast two different tissues sharply. Epithelium and endothelium stain a brownish-yellow, and stand out in brilliant relief against the bright red connective tissue. It is unsurpassed for demonstrating the connective tissue of the optic nerve in its normal and pathological conditions. The nuclei are coloured violet, the axis-cylinders red, and the medullary sheaths yellow.

Still more beautiful is the colouring if the following stain, recommended by Weigert, is employed :-

$\begin{array}{lllll}\text { Hæmatoxylin (I per cent. in absolute alcohol) } & \ldots & & 7 \\ \text { Liquor ferri sesquichlorati ( } 4 \text { per cent.) } & \ldots & \ldots & \ldots & 5\end{array}$

The sections are washed and differentiated in a concentrated aqueous solution of picric acid, to which a solution of acid-fuchsin is added till the mixture becomes bright red. The sections should be overstained in the hæmatoxylin. The composition of liquor ferri sesquichlorati is given under "Elastic Fibres."

$$
\text { Alcohol. Carbol-xylol. Balsarn. }
$$

II. Biondi-Heidenhain Method.

I. Hardening in corrosive sublimate.

2. Imbedding. The method was originally intended for paraffin sections, 
but it can be applied to celloidin sections provided these are thin. Otherwise the celloidin, which is also affected by the stain, proves a disadvantage.

3. Staining in a weak solution for six to tiventy-four hours. The stain consists of-

Saturated aqueous solution of orange G. (8: 100), filtered . 100

Saturated aqueous solution of acid-fuchsin . . . . $\quad 20$

Saturated aqueous solution of methyl-green . . . . . jo

These solutions should be made up scparately, and allowed to stand for a few days in presence of excess of colouring-matter. The stain can also be procured from Grübler, ready for usc. One part of the mixture, diluted with IOO parts of distilled water containing 2 drops of acetic acid, is cmployed. The solution is known to consist of the proper proportions, if a drop placed on blotting-paper leaves a mark which is bluish-green in the centre and orange towards the margin. If the margin is red, too much fuchsin is present.

4. Washing for a minute or two in go per cent. alcohol.

5. Dehydration in absolute alcohol.

6. Xylol, Canada balsam.

Resting nuclei stain blue; nuclei undergoing karyomitosis and the fra:smentary nuclei of leucocytes, intensely green; protoplasm, fibrillar connective tissue, and the coloured blood corpuscles, red.

The method is adapted for staining tissues abounding in lcucocytes. It has becn used for the normal retina, and Birnbacher has discovered that the frog's retina reacts differently to this stain, according as the animal has been kept in the dark, or in the light, before the removal of the eyc.

\section{Carmine.}

Carmine is one of the oldest and most popular of stains. It is principally a nuclear stain, but it tinges also the protoplasm of the cell body. It acts more slowly than hæmatoxylin; its solutions keep better, and are not so sensitive to acids. For tissues which are difficult to stain hæmatoxylin is preferable.

Only one or two of the following solutions need be kept :-

I. Alum-Carmine or Grenacher's Carmine.-This stains the nuclei cherryred, and is almost a purely nuclear stain. Overstaining does not readily occur.

2-5 grammes of powdered carmine are boiled for $\frac{1}{2}-\mathrm{I}$ hour with $100 \mathrm{c.cm}$. of a 5 per cent. solution of ammonia-alum. The solution is filtered when cool.

For use 3 or $4 \mathrm{c.cm}$. are filtered into a watch-glass.

Staining, 10 minutes to 2 hours.

Washing in water for a few minutes.

2. Borax-Carmine (alcoholic solution). -3 grammes of carmine and 4 grammes of borax are dissolved in $93 \mathrm{c.cm}$. of water. The solution is allowed to stand for 1 or 2 days, and then added to $100 \mathrm{c.cm}$. of $; 0$ per'cent. alcohol. The mixture is again set aside for several days, stirred occasionally, and, finally, is filtered.

Since this is an alcoholic solution, the sections are transferred to it from the 70 or 80 per cent. alcohol in which they are preserved, without previous immersion in water.

Staining for $\frac{1}{4}$ hour or longer. Overstaining does not occur.

Differentiation in acidulated spirit for about the same time.

Alcohol, 70 per cent.

Alcohol, 96 per cent., etc. 
The celloidin is hardly tinged by this stain. The nuclei become bright red the protoplasm remains pale. Borax-carmine is highly recommended.

It is also very suitable for staining tissues in bulk. Thin sections of delicate structures should be subjected to as few manipulations as possible. Hence it is convenient, instead of staining the individual scctions, to stain the tissue en masse before placing it in the microtome. This method is applicable only in the case of small objects. These are stained for I-3 days in borax-carmine, and are then washed in acidulated spirit, which is to be changed every quarter hour as long as it becomes coloured.

3. Ammonia carmine stains the nuclei splendidly, and also the axiscylinders.

The sections are transferred from water to the stain, and are then washed in water. Alcohol. Carbol-xylol. Balsam.

4. Borax carmine (aqueous solution). -8 grammes of borax are rubbed up with 2 grammes of carmine and added to I 50 c.cm. of distilled water. After 24 hours the liquid is decanted and filtered.

Immersion of the sections in water for a few minutes.

Staining, half to several hours.

Acidulated spirit, for the same time.

Alcohol, 70 per cent., etc.

5. Lithic Carmine. - 3 grammes of carmine arc added to $100 \mathrm{~cm}$. of a saturated aqueous solution of lithium carbonate.

Staining for two or three minutes.

Differentiation in acidulated spirit.

Thorough washing.

\section{Double Staining with Carmine.}

I. Alum-Carmine-Picric Acid.---Preliminary staining with alum carmine for IO-30 minutes.

Washing in water for a few minutes.

Staining in a 3-5 per cent. aqueous solution of picric acid for 2-5 minutes. Some prefer an alcoholic solution.

Washing for a short time in water tinged yellow with a trace of picric acid.

Alcohol, 70 per cent., etc.

2. Picrocarmine.-Dcuble staining is accomplished in this solution in the following manner :-

$\begin{array}{llllr}\text { Powdered carmine } & \ldots & \ldots & \ldots & \text { I } \\ \text { Liquor ammon. fort. } & \ldots & \ldots & \ldots & 5 \\ \text { Distilled water } & \ldots & \ldots & \ldots & 50\end{array}$

The carmine is carefully dissolved by stirring, and then there is added-

Saturated aqueous solution of picric acid

50

The mixture is allowed to stand in an open vessel until the ammonia has evaporated, and is then filtcred.

Staining, I hour or longer.

Washing in I per cent. hydrochloric acid-glycerine tinged yellow bv a trace of picric acid, for the same time.

Washing in pure water containing a trace of picric acid.

Alcohol. Oil. Canada balsam.

Orange $G$. or Aurantia may be used as a contrast stain after carmine.

Anilin blue can also be recommended. One or two drops of a concentrated aqueous solution are added to a watch-glassful of water. The scctions are immersed in this for I-2 minutes, either before or after receiving the carmine 
stain. If the blue tinge is too faint, it can be intensificd by passing the section through acidulated spirit. If it is too deep, it may be weakened by immersion in a weak solution of ammonia.

Washing. Alcohol. Carbol-xylol. Balsam.

Nigrosin is employed in a similar fashion.

Alkaline anilin dyes (methylen blue, methyl violet, gentian violet, malachite green, vesuvin (Bismark brown) may be employed as nuclear stains in the same manner. A few drops of an alcoholic solution are added to the water in the staining dish. The sections are exposed therein for five minutes. They are then washed in water containing a trace of acetic acid. Alcohol, 70 per cent. Absolute alcohol. Xylol or ccdar oil (not carbol-xylol). Balsam.

\section{Safranin.}

Safranin, one of the anilin dyes, is an important stain. It is employed principally for tissues which have been hardened in osmic acid or Flemming's solution, and which consequently do not takc up hamatoxylin and carmine well. With such material safranin produces a good nuclear stain.

\begin{tabular}{|c|c|c|c|}
\hline Safranin & • & $\cdots$ & $\cdots$ \\
\hline Absolute alcohol & & $\ldots$ & $\ldots$ \\
\hline Distilled water & $\ldots$ & $\ldots$ & $\ldots$ \\
\hline
\end{tabular}

The safranin is dissolved in the alcohol, and the water is then added. This mixture is kept in stock, and the sections are stained in it for I hour, or better still for 24 hours.

They are then washed in absolute alcohol for 5-10 minutes. Red clouds of stain are given off, and washing is continued till the celloidin is colourless. Acidulated spirit can also be used for differentiating, but in this case the chromatin of the nucleus alone remains coloured.

Cedar oil or xylol.

Canada balsam.

\section{Specific Methods of Staining.}

It has been pointed out that the older stains are adapted for the demonstration of all the nuclei present in the tissue. In recent times however, the art of staining has been elaborated, and methods have been discovered which act in a specific manner on definite elements without affecting others. There is quite a number of these methods, and they are of great value to the ophthalmologist.

\section{Weigert's Stain for the Medullary Sileaths.}

By this method the medullary sheaths of the nerve fibres alone are rendered bluish-black.

I, For the success of the process, which gives beautiful pictures of degenerative changes in the optic nerve, it is indispensable that the tissues should be hardened from the first in Müller's or Erlitzki's fluid ; tissues prepared otherwise are unsuitable. (For the exception formed by formalin, see below.)

The tissues are not washed after leaving Müller's fluid, but are transferred directly to alcohol.

2. Imbedding in celloidin. 
3. The celloidin block containing the tissuc is placed for 24-48 hours in a saturated aqueous solution of acetate of copper diluted with an equal volume of water. This stage is best carried out in the incubator. The preparation takes on a permanent bluish-green colour.

4. The block is placed in alcohol, 70 per cent., for at least $2+$ hours.

5. Sections are made.

6. The sections are stained for $\frac{1}{4}-24$ hours in Weigert's Hamatoxylin, which consists of -

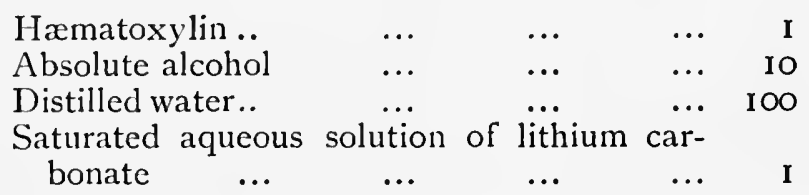

The solution of lithium carbonate is not added to the hæmatoxylin till the sections are ready to be stained, since the mixture does not keep well.

7. Washing in water till the stain is no longer given off.

The sections must be handled very gently since they are now very brittle. After differentiation they become plastic once more.

8. Differentiation in the following solution :-

$\begin{array}{lcccr}\text { Borax } \ldots & \ldots & \ldots & \ldots & 4 \\ \text { Ferricyanide of potassium } & \ldots & \ldots & 5 \\ \text { Distilled water } & \ldots & \ldots & \ldots & 200\end{array}$

No rule can be given regarding the length of time during which differentiation should be continued, since this depends upon the tissue and the thickness of the section. The sections are left in the solution till the nerve fibres, so far as they are supplied with medullary sheaths, appear dark violet, and the other structures, e.g., the sheaths of the optic nerve, become bright brown or colourless. If in the case of thick sections the differentiation is slow in appearing, the sections should be placed in alcohol for 24 hours, and once more passed through the ferricyanide solution.

9. Thorough washing in water for 2 or 3 days.

1o. Alcohol.

I I. Xylol.

I2. Canada balsam.

The medullary sheaths appear bluish-black, the degenerated portions bright brown. Thus, in cases of multiple sclerosis, bright foci of degeneration are frequently observed in the optic nerve, and in tabes with partial atrophy of the nerve certain strands may be recognised as affected.

$N . B .-W h e n$ the tissues have lain too long in alcohol they become greenish and do not react well to Weigert's stain. In such cases they should be left for a few hours in a 2-3 per cent. solution of chromic acid before being imbedded.

Formalin can be employed for hardening, the process occupying only 4 or 5 days. The tissue is placed in

$\begin{array}{lrlrr}\text { Bichromate of potash } & \ldots & \ldots & 5 \\ \text { Chrome-alum } & \ldots & \ldots & \ldots & 2 \\ \text { Distilled water } & . . & \ldots & \ldots & \text { 100 } \\ \text { Formalin, ro per cent. } & \ldots & \ldots & \text { IO }\end{array}$

Or the pieces may be hardened in formalin, and then placed in the chromic mixture for 4 days. 
Weigert's Nezw Method.- Hardening in Müller's fluid for 4-6 weeks. Treatment for I $2-24$ hours in :

$\begin{array}{lcccr}\text { Chromium fluorate pure } & \ldots & \ldots & 7.5 \\ \text { Copper acetate } & \ldots & \ldots & \ldots & \text { I5 } \\ \text { Dilute acetic acid } & \ldots & \ldots & \ldots & \text { I } 5 \\ \text { Distilled water } & \ldots & \ldots & \ldots & 300\end{array}$

This solution must be boiled for an hour or longer $\ldots$ till it $\begin{aligned} & 300 \\ & \text { assumes a green }\end{aligned}$ colour.

Washing in water or, better, 75 per cent. alcohol.

Staining for 6-12 hours in a mixture of equal parts of the following solutions :

I. One gramme of hæmatoxylin is dissolved in $9 \mathrm{c.cm}$. absolute alcohol, and added to $90 \mathrm{c.cm}$. 96 per cent. alcohol. The mixture should be at least three weeks old.

2: Liquor ferri sesquichlorati ...

$$
\text { Distilled water }
$$

Washing in water for 6 hours.

Differentiation in :

\section{Borax}

Ferricyanide of potassium

Distilled water

This should be filtered.

Washing for 12 hours.

\section{Pal's Stain for the Medullary Sheaths.}

Pal's method is a modification of Weigert's. It is simpler and possesses this advantage, that it may be followed by a nuclear stain. The finer fibres are apt to be decolourised, as it is very difficult to determine when the differentiating process should be interrupted.

I. Hardening in Müller's fluid.

2. No washing.

3. Completion of the hardening process in alcohol.

4. Imbedding in celloidin.

5. Sections are made.

6. These are treated with a saturated solution of copper acetate in the incubator for 24 hours.

7. Washing.

8. Staining for 24 hours in Weigert's solution of hæmatoxylin to which a few drops of a saturated solution of lithium carbonate are added before use.

9. Washing in water containing a few drops of a I-2 per cent. solution of lithium carbonate till the sections appear deep blue.

10. The sections are now placed in $\frac{1}{4}$ per cent. solution of permanganate of potash for perhaps 20-30 seconds, till the non-medullary substance of the nerve appears yellow. This solution keeps badly, and should therefore be specially prepared or diluted from a concentrated solution as required.

II. Further differentiation in

$\begin{array}{llllr}\text { Oxalic acid } & \ldots & \ldots & \ldots & \text { I } \\ \text { Sulphite of potash } & \ldots & \ldots & \ldots & \text { I } \\ \text { Distilled water } & \ldots & \ldots & \ldots & 200\end{array}$

The medullary substance should now become dark blue while the sheaths and rest of the tissue are decolourised. If this does not happen after a few seconds, the section is returned to No. 7 , then to 8,9 , etc., and these stages 
are repeated till the desired effect is obtained. The sections may be examined under the microscope to determine when the non-medullary substance has become colourless. Then the process is interrupted. The fibres of the ciliary nerves possess medullary sheaths, and therefore appear dark blue.

I2. Thorough washing in pure water.

13. Alcohol. It. Xylol. I5. Canada balsam.

In longitudinal sections of the optic nerve the medullary sheaths are seen to disappear gradually at the level of the lamina cribrosa. The retina of the rabbit contains for the most part medullated nerve fibres, and these react to the stains of Weigert and Pal.

If desired, the section can be stained with carmine and orange $G$. The nuclei are then red, the connective tissue yellow, and the nerve fibres dark blue.

\section{MaRChI'S Method.}

Marchi's method (see Marchi Rivista sperimentale di freniatria $e$ di med. legale, I887, XII, and Singer und Münzer, Beiträge zur Kenntniss der Sehnervenkreuzung, LV., Band der Denkshriften der mathnaturu. Klasse der kaiserl. Academie der Wissenschaften zu Wien, 1888) possesses the remarkable and valuable property of staining the medullary sheaths of degenerated nerves, or the products of their disintegration, deep black, while the medullary sheaths of the normal nerves are only tinged grey. There is no better method for demonstrating recent and slight degenerative changes in the optic nerve, chiasma, brain, etc.

The tissue must be in no way compressed or crushed while being removed from the body.

The optic nerve in toto is placed for at least 8 days (if necessary as long as 3 months) in Müller's fluid.

Pieces, which should be as small as possible, are then placed in a freshly prepared mixture of-

for 5-8 days.

$\begin{array}{lllll}\text { Müller's fluid ... } & \ldots & \ldots & \ldots & 2 \\ \text { Osmic acid, I per cent.... } & \ldots & \ldots & \text { I }\end{array}$

Thorough washing in running water, $12-24$ hours.

Further hardening in alcohol.

Imbedding in celloidin.

Section-cutting.

Oil.

Canada balsam (best melted by means of heat without any solvent).

When degeneration has taken place, the medullary sheaths break up into fatty globules which are blackened by osmic acid.

The degenerated sheaths accordingly appear black, and the medullary substance is arranged in chains of globules. The medullary sheath of a normal nerve appears bright yellow, or varies from pale grey to olive in colour. In rare cases solitary black drops may be seen between the medullary sheath and the sheath of Schwann.

Of course any fat in the tissue is stained black by the osmic acid.

On the surface of the sections of the optic nerve there is always a plentiful deposit of black masses. These, however, extend for only a short distance into the nerve.

\section{4.-Staining the Ganglion Cells-Nissl's and other Metirods.}

Nissl's method is an excellent one for demonstrating the finer structure of the nerve cells. Both normal structure and commencing degeneration are 
rendered evident. By means of this method Bach found certain brightly stained granules in the ganglion cells of the normal retina. They occur throughout the whole of the cell body, and are arranged, in part regularly, in part irreguiarly, in the almost unstained ground mass.

On the other hand, in degenerating cells, e.g., those of a detached retina, the granules are smaller and are grouped together towards the circumference of the cell. When degeneration is advanced the granules are no longer visible (Bach. von Graefe's Archiv, Bd. XLI, Heft iii, S. 62; and A. BirchHirschfield, von Graefe's Archiz', Bd. L, Heft i, S. I66.)

Nissl's Method.-Nissl has described two processes, both equally good.

A. I. Small pieces of fresh material are hardened in alcohol gradually increased in strength. Formalin may also be used.

2. The pieces are mounted on a support by means of fish-glue or gum without being imbedded. Imbedding in celloidin is also permissible.

3. Sections are made by hand or with the microtome ( $30 \mu$ thick.)

4. These are stained in $\frac{1}{2}$ per cent. solution of methylen bluc, which is heated in a watch-glass over the flame of a spirit lamp till bubbles begin to rise $\left(65^{\circ}-70^{\circ} \mathrm{C}\right.$. $)$. The solution consists of -

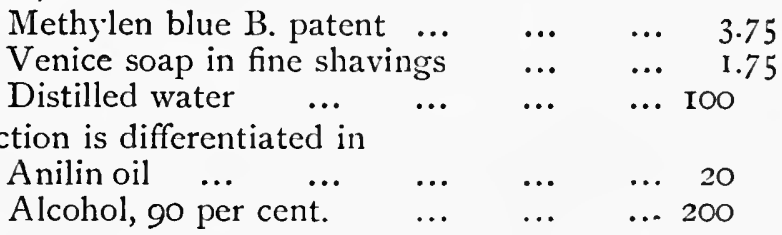

till large clouds of stain are no longer given off. This solution should be kept in a dark bottle and protected from the light.

6. The section is transferred to a slide, dried, cleared with oil of origanum or cajeput, again dried, and saturated with benzine.

7. A thin solution of colophonium in benzine is poured over the section.

8. The benzine is driven off by holding the slide over a flame.

9. A cover-glass is applied.

N.B.-After being differentiated the section can be mounted in Canada balsam in the usual fashion.

B. Stages I, 2, 3, of the alternative process are similar to those of A.

4. The sections are stained in a concentrated aqueous solution of basic fuchsin, which is held over a flame till steam begins to rise.

5. Washing in absolute alcohol, I-2 minutes.

6. Clove oil, till clouds of stain cease to be given oft.

7. Canada balsam.

Held's Modification of Nissl's method gives a double stain, erythrosin being employed to demonstrate the protoplasm in which Nissl's chromatic granules are imbedded (Archiv' fiir Anatomie, Bd. I, I 895, S. 396).

Birch-Hirschfeld treats the retina in the following manner (von Graefe's Archiv, Bd. I, S. I75).

Thionin-Erythrosin Stain:-

I. Imbedding in paraffin. The sections are fixed to the slide.

2. Staining in a I per cent. solution of thionin for about ro minutes.

3. Rinsing in water.

4. Held's solution of erythrosin is poured over the section.

$\begin{array}{llllll}\text { Pure erythrosin } & \ldots & \ldots & \ldots & \ldots & \text { I }\end{array}$

Distilled water $\quad \ldots \quad \ldots \quad \ldots \quad \ldots \quad$ I 50

Glacial acetic acid $\quad \ldots \quad \ldots \quad \ldots \quad \ldots 2$ drops. 
5. Rinsing in distilled water.

6. Alcohol. Oil. Canada balsam.

Nissl's granules are stained bluc, thionin being a specific stain for them, the interstitial substance brilliant red.

\section{Weigert's Stain for time Neuroglia.}

This is the best method for demonstrating the neuroglia although it is not easy to carry out. It yiclds beautiful results with the optic nerve. Its application to the retina is more difficult. The fibres of the zonule of Zinn are also coloured. (C. Weigert, Beiträge zur Kenntniss der normalen menschlichen Neuroglia. Frankfurt, a. M., Diesterweg, 1895).

I. Fixation of the tissue in Weigert's neuroglia-mordant (chrome-alumcopper oxide). The pieces must not be more than $\frac{1}{2} \mathrm{~cm}$. in diameter. They lie in the fluid for 8 days, and it is advisable to keep this warm by placing it on the incubator. The fluid is changed on the second day. The tissue should be as fresh as possible.

The mordant consists of-

$$
\begin{aligned}
& \begin{array}{lllll}
\text { Chrome-alum } & \ldots & \ldots & \ldots & 25
\end{array} \\
& \begin{array}{lllllr}
\text { Water } & . . & \ldots & \ldots & \ldots & 25 \\
& \ldots & . & \ldots & \text { IOO }
\end{array}
\end{aligned}
$$

The chrome-alum is dissolved by heat, and while the solution is boiling the flame is put out, and there is added, first-

$$
\begin{array}{llll}
\text { Ordinary acetic acid } & \ldots & \ldots & 5
\end{array}
$$

then- $\quad$ Powdered neutral acetate of copper $\quad \ldots \quad$...

the whole being stirred with a glass rod. After cooling there is added -

Formalin ... $\quad \ldots \quad$... $\quad .$. IO

2. Thorough washing in water. Further hardening in alcohol. Imbedding in celloidin.

3. Sections are made, and these are immersed in $\frac{1}{3}$ per cent. solution of permanganate of potash for 10 minutes, carefully washed in water, and then placed in the reducing fluid.

4. The sections remain in the reducing fluid 2-4 hours, where they become decolourised. The reducing mixture consists of -

$$
\begin{array}{lcccr}
\text { Chromogen (Höchster Farbwerke) } & \ldots & 5 \\
\text { Formic acid } & \ldots & \ldots & \ldots & 5 \\
\text { Water } \quad \ldots & \ldots & \ldots & \ldots & \text { IOO }
\end{array}
$$

Before use $10 \mathrm{c.cm}$. of a 10 per cent. solution of ordinary photographic sodium sulphite are added to every $90 \mathrm{c.cm}$. of the filtered reducing fluid.

5. Staining (modified fibrin method). This is carried out on the slide. The section is first dried, then the stain is poured over it. Staining takes place very quickly (one minute). The stain consists of a saturated solution of methyi-violet in 80 per cent. alcohol. This should be saturated while hot, and decanted when cold. To every $100 \mathrm{c.cm}$. of this are added $5 \mathrm{c.cm}$. of a 5 per cent. aqueous solution of oxalic acid.

The sections are dried and treated with iodine, a saturated solution of iodine in a 5 per cent. solution of iodide of potash being poured over them.

7. They are thoroughly differentiated in equal parts of anilin oil. and xylol.

8. The anilin-xylol is now removed by means of pure xylol.

9. Canada balsam.

The preparations keep better if they are exposed to daylight for a day or two after being mounted. 


\section{Stains for Elastic Fibres.}

In recent years quite a number of methods have been devised for demonstrating elastic fibres by means of selective stains.

A. The best known, and until lately the most popular, method is the Orcein Process of Unna-Taenzer.

I. Hardening in any of the common media ; formalin seems most suitable.

2. Section cutting.

3. The sections are stained for 12-24 hours in the following solution-

$\begin{array}{lllll}\text { Orcein } \ldots & \ldots & \ldots & \ldots & 0 \% 5 \\ \text { Absolute alcohol } & \ldots & \ldots & \ldots & 40 \\ \text { Distilled water } & \ldots & \ldots & \ldots & 20 \\ \text { Hydrochloric acid } & \ldots & \ldots & \text { drops } & 20\end{array}$

4. Differentiating in-

$\begin{array}{llllr}\text { Concentrated hydrochloric acid ... } & \ldots & \text { O I } \\ \text { Alcohol, } 95 \text { per cent. } & \ldots & \ldots & \ldots & 20^{\circ} \\ \text { Distilled water } & \ldots & \ldots & \ldots & 5^{\circ}\end{array}$

5. Rinsing in water. Dehydrating in alcohol. Oil. Canada balsam.

The elastic fibres are stained dark reddish brown, the nuclei light reddishbrown. A slight tinging with anilin blue causes the elastic elements to stand out better against the delicate red connective tissue.

B. The recently published Method of Weigert demonstrates admirably the rich network of elastic fibres present in the tissues of the eye. It yields complete and extremely beautiful pictures. Moreover, it is simple (Centralblatt fïr allgem. Pathologie und pathol. Anatonie, I 898, Nos. 8, 9).

The process is successful with material prepared in most of the hardening fluids. It is specially so when alcohol has been employed ; but Müller's fluid, Flemming's fluid, corrosive sublimate, etc., may be used.

A mixture containing equal parts of-

Aqueous solution of fuchsin-rubin I per cent.

" " resorcin $\ldots . \quad 3$ ",

is prepared, and $220 \mathrm{ccm}$. "are placed in a porcelain vessel and brought to the boiling point. To this are added $25 \mathrm{c} . \mathrm{cm}$ of liquor ferri sesquichlorati ( $\mathrm{Ph}$. G. III) and the whole is boiled for 2-5 minutes. A deposit is thrown down. The contents of the vessel are allowed to cool, and are then filtcred. The filtrate is rejected, and the filter paper is left until all the liquid has drained away. The paper is now placed in the dried porcelain vessel and boiled with $200 \mathrm{c.cm}$. of 94 per cent. alcohol. The liquid is once more allowed to cool, again filtered, and after removal of the paper made up with alcohol to 200 c.cm. After the addition of $4 \mathrm{c.cm}$. of hydrochloric acid the staining solution is ready for use.

The sections are placed in the solution for twenty minutes to onc hour. They are then dehydrated in alcohol, cleared in xylol, and mounted in Canada balsam.

The elastic fibres appear dark blue or almost black on a light background. The nuclei can be rendered evident by means of carmine, and if a diffuse orange stain is added, the sections are very beautiful.

Liquor Ferri Sesquichlorati is prepared as follows:-

One part of iron is dissolved in 4 parts of hydrochloric acid; and then there are added for every 100 parts of iron dissolved, 260 parts of hydrochloric acid and 135 parts of nitric acid.

See also Pranter's excellent modifications of the processes (Orccin, Resorcinfuchsin, Cresofuchsin). Centralblatt für allgem. Pathologie und forthol. Anatomie, Bd. XIII, S. 292, 1902. 


\section{Demonstration of Karyomitotic Figures.}

Müller's fluid destroys the chromatin threads, and should not be employed when it is desired to demonstrate the structure of the nuclei. It may be of importance to display this, e.g., in the repair of epithelial tissues or in the case of rapidly growing tumours. The tissues should be placed as soon as possible after death, or after excision of the eyc, in a quickly acting fixing fluid, and the pieces should be small to admit of rapid fixation. Osmic acid, as contained in Flemming's solution, can be highly recommended, the staining being in this case carried out with safranin. The resting nuclei are left pale, while those which are in the act of dividing are deeply stained. Or Benda's Method may be adopted (see below). Corrosive sublimate with subsequent staining in hæmatoxylin exhibits the mitotic figures well. Perhaps the best methods are those of Heidenhain and Benda.

Heidenhain's Iron-Homatoxylin Method.-When it is desired to demonstrate the finer construction of the cell, such as the centrosome, the achromatic portion of the nucleus, etc., the following is the procedure :-

I. Fixing in a saturated solution of corrosive sublimate. Removal of the sublimate by means of iodine. Imbedding. The sections should be as thin as possible.

2. The sections are mordanted in $1 \frac{1}{2}$ per cent. solution of ferric-alum $\left(\mathrm{NH}_{4}\right)_{2} \mathrm{Fe}_{2}\left(\mathrm{SO}_{4}\right)_{3}$, for $\frac{1}{4}-24$ hours.

3. Rinsing in water.

4. Staining in $\frac{1}{2}$ per cent. solution of hæmatoxylin purissimum (Grübler) for 1 2-1 8 hours. The iron-hæmatoxylin is deposited in the interior of the sections, staining them a decp black.

5. Rinsing in water.

6. The overstained sections are again treated with the ferric-alum solution, which removes the stain, first from the protoplasm and then from the resting nuclei, so that at last the karyomitotic figures are almost the only structures which are stained. Finally these also are decolourised. The sections must therefore be examined from time to time under the microscope, so that the process of differentiation may be interrupted at the moment when the resting nuclei have become pale, and the karyomitotic figures, on the other hand, are still dark. Differentiation proceeds pretty quickly.

7. Washing in tap water.

8. Alcohol. Oil. Canada balsam.

The nuclei and the nuclear structures appear deep blue or black. Heidenhain's Method is specially adapted for the demonstration of the nuclear structures. It can, however, be recommended as an excellent nuclear stain for general use.

For the demonstration of the finer structures of the cell (centrosome, achromatic spindle, etc.) Heidenhain prefers paraffin sections, $3 \mu$ thick. These are fixed to the slides by means of distilled water, and the sublimate is extracted with iodine.

Preliminary staining with a weak aqueous solution of Bordeaux R.

Rinsing in water.

Mordanting.

Rinsing, etc.

The stain with Bordeaux can also be applied after the hæmatoxylin (Archiv für mikrosk. Anatomie, Bd. XLIII, I894, S. 423).

Bendas Iron-Hamatoxylin Method:-

I. Hardening in corrosive sublimate, Flemıming's solution, or nitric acid.

2. Section cutting. 
3. The sections are placed for $\frac{1}{2}-24$ hours or longer in Liquor Ferri Sulphurici Oxydati. (The Liquor consisted of sulphate of iron 80, water 40, sulphuric acid I5, and nitric acid I8. It contains Io per cent. of iron. Bolles Lee.)

4. They are washed in three changes of tap-water.

5. They are stained in I per cent. solution of hæmatoxylin till they become deep black. This, as a rule, takes place quickly.

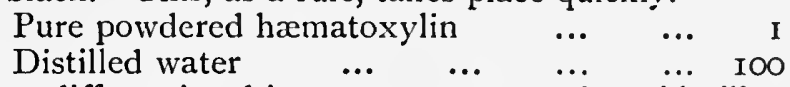

6. They are differentiated in 30 per cent. acetic acid till, as in the last method, only the active nuclei are left stained.

7. Washing. Contrast staining if desired.

8. Oil. Canada balsam.

This method is similar to Heidenhain's and produces a good nuclear stain even in the case of resistant tissues. The nuclei become almost black. If differentiation is carried farther, the karyomitotic figures remain deep black to the last and stand out in bold relief.

\section{Mallory's Connective Tissue Stain.}

I. Hardening in Zenker's fluid.

2. Imbedding in paraffin or celloidin.

3. The sections are stained for I-3 minutes in a $I$ per cent. aqueous solution of acid-fuchsin.

4. Washing in water.

5. The sections are placd for I minute or longer in a I per cent. aqueous solution of phosphoro-molybdic acid.

6. Washing in water, which should be changed twice.

7. Staining in the following solution:

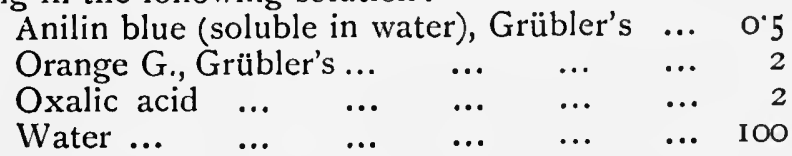

8. Washing in water.

9. Alcohol, 95 per cent., or absolute.

Io. Xylol. Balsam.

The connective tissue presents a striking contrast to the other tissues, e.g., tumour cells (L. Aschoff).

\section{io. Epithelial Cell Boundaries.}

Shreds of fresh tissue (e.g., conjunctiva) are exposed for Io minutes to bright sunlight in a $\frac{1}{4}$ per cent. solution of nitrate of silver, which should be freshly prepared.

2. They are then left for $\frac{1}{4}$ hour in distilled water containing a trace of acetic acid ( 2 drops to a watch-glass).

3. Thorough washing in water.

If desired the preparation may now be hardened.

\section{Demonstration of Definite Substances and Tissue Elements.}

\section{Fat and Fatty Degeneration.}

Normally, the eye rests on a thick cushion of fat, the retrobulbar fatty tissue. Each cell of this tissue consists of a large fat globule surrounded by 
a thin protoplasmic membrane in which is embedded a flattened nucleus. Fat is found also under the skin of the lids, under the conjunctiva, etc.

Tumours consisting of fat cells are sometimes developed from the connective tissue around the cye, and more frequently from the fat itself (Lipomata).

Fatty degeneration is a condition different from, and not to be confounded with, this Lipomatosis. In Lipomatosis the increase in the quantity of fat is derived from without; in fatty degeneration the increase of fat is not due to a deposition of this in the tissue, but results from disintegration of the albumen of the cells. Fatty degeneration is, therefore, always associated with atrophy of the organ. The cells affected contain oil droplets, and, when the process is advanced, the protoplasm of the cell is replaced by a mass of detritus consisting of variously sized globules and granules of fat. In connection with old inflammatory changes in the interior of the eye, especially in old exudations, large vesicular cells are frequently found which are quite filled with fatty granules ( $f$ at-granule cells). These are generally migratory corpuscles which have taken up the fatty products of degenerative processes, and which by their aggregation form the white patches characteristic of albuminuric retinitis.

The microscopic examination can be easily made in the fresh specimen, either single cells or sections being selected. The fatty granules in the interior of the cells are colourless, bright, and possess a dark contour and clear centre. Their behaviour towards reagents is as follows :-

I. They are unaffected when treated with acetic acid.

2. They resist the action of dilute caustic potash and soda (I-3 per cent.).

3. They are stained black on the addition of I per cent. osmic acid.

4. They are dissolved by chloroform and ether. To obtain this reaction, the preparation must first be thoroughly dehydrated in absolute alcohol, then expused for a considerable time to the solvents, again washed in alcohol to remove these, and finally examined in salt solution.

5. When treated with iodine-violet they assume an intense violet colour.

Alcohol should not be employed for hardening, since it gradually dissolves fat. If Müller's fluid is used, the fat granules, although preserved, coalesce into larger drops. The fat-granule cells are thus altered in appearance, and look like vesicles.

I. Osmic Acid $\left(\mathrm{OsO}_{4}\right)$ possesses the valuable property of rendering black even the smallest particle of fat. When, therefore, it is desired to demonstrate fat or fatty degeneration in a preparation, the hardening fluid employed should be one of those containing osmic acid. This is the case when a retina is being, examined for signs of albuminuric retinitis. Pure osmic acid (I-2 per rent.) is seldom taken; Flemming's solution is more suitable. The eye is opened by two or three short incisions in the equatorial region in the manner already described. It is fixed for 2-3 days in the dark. Longer exposure to the action of the solution renders the tissues too brittle.

The eye is then washed for 24 hours in running water. If the washing is not thorough, the alcohol may extract the uncombined osmic acid, and this may be deposited as black specks giving the appearance of fat where none exists.

I Iardening in alcohol, 30, 60, 90, 96 per cent., 24 hours in each.

Imbedding in celloidin.

The sections are stained with safranin.

They are then washed, dehydrated rapidly in absolute alcohol, cleared in oil, and mounted in Canada balsam.

The oil used for clearing must not be allowed to act on the section for a 
lengthened period, and must be carefully removed as soon as the process is complete. Oil of turpentine and xylol should be avoided as far as possible, because they tend to dissolve the fat which has been acted on by osmic acid. For the same reason xylol-balsam is not chosen for mounting, but solid Canada balsam melted by being warmed over a flame.

Fat which has been exposed to the influence of osmic acid is quite insoluble in alcohol, chloroform, and clove oil.

2. Sudan III, a red powder belonging to the diazo group of colouring matters, is a reliable stain for fatty tissue. A saturated solution of the reddish-brown powder made with ordinary alcohol stains in a few minutes. The preparation is then washed, and mounted in glycerine. Alcohol should be avoided as far as possible, since it dissolves the stain and the fat. Large drops are stained bright-red, small drops yellow or orange-red.

Hardening and fixing solutions which dissolve fat must not be employed. Müller's fluid and glycerine are practically the cnly media admissible. Sections may be cut with the freezing microtome, whereas the paraffin and celloidin processes must be avoided. Absolute alcohol, which dissolves fat, cannot be used for dehydrating. The clearing oils and Canada balsam are also prohibited.'

\section{Calcareous Degeneration.}

Petrification is a process characterised by the deposition in the tissues of certain salts. These are usually carbonates or phosphates of calcium. The tissues attacked are already necrosed as a result of degenerative or chronic inflammatory changes. Thus, areas which have undergone fatty degeneration and have not been absorbed are frequently affected. The process may even go on to Ossification, the formation of true bone with lamella and canaliculi. In this condition, however, there is a deposition of salts in a ground substance which has replaced the original tissue. In Petrification, on the other hand, there is no alteration in the structure of the tissue. Calcified areas are evident to the naked eye by their white aspect. When touched with a needle they yield a grating sensation. Calcification is often not detected until the mounted specimen is being cut with the microtome. Such tissues must be decalcified. See "Decalcification."

Calcareous deposits when viewed by reflected light are white and glittering, resembling fat; examined by transmitted light they are intensely dark. When a 5 per cent. solution of hydrochloric acid is allowed to flow in from the edge of the cover-glass, the calcium salts are dissolved, the carbonates with the evolution of bubbles of carbonic acid gas, the phosphates without.

If we desire to show the deposit in the tissue unstained, we should employ an aqueous solution of methylen blue. In this way, if we examine with focal illumination or in the dark field, the smallest granules or needles exhibit a glistening appearance.

Alum-hærnatoxylin is by far the best stain for sections which contain, or have contained, lime salts. The chalky portions stain dark blue, sometimes with a tinge of red. It is remarkable that tissue from which the salts hare been removed stains almost equally intensely, provided the process of decalcification has not lasted too long. A similar staining reaction is given by tissues which have been deprived of fat, e.g., gliomata, and by the corpora amylacea found in the optic nerve. Larger calcareous areas are, however, readily recognised by their homogeneous appearance, and still more by their contour which is usually sharp and angular. 
According to Leutert the slightest trace of lime can be demonstrated by the following process :-

I. Staining celloidin sections in a concentrated alcoholic solution of hæmatoxylin, $\frac{1}{4}$-hour.

2. Washing in tap-water, $\frac{1}{4}$-hour.

3. Further staining in I per cent. aqueous solution of safranin.

4. Rinsing in water.

5. Differentiating and dehydrating in alcohol. Oil. Balsam.

Lime is stained a deep steel blue; nuclei red. The preparations do not kecp well.

\section{Cholestearin.}

Cholestearin Crystals are generally present in masses of fatty detritus. In the eye they are often discovered floating in the degenerated vitreous, in the anterior chamber, and in subretinal and subchoroidal exudations. Suspended in the aqueous or vitreous, they present the appearance of minute glittering points. When a fresh eycball affected with detachment of the retina or degeneration of the vitreous is opened, it is astonishing how often these crystals are present in the liquid evacuated. If numerous they are readily seen with the naked eye as small scintillating dots. Under the microscope they appear as thin transparent rhombic plates, often notched at the angles.

When a few drops of a 30-40 per cent. solution of Sulphuric acid is allowed to flow in under the cover glass, characteristic changes of colour take place. The plates become orangc, then a beautiful rose-red, and finally are dissolved.

Treated with Lugol's Solution (iodine I, iodide of potassium 2, water 300), the crystals become dark brown, and on the further addition of a trace of sulphuric acid the colour changes to bright blue.

Cholestearin is soluble in alcohol and ether. Hence it follows that, owing to the long exposure in these liquids demanded by the paraffin and celloidin processes, the crystals are, as a rule, no longer visible in hardened and stained sections. Characteristic gaps, however, indicate that they have been present, and these spaces when once recognised can hardly be mistaken.

\section{Mucoid Degeneration.}

The normal epithelium of the conjunctiva, like that of other mucous membranes, contains cells filled with mucin. These resemble goblets, and have been styled goblet-cells. Mucin is a transparent substance formed from the cell protoplasm. During secretion the cell swells up, finds its way to the surface, and discharges its contents, the protoplasm being reduced to small groups of granules. The cell may now resume its original form, or it may perish.

In pathological conditions of the conjunctiva the goblet-cells are largely increased in number, e.g., in chronic conjunctivitis, in trachoma, here especially in the gland-like depressions, etc.

Detached cells may be examined while fresh. Mucin swells up readily in water ; it is coagulated in the form of threads or streaks by acetic acid.

Fixation is best performed in formalin or corrosive sublimate. Thereafter the mucous cell contents can be coloured with a simple solution of hæmatoxylin. By this they are stained dark blue, but the flattened nucleus is, as a rule, readily recognised lying against the wall in the deeper part of the cell. Mucin is not stained by carmine or eosin; when these stains are used the goblet-cells appear as bright spaces in the epithelium. On the other hand, 
it is particularly well stained by acid-fuchsin (van Gieson's stain), safranin, and methylen blue.

Hoyer strongly recommends Thionin for staining mucin. Fixation in sublimate. Washing in water.

The following is the Method of Leedham Green :-

The tissues are removed from the animal immediately after death, and placed in a saturated solution of corrosive sublimate for 2-8 hours, the period depending on their thickness and consistence. They are then transferred to 80 per cent. alcohol. Here they are treated with iodine till the sublimate is removed. Next they are dehydrated and imbedded in paraffin or celloidin. The sections are fixed on slides, and stained with a weak solution of thionin ( 2 drops of a saturated aqueous solution of thionin to $5 \mathrm{c.cm}$. of distilled water). The staining process lasts 5-I5 minutes, till the sections have assumed a dark colour.

Rinsing in alcohol, 90 per cent.

Alcohol, absolute or 96 per cent., for a few minutes.

Clearing in an ethereal oil. Canada balsam.

The mucin of the goblet cells is stained a bright reddish violet, the rest of the tissue bright blue.

Unfortunately this stain is not permanent.

The author finds a weak solution of hæmatoxylin quite as satisfactory.

Meyer's Muci-carmine (Grübler) is a selective stain for mucin.

The sections are stained for $\frac{1}{4}$-I hour in the aqueous solution diluted ro times, and then washed in water. Thereafter they may be stained with hæmalum and orange $G$.

I. Green, "Ueber die Bedeutung der Becherzellen," von Gracfe's Archiv' Bd. XL., Heft. i, S. 3.

2. Hoyer, Archiv fïr mikrosk. Anatomie, Bd. XXXVI, I\$90.

3. Wagenmann, "Papillom der Conjunctiva," von Graefe's Archiv, Bd. XL. Heft. i, S. 250.

\section{Hyaline Degeneration.}

Hyaline material was separated by von Recklinghausen from the large group of colloid substances. It resembles amyloid substance, being an insoluble albuminous body, and is found in tissues whose nutrition has been impaired.

Hyaline degeneration occurs very frequently in the eyeball as a natural change in old age, but also after any form of chronic inflammation. In an excellent paper Fuchs instances hyaline degeneration as attacking the most diverse structures of the eye. It is found in the arcus senilis and in the primary transverse opacity of the cornea known as Keratitis en Bandelette. It is especially common in the hyaloid membranes (Descemet's membrane, membrana vitrea of the choroid and ciliary body, lens capsule). These membranes inay not only become diffusely thickened, but may also exhibit local deposits, the so-called "glands" of the membrana vitrea of the choroid, and of Descemet's membrane. Von Recklinghausen instances these "glands" as types of hyaline degencration. Among senile processes of the same nature are thichening of the supporting fibres of the retina, and the hyaline changes which occur in the connective tissue of the ciliary processes, and in the walls of the blood vessels in that region. Also of a hyaline nature are the globules of Morgagni, which are separated from the lens fibres in senile cataract. Hyaline degerieration has likewise been found in the optic papilla. Berlin describes hyaline masses as 
occurring in the infiltration of Sclerosing Keratitis, and Hess has seen a similar change in the epithelial cells in Filamentous Keratitis. Hyaline concretions are common in old corneal opacities (Atlas of IVedl-Bock). Vossius has given an exhaustive account of hyaline degeneration of the conjunctiva.

The characteristics of the hyaline substance are, according to von Recklinghausen, as follows :-

I. It possesses a homogeneous structure and high refracting power.

2. It resists most reagents, being insoluble in strong acids and alkalies.

3. It is readily stained by carmine and picrocarmine, less so by hxmatoxylin. Eosin and acid-fuchsin tinge it decply. It does not give the iodine-reaction with iodine, although its appearance resembles that of the amyloid substance.

The tissue may be fixed in formalin, Müller's fluid, sublimate, alcohol, etc.

I. Berlin, von Graefe's Archiv, Bd. XXXIII, Heft iii.

2. Fuchs, von Graefe's Archiv, Bd. XXXVII, Heft iii, S. I50.

3. Hess, "Fädchenkeratitis," von Graefe's Archiv, Bd. XXXVIII, Heft. iii, and Bd. XXXIX, Heft. ii.

4. Kerschbaumer, von Graefe's Archiv, Bd. XXXIX, Heft. iii, S. 24.

5. Von Recklinghausen, Handbuck der Allgem. Patholgie, S. 405, I 883.

6. Vossius, "Die hyaline Degeneration der Conjunctiva," Zieglee's Beitrige sur path Anatomie, Bd. V., I890.

7. Wedel und Bock, Pathologische Anatomie des Auges, S. 43. Vienna, I 886 .

\section{Amyloid Degeneration.}

Amyloid degeneration is a peculiar process which frequently attacks the connective tissue of the vascular system; it is progressive in character. It leads to the deposition of an albuminoid body (amyloid substance) in the affected parts. These as a consequence increase in bulk, and present under the microscope a peculiar homogeneous appearance. When well advanced the morbid change is recognisable with the naked eye, the degenerated tissuc being semi-translucent and resembling the fat of fried bacon (Ziegler).

The amyloid substance usually occurs in homogencous shining patches.

The "waxy" appearance is at once detected when one of the nodular masses is cut open.

The firm consistence of the tissues allows sections to be made in the fresh condition; or the examination may be performed after hardening in Muller's fluid, formalin, sublimate, or alcohol.

The amyloid substance is stained a rose colour by hæmatoxylin-eosin, a brilliant red or brownish-red by van Gieson's method

Amyloid substance exhibits certain specific reactions :-

I. Iodine Reaction (Virchozv) :- The sections are placed for 3-6 minutes in Lugol's Solution dlluted with 3 parts of distilled water. They are then waslied, and examined in glycerine. The degenerated areas are stained brownish-red, while the unaffected tissue remains bright yellow. The brownish-red colour is rendered still more brilliant if 25 per cent. of glycerine is added to the iodine solution.

This stain is not so permanent as that obtained by the next process.

2. Iodine and Sulphuric Acid Reaction (Langhans):-If a section, which has been stained with iodine in the manner described, be treated with a $I$ per cent. solution of sulphuric acid, the amyloid substance is tinged a darker brown, or becomes violet, blue, or greenish, according to the length of time the degeneration has been in progress. 
3 Methyl-violet Reaction:-

(I) Staining for 3-I 5 minutes in a I-2 per cent. methyl-violet solution.

(2) Washing in water containing I per cent. hydrochloric, or 2 per cent. acetic, acid.

(3) Thorough washing in water.

(4) Mounting in glycerine.

The preparation keeps for a considerable time if the cover-glass is ringed. Canada balsam is not admissible.

The waxy material becomes purple-red, the rest of the tissue blue.

4. Gentian-violet Reaction :-This gives almost the same reaction as methyl-violet. The procedure is identical.

Reactions 3 and 4 are not absolutely characteristic. Under certain circumstances other tissues, such as mucin, young cartilage, etc., are stained purple-red.

5. Methyl-green Reaction: This is employed in the same manner as methyl-violet. The waxy material stains violet, the nuclei and the rest of the tissue green.

6. Iodine-green Reaction:-Sections of fresh or hardened tissue are stained for twenty-four hours in a solution of iodine-green in distilled water (I-300).

They are then washed in water and mounted in glycerine.

The tissue affected stains a reddish-violet, the rest of the section green.

7. Thionin Stain (Kantorowicz):-Staining in a concentrated aqueous solution of thionin, 5 minutes.

Washing in distilled water.

Drying on the slide with blotting-paper.

Dchydrating and clearing in anilin oil-xylol $(2: \mathrm{I})$.

Pure xylol. Canada balsam.

The amyloid parts stain bright blue or lilac, the unaffected parts bluish or violet.

8. Method of Birch-Hirschfeld:-

(I) Staining for 5 minutes in a 2 per cent. alcoholic solution of bismarkbrown.

(2) Rinsing in absolute alcohol.

(3) Washing in distilled water, Io minutes.

(4) Staining in a 2 per cent. solution of gentian-violet for 5-IO minutes.

(5) Washing in acidulated water (Io drops of acetic acid to a watch-glass of water).

(6) Thorough washing in pure water.

(7) Mounting in lævulose.

The degenerated tissues are stained a brilliant red, and stand out in bold relief against the rest of the tissue with its brown nuclei.

Amyloid substance is best distinguished from other semi-transparent material, e.g., hyalin, by means of Virchow's iodine-reaction.

The iodine reaction is also obtained with :-

A. Corpora Amylacea.-Amyloid degeneration proper is an affection in which the morbid change occurs diffusely throughout the organ. But in addition to this general form there is a local one, characterised by the occurrence of circumscribed foci of degeneration, or of amyloid concretions. These localised changes are found in the prostate, in the brain, and in the optic nerve, etc. Indeed, they are sometimes found in the otherwise normal optic nerves of old people, especially in the intracranial portion of the nerve and in the chiasma. The patches are usually more numerous if ascending degeneration be present, and are found as far back as the corpora geniculata externa and the optic thalami. They vary in size, and are spherical 
homogeneous structures lying between the nerve fibres. Iodine in the form of Lugol's solution stains them brown or violet, the rest of the tissue yellow. Acids produce a similar reaction. Carmine stains them red, hæmatoxylin blue.

B. Beselin and von Hippel have reported the discovery of concretions resembling amyloid substance in old corneal scars. When the tissue is fixed in Müller's fluid, and the sections are stained with hæmatoxylin, alumcarmine, gentian-violet, acid-fuchsin (van Gieson), thionin, or Weigert's fibrin stain, the deposits become yellow. Gabbet's method for tubercle bacilli (Carbol-fuchsin, 2 minutes; mixture containing 2 per cent. of methylen blue and 25 per cent. of sulphuric acid, I minute) stains the greater part of the masses brilliant red, and the background blue. When treated with a solution of iodine, one portion of the deposit becomes markedly mahogany-brown, another part only straw-coloured.

I. Beselin, "Amyloid in der Cornea eines staphylomatösen Auges," Archiv fïr Augenheilkunde, Bd. XVI, S. I30. I 886.

2. Von Hippel, "Ueber das Vorkommen homogener Gebilde mit AmyloidReaction in Hornhautnarben," von Graefe's Archiv, Bd. XLI, Heft iii.

3. Kubli, "Die klinische Bedeutung der Sogen- Amyloid-tumoren der Conjunctiva," Archiv für Augenheilkunde, Bd. X.

4. Raehlmann, "Zur Lehre von der Amyloiddegeneration der Conjunctiva," Archiv fïr Augenheilkunde, Bd. X.

5. Virchow, Virchoze's Archiv, Bd. VI, VIII, XI, XIV, XV.

6. Vossius, "Ueber Amyloide Degeneration der Conjunctiva," Ziegler's Beiträge zur pathol. Anatomie, Bd. IV, S. 335. I889.

\section{FIBRIN.}

Fibrin stains well with acid anilin dyes, e.g., picric acid, eosin, acid-fuchsin, etc. Double staining with hæmatoxylin and eosin is often very successful. When the eosin stain is somewhat intense, the network of fibrin is exquisitely depicted, the fibrin being rose-coloured. Van Gieson's stain is also suitable ; it colours fibrin a brilliant red. Sublimate is the best fixing medium.

\section{Weigert's Specific Fibrin Stain:-}

I. Hardening in alcohol, sublimate, or formalin.

2. The sections are stained for five to fifteen minutes in a concentrated anilin water solution of gentian-violet.

N.B.-The solution should not be made up till it is about to be used. It is prepared by adding $5 \mathrm{c.cm}$. of anilin oil to Ico c.cm. of water, and shaking these thoroughly in a vessel for several minutes. The liquid is then passed through a moistened filter. The filtrate should be clear and free from globules of oil, and should not become cloudy when shaken. A concentrated alcoholic solution of gentian-violet is then added to the anilin water till this is saturated. Saturation is indicated by the appearance of an iridescent metallic-looking film on the surface of the liquid. For $90 \mathrm{c.cm}$. of anilin water IO-I $2 \mathrm{c.cm}$. of the gentian-violet are required. This stain does not keep long.

3. Washing in 0.6 per cent. salt solution.

4. Thorough drying with blotting paper on the slide

5. Lugol's Solution is poured over the preparation.

6. Drying with blotting paper.

7. Decolourization in

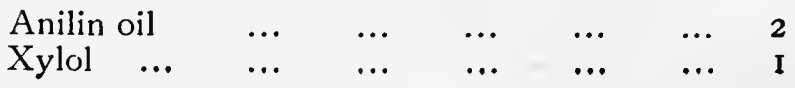


8. Removal of the anilin oil by means of pure xylol.

9. Canada balsam.

In this way the fibrin is stained an intense blue colour; everything else, except bacteria, is decolourized.

I. Baumgarten, "Ueber eine eigenthümliche Hornhautveränderung," von Graefe's Archiv, Bd. XXIX, Heft iii.

2. Greeff, "Refunde am corpus ciliare nach Punction der vorderen Kammern," Archiv für Augenteilkunde, Bd. XXVIII, S. I28.

3. Leber, "Die Fibringerinnung in der Hornhaut," von Graefe's Archiv, Bd. XXXV, Heft ii.

4. Vossius, von Graefe's Archiv, Bd. XXXV, Heft ii. and Ziegler's Beiträge, Bd. V.

5. Wagenmann, "Experimentelle Untersuchungen uber den Einfluss der Circulation," von Graefe's Archiv, Bd. XXXVI, Heft iv.

6. Weigert, "Ueber eine neue Untersuchungsmethode des Centralnervensystems," Centralblatt fïr a'ie medicin. Wissenschaften. I882.

7. Weigert, Beiträge zur Kentniss der normalen menschlichen Neuroglia. Frankfurt, I895.

\section{IRON IN THE INTERIOR OF THE EyE.}

When pieces of iron are present in the interior of the eye for considerable periods, the metal is dissolved and deposited throughout the organ. Leber suggests that the iron is dissolved by carbonic acid, carried away as a bicarbonate of the suboxide of iron, and again precipitated in an insoluble form under the influence of the oxygen introduced to the tissues in the blood. Bunge gave the title Siderosis Bulbi to the condition in which the cornea, iris, etc., are stained brown by rust. The lens is the structure most frequently attacked. In recent times the condition of Siderosis has been thoroughly investigated by $\mathrm{E}$. von Hippel. He has shown that the brown discolouration of the cornea, iris, and lens, cannot with certainty be ascribed to the presence of foreign particles of iron in the eye, because the same appearances can be produced by the iron contained in the blood. There are therefore two kinds of siderosis, Xenogenous Siderosis, due to the presence of a foreign body consisting of iron, and Hematogenous Siderosis, occurring as a result of hæmorrhages and due to the iron normally present in the blood.

Iron may be demonstrated by two different reactions :-

I. Perls' Reaction (Berlin Blue):-

The bulb should be fixed in alcohol or formalin.

According to von Hippel, the reaction is obtained with sections which have lain for years in Müller's fluid, although it appears more slowly.

Imbedding in celloidin.

The sections are placed in a 2 per cent. aqueous solution of ferrocyanide of potassium for a few minutes.

They are transferred to a $\frac{1}{2}$-I per cent. solution of hydrochloric acid.

They are then washed.

The examination is made in water, alcohol, or glycerine.

Oil. Canada balsam.

Tissues which have been kept in Müller's fluid for long periods, since they are more difficult to stain, are treated by von Hippel as follows :- -

The sections are placed for 12-18 hours in a mixture of equal parts of a 
Io per cent. solution of ferro-cyanide of potassium and chemically pure hydrochloric acid, which is well diluted with distilled water.

They are then carefully washed in tap-water. Berlin blue is dissolved slowly by distilled water.

The section can now be stained with alum-carmine.

They are dehydrated, cleared in oil, and mounted in Canada balsam.

Pigment containing iron is stained a fine blue colour by this method, and the reaction is so exact that mistakes cannot arise. Iron instruments must not be employed. The normal pigment of the eye, even when it is displaced as in retinitis pigmentosa, does not give the reaction. The siderosis is most apparent in certain groups of cells, viz., in the epithelium covering the ciliary processes (the pars ciliaris retinæ), in the retina, and in the epithelium under the lens capsule.

After intraocular hæmorrhages the retinal pigment epithelium under certain circumstances takes up iron which has resulted from the disintegration of hæmoglobin (von Hippel); and Leber states that it is possible in this way to distinguish between cells derived from the pigment epithelium, and those derived from the pigmented cells of the choroidal stroma. Thus when hæmorrhages have occurred in an eye affected with a tumour of the choroid, the pigment epithelium and its derivatives in the detached retina and pars ciliaris are found to contain a very large amount of iron derived from hæmoglobin. The stroma cells do not take up iron under these circumstances, and consequently do not give Perls' reaction.

\section{Quincke's Sulphide of Ammonium Reaction:-}

The sections are placed in a freshly prepared solution of sulphide of ammonium till they acquire a dark green colour, IO-20 minutes.

They are rinsed in water.

Alcohol. Oil. Canada balsam.

The iron appears in the form of dark green granules.

The sections may be stained with alum-carmine either before or after treatment with the sulphide.

I. Bunge, "Ueber Siderosis bulbi," Verhandl. des intern. med. Congresses zu Berlin, Bd. III. I 890.

2. Gruber, "Ueber Rostablagerung in der Hornhaut," von Graefe's Archiv, Bd. XL, Heft ii.

3. Hertel, "Anatomische Untersuchungen eines Falles von Siderosis bulbi," von Graefe's Archiv, Bd. XIIV, Heft ii.

4. Von Hippel, "Ueber Siderosis bulbi, etc," von Graefe's Archiv, Bd. XL, Heft i.

5. Leber, "Ueber Aderhautsarkome und die Herkunft ihres Pigmentes," von Graefe's Archiv, Bd. XLIV, Heft iii.

6. Perls, "Nachweis von Eisenoxyd," Virchow's Archiv, Bd. XXXIX.

7. Quincke, "Ueber directe Eisenreaction," Archiv für exper. Pathologie, Bd. XXXVII.

\section{COPPER.}

Copper in the interior of the eye can be demonstrated in sections by means of Perls' reaction (ferrocyanide of potassium and acetic acid). The impregnated tissues are coloured brown owing to the precipitation of ferrocyanide of copper.

R. Schmidt, " Ueber den Nachweis von Kupfer in den Geweben des Auges," von Graefe's Archiv, Bd. XLVI, Heft iii. 


\section{IO. MERCURY.}

Considerable attention has been paid to the detection of mercury in the tissues of the eyeball, since the deeper affections of the organ began to be treated with subconjunctival injections of sublimate.

Stuelp has shown that the chemical processes hitherto employed for this purpose are not trustworthy. A certain method for the detection of mercury has, however, been found in electrolysis. Stuelp proceeds as follows :-

If the aqueous is to be examined, it is mixed with a few drops of a weak solution of hydrochloric acid; while if it be the vitreous, lens, choroid, or retina, the tissue is divided into small pieces, and allowed to stand in a weak solution of hydrochloric acid for twenty-four hours before being placed in the circuit. The acidulated fluid thus obtained is placed in a glass tube, $\mathrm{A}$, the lower end of which is closed by a porous membrane of parchment paper.

The cell, A, with its contents is immersed in a second cell, B, which contains a weak solution of sulphuric acid, the level of the liquid in each cell being the same. A small gold plate attached to a platinum wire is suspended in $\mathrm{A}$, and a similar plate of platinum attached to a platinum wire is placed in B. The two plates should be as close together as possible, separated from each other by the membrane unly. The conductor attached to the gold plate is carried to the negative (zinc) pole, and that attached to the platinum plate to the positive (carbon) pole, of an element. The circuit is then closed.

Any mercury which may be present in the liquid in $\mathrm{A}$ is deposited on the gold plate. After twenty-four hours the gold plate is washed in distilled water, dried, and placed in a chemically-clean glass tube. The ends of the tube are sealed by heating, and the portion of the tubc where the plate is lying is gently warmed in a spirit lamp. The mercury on the plate volatilises, and is deposited on the colder portions of the tube in the form of minute drops. With a magnifying-glass these can be recognised as globules of mercury.

If, however, the quantity of mercury is very small the following method should be adopted. After being heated, the tube is filed at one end, and opened so that the gold plate can be removed. A small granule of crystalline iodine is placed in the tube, and this is again sealed. The tube is then warmed over the site of the iodine. The vapour of iodine unites with the mercury to form red iodide of mercury, and on cooling, the vapour condenses in the form of bluish-black crystals.

I. Stuelp, "Wird nach subconjunctivalen Sublimatinjectioncm Quecksilber ins Augeninnere resorbirt?" Archiv für Augenheilkunde, Bd. XXXI, 1895.

2. Addario, "Ueber den Nachweis von Quecksilberoxyd, etc.," von Graefe's Archiv, Bd. XLVIII, Heft ii, S. 375.

\section{Stains which do not act similarly on all cells.}

In recent years there have been discovered certain peculiar methods of staining, or rather of impregnation, which, unlike those hitherto known, do not act in the same manner on all the cells contained in a section, but which, as if at random, pick out a limited number of cells from the general mass. The cells selected are, however, displayed in their entirety. Only in this way has it become possible to study the form of cells which lie densely packed together. If all the cells with their processes were rendered equally distinct, the confusion resulting would prevent the recognition of any detail. These methods have in the case of the retina and optic nerve yielded astonishingly complete pictures. The cells are revealed even to their finest processes, 
and appear as if drawn diagrammatically. The sections should be pretty thick, so as to show, not only the cell processes which lie in the plane of the section, but also those which extend vertically into adjacent planes.

The new epoch dates from the discovery of two new methods, which are due to Camillo Golgi, of Pavia, and P. Ehrlich, of Berlin. With these names should be associated a third, that of Ramón y Cajal, of Madrid, who by his modification of Golgi's method rendered it applicable to wider fields of investigation and brought it into the general favour which it now enjoys.

\section{Golgi's MethoD.}

The publication of Golgi's method and the results attainable by means of it dates from the year I875. It was only slowly, however, that its importance was recognised, and that it came to be so widely adopted as it now is. Golgi's principal work appeared in $\mathbf{1} 885$. His researches were directed mainly to the study of the nervous elements in the spinal cord of fully-grown animals; and it was not till Ramón y Cajal began to apply the method to the central nervous organs of young animals and embryos that the value of Golgi's discovery was fully appreciated. Cajal, moreover, deserves credit for his successful investigations into the structure of the retina.

Golgi's method has been developed in three forms. These are described as the Slow Method, the Mixed Method, and the Rapid Method. At present the Rapid, often wrongly called Cajal's Method, is the one almost universally employed. The other methods may, therefore, be dismissed with a short description.

\section{Corrosive Sublimate Method.}

Small pieces of tissue, e.g., portions of the optic nerve, are hardened for at least two months in a 2 per cent. solution of bichromate of potash, which is to be renewed from time to time. The duration of the immersion is important for the subsequent impregnation. A small piece is therefore removed from the fixing solution every ten days, and placed in an $0.35-0.50$ per cent. solution of corrosive sublimate, which is renewed daily for the first ten days, and thereafter once every five days. The impregnation is complete after two months, and the pieces are then ready for cutting.

\section{Nitrate of Silver Method.}

In his later researches Golgi employed nitrate of silver instead of corrosive sublimate. Small pieces of tissue are hardened in Müller's fluid for 2 months, and are placed for $24-48$ hours in a 0.75 per cent. solution of nitrate of silver. They are then quickly imbedded and cut.

\section{Rapid or Chrome-Osmium-Silver Method.}

Golgi's method demonstrates nerve fibres, ganglion cells, and neuroglia. These structures appear dark brown or black on a bright yellow background The tissues should be taken from the animal immediately after death, and the pieces must not be larger than I c.cm. Usually they are chosen not thicker than 3 or $4 \mathrm{~mm}$. They are placed at once in the osmio-bichromate solution, which consists of-

Solution of osmic acid, I per cent. ... $\quad \ldots \quad$ I

Solution of bichromate of potash, 3.5 $\begin{array}{lllllll}\text { per cent. } . . . & \ldots & \ldots & \ldots & \ldots & 4\end{array}$

The precautions necessary in the employment of $\cdots$ osmic acid ought to be observed. 
The solution must not be used too sparingly. For a piece of tissue $5 \mathrm{~mm}$. in diameter at least Io c.cm. are taken. The solution should be freshly prepared. The pieces remain in it for $24-48$ hours or longer, and are kept in the dark. They are then removed by means of a platinum needle, dried on blotting paper, and placed in a

Solution of nitrate of silver, 0.75-I per cent.

Brown clouds of chromate of silver are immediately given off. The solution is renewed, and the pieces of tissue are left in it for about 24 hours, or longer if necessary.

The pieces must then be sectioned without delay. This can be conveniently carried out if the tissue is held between two pieces of elder-pith or hardened liver, since the sections are to be thick. Or the tissue may be superficially imbedded in paraffin. A hot needle is applied to the surface of a cube of paraffin, and the tissue is placed in the cavity so formed. The author usually employs celloidin. The pieces are placed for about two minutes in 80 per cent. alcohol, for the same time in absolute alcohol, and again for an equal period in thin celloidin. They are next mounted on a block by means of thick celloidin, immersed in 80 per cent. alcohol, and are ready for cutting five minutes later.

Each section is examined in alcohol as it is cut. Worthless sections are cast aside. Those in which the impregnation has been successful are transferred for a minute to absolute alcohol, next for a minute to clove oil, and then dipped for a second in xylol to remove the clove oil which would ultimately prove injurious. They are fixed to a cover-glass by means of a thin layer of dammar. The cover-glass must not, however, be applied to the slide directly, since exclusion of air leads to destruction of the preparation. In order to protect the tissue from dust the cover is rested on two slips of glass which are glued to the slide, the side of the cover carrying the section being under.

If it is found that the sections are not well impregnated, the tissue should be removed from the block, and the process repeated beginning with the osmic acid solution. This is Cajal's Method of Double Impregnation.

Golgi's method is best learned by practising on the optic nerve, the delicate neuroglia cells of which are relatively easy to demonstrate. Short pieces of a fresh nerve should be chosen, and their sheaths should be removed. They are left in each of the fluids not longer than twelve hours. The sections should be thick, and cut parallel to the course of the nerve fibres.

Cajal's Roll Method.-The retina yields beautiful pictures, but is much more difficult to handle. It is best to detach it, and cut it into strips, which are rolled round a thin rod of elder-pith. To prevent the roll from unwinding it is dipped for a moment into a thin solution of celloidin. It is then exposed to a double or treble impregnation, and sections are cut at right angles to the axis of the roll. By this method a considerable length of retina is presented in each section. There is thus a greater probability of finding a layer in which the cells are well impregnated.

Formalin Bichromate Mixture.--. Recently it has been discovered that formalin can be employed instead of osmic acid which is costly and difficult to manipulate. Small pieces, not more than $5 \mathrm{~mm}$. in diameter, are placed in-

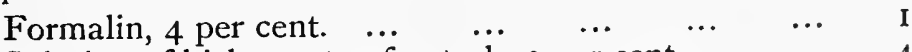

Solution of bichromate of potash, 3 per cent... $\quad \ldots \quad 4$

Here they remain for three days, and are then transferred tofor three days.

Solution of nitrate of silver, 0.75-I per cent. 
The subsequent treatment is identical with that of the Rapid Method.

All the structures are never demonstrated in the same section. Müller's supporting fibres are first impregnated, the ganglion cells later.

\section{Ehrlich's Intra Vitam Methylen Blue Method.}

Beautiful results are obtained by this method with different portions of the eye, and more especially with the retina. At first Ehrlich used a $\frac{1}{4}$ per cent. solution of Grübler's rectified methylen blue in normal salt solution, which was filtered and injected into the veins of the animal immediately after death. The colouring-matter is absorbed principally by nervous plexuses and ganglion cells. Other cells, however, and endothelium are affected.

The animal dies as a rule before a complete nerve stain has been obtained, if the colouring solution is injected during life. It is, therefore, better to perform the injection immediately after death. When it is desired to colour the tissues of the eye, a 4 per cent. solution of methylen blue is injected into the carotid artery. The procedure is the same as that for injecting the blood vessels. The injection is stopped when the tension in the veins is considerable To avoid spasm of the blood vessels, which would prevent the injection from reaching the head, the solution should be warmed in a water-bath. The organs, now coloured blue, are removed from the body. The stain is intensified by exposing the preparation to the air for some time. Continued exposure causes it to fade. The preparation should, therefore, be examined under the microscope, and fixed quickly when the maximum effect has been obtained.

The method is naturally rarely applicable to the human subject. For this reason and on account of its greater simplicity Dogiel's modification of the method is a marked improvement.

S. Meyer recommends the introduction of the methylen blue by means of subcutaneous injections, each of 2 c.cm., at intervals of $\frac{1}{4}$ to $\frac{1}{2}$ an hour. The solution should be saturated and used at a temperature of $37^{\circ} \mathrm{C}$. Death follows after 3-6 injections.

Dogiel's Process.-Dogiel showed that the tissues of the recently enucleated eye could be impregnated equally well if the colouring fluid was allowed to reach them from their margins.

In the case of the retina the procedure is as follows (Archiv für mikrosk. Anatomie, Bd. XL., S. 34): For successful staining it is requisite that the examination be made immediatcly, at all events not later than 3-4 hours, after the removal of the eye.

The organ is divided in the equatorial region into an anterior and posterior half. The posterior half is again divided, most conveniently by meridional incisions, into three or four pieces.

A segment of retina is now carefully detached with forceps from the choroid, and transferred along with some vitreous to a large slide. On this it is spread out, the nerve fibre layer being uppermost, and covered with more vitreous to prevent drying during the examination.

A few drops of $\frac{1}{16}$ per cent. methylen blue solution are placed on the preparation, or rather applied to its margins.

Staining of the nervous elements begins at the circumference very soon, usually in the course of 15-20 minutes. Progress is watched under the microscope. The axis-cylinders stain first, then the cells. Several hours may elapse before the nervous elements of all the layers are coloured.

The process can be hastened by placing the slide in the incubator at $35^{\circ}-40^{\circ} \mathrm{C}$., and examining every five minutes to determine when staining is 
sufficiently advanced. The methylen blue solution is applied to the margin of the tissue from time to time.

So far all is simple. It is, however, most important to interrupt the process at the right moment, and to fix the stain. Herein lies the difficulty. If staining is carried too far the capillaries become filled with the methylen blue, and finally so many structures are coloured that it is no longer possible to distinguish individual cells.

Dogiel fixes in this manner.-The vitreous covering the specimen is removed, and the surface of the retina is moistened with a saturated aqueous solution of ammonium picrate. The preparation is now placed under an inverted watch-glass and left protected from the air till next day. The fixing solution is then replacea by a mixture of equal parts of chemically pure glycerine and water, and a cover-glass is applied. To prevent pressure the glass rests on a circle of thick paper placed around the tissue. The paper should be saturated with glycerine.

After one or two days the preparation has usually attained such a degree of transparency that, by focussing, the branching of the nervous elements in the different layers of the retina can be clearly distinguished.

Apathy (Zeitschr. fiir ivissenschaftl. Mikroskopie, Bd. XIX) has improved the method of fixation essentially by adding to the picrate of ammonia a few drops of strong liquor ammoniz. The preparation is mounted in a solution of gum arabic and sugar.

Kallius (Anatomische Hefte, Bd. III, Heft x, I894) directed attention to the fact that tissues treated with Apathy's fixing fluid could, when quickly dried in the incubator at a moderately high temperature, be nounted in Canada balsam under a cover-glass. In this way he had secured excellent specimens which, as the author can testify, have kept well for a long time.

Bethe has introduced an admirable method of fixing. It possesses, amongst other advantages, that of allowing the stained pieces of tissue to be imbedded in paraffin or celloidin and cut with the microtome. Small pieces are stained in the usual way in a watch-glass or on the slide (Dogiel).

Bethe proceeds as follows :-

I. After staining is complete, the excess of colouring-matter is washed away by salt solution.

2. The tissue is transferred to the fixing fluid. In the case of the retina, however, it is better, after removing the vitreous, to leave the tissue on the slide, to pour the fixing fluid over it, and then to protect it from the air.

Bethe recommends as a fixing fluid-

$$
\begin{array}{lllll}
\text { Molybdate of ammonia } & \ldots & \ldots & \ldots & \text { I gramme } \\
\text { Distilled water } \ldots & \ldots & \ldots & \ldots & \text { Io } c . c m . \\
\text { Peroxide of hydrogen } & \ldots & \ldots & \ldots & \text { I c.cm. } \\
\text { Strong hydrochloric acid } & \ldots & \ldots & \ldots & \text { I drop }
\end{array}
$$

This solution does not keep longer than eight days. It should be used as cold as possible, and preserved in a vessel surrounded by ice. It is applied in the cold state for 2 or 3 hours, and after this can be left to act a little longer at the ordinary temperature of the room.

3. Washing for $\frac{1}{2}-2$ hours to remove the molybdate of ammonia.

4. Dehydration as quickly as possible with cold alcohol, So per cent. It is important that the alcohol should be cooled in ice or snow, otherwise it extracts the colouring matter. The tissue may be left for several hours in the cold alcohol, where it undergocs further hardening.

It is now dehydrated in absolute alcohol, imbedded in paraffin or celloidin, and sectioned. 
The natural blue tone of the stain is preserved by Bethe's method of fixing, whereas, after Dogiel's fixation process, the blue becomes dark violet.

\section{Injection of Tissues.}

\section{BLoOD VESSELS.}

Injections of colouring-matter are employed to demonstrate the distribution of blood vessels and lymphatics. The author has had little practice in these processes, the application of which to the eyeball is peculiarly difficult. Only a few ophthalmologists are skilled in this department of histology, and the literature of the subject is scanty.

The material used for injection is generally a solution of gelatine in which is suspended the colouring matter. This may be either red or blue. The solution is injected into a blood vessel by means of a good syringe, under uniform, and not too high, pressure lest the vascular walls should be ruptured. Cannulæ of different sizes are required. The cannula is tied into the trunk of a blood vessel, and the nozzle of the syringe is set into the distal end of the cannula itself, or a short piece of rubber tubing is inserted between them. Care should be taken that no air is injected.

The animal is allowed to bleed to death, and the injection is then performed without delay. If the animal is small it is injected as a whole by introducing the cannula into the left side of the heart or into the aorta. In the case of larger animals, if it is desired to inject only one of the afferent arteries, some of the other vessels require to be ligatured; or pressure forceps are applied wherever the injection mass appears in a wound or issues from a ruptured vessel. The injection process is continued till the organ becomes coloured, or till the mass has been escaping from a vein for some time.

The masses employed may be cold, the colouring-matter being suspended in water or glycerine. It is, however, better to use warm masses. These latter contain gelatine which solidifies on cooling. In this case not only the mass but also the body of the animal must. be maintained at a temperature of about $40^{\circ} \mathrm{C}$. The injection is therefore carried out in a warm bath.

Only a few of the numerous injection masses can be noticed here. Many of them can be purchased ready for use from the firm of Grübler in Leipzig, and elsewhere.

\section{A. Red Masses.}

I. Warm Gelatine-carmine.-This is, according to Böhm and Davidoft (Lehrbuch der Histologie), prepared in the following manner: I. A paste is made by rubbing up 4 grammes of carmine with $8 \mathrm{c.cm}$. of water. To the paste a solution of ammonia is added till the whole becomes dark cherry-red and transparent. 2. 50 grammes of fine gelatine are placed in distilled water for twelve hours, and allowed to swell. The gelatine is then compressed with the hands, and melted in a porcelain vessel at a temperature of about $70^{\circ} \mathrm{C}$. The melted gelatine is carefully added in small quantities to the carmine paste, the whole being stirred till a complete mixture of the two fluids is obtained. The mass is allowed to cool to $20^{Q} \mathrm{C}$, and there is added, drop by drop, a 25 per cent. solution of acetic acid till the cherry-red colour begins to change to a brick red opaque tint, the stirring being continued. Next the mass is filtered through flannel, while still warm.

II. Cold Carmine Mass (Kollmann).-Carmine, I gramme, is dissolved in a little water containing I 5 drops of concentrated ammonia solution, and diluted 
with $20 \mathrm{c.cm}$. of glycerine. To this there is added a mixture of $30 \mathrm{c.cm}$. of glycerine and I gramme of ordinary salt. The whole is diluted with an equal quantity of water.

\section{B. Blue Masses.}

I. Berlin Blue Mass (Thiersch).-Four solutions are prepared :-

I. A cold saturated solution of sulphate of iron.

2. A cold saturated solution of red prussiate of potash.

3. A cold saturated solution of oxalic acid.

4. A solution of gelatine in the proportion of 2 to I.

In a porcelain vessel 15 grammes of No. 4 are mixed with 6 c.cm. of No. I. In a second vessel 30 grammes of No. 4 are mixed with $I_{5}$ c.cm. of No. 2, and to the mixture are added $12 \mathrm{c.cm}$. of No. 3. The contents of both vessels are brought to $30^{\circ} \mathrm{C}$, and the liquid in the first is added to that in the second, drop by drop, stirring being continued all the time. Then the whole of the deep-blue mass is heated to $75^{\circ}-\mathrm{JO}^{\circ} \mathrm{C}$., and filtered through flannel on a hot water filter. (v. Kahlden, Technik der histol. Untersuchung.)

II. Cold Blue Mass. - I gramme of Berlin blue is dissolved in 20 c.cm. of water.

After warm injections the body of the animal is placed in cold water to hasten the solidification of the mass. The organs are then excised, and immersed in 80 per cent. alcohol. When cold injections are used, the organs are transferred directly to spirit, and cut into suitable pieces after a few hours.

The sections must be preserved from contact with acids and alkalies.

\section{Injections by Puncture.}

In this process the lymphatic spaces and vessels are filled with colouring matter. The method is applicable to the eye, and demonstrates well the lymph spaces of the cornea. A small pointed syringe is pushed into the tissue to be injected, and it is left to chance to determine what spaces are opened. The injection is performed under a low and constant pressure Cold aqueous solutions are most suitable for the purpose.

The lymplatic spaces in the corned, are well exhibited when Berlin blue is injected by means of a hypodermic syringe into the posterior layers of the cornea. Berlin blue possesses the advantage of not staining the corneal tissue. Tangential sections are made from the back of the cornea.

\section{Decalcification.}

It is often necessary to decalcify the tissues of the eye before sections can be made with the microtome. It is rare to find a shrunken and atrophic bulb in which there is not a deposit of calcareous material. This is most commonly situated in the choroid, and not only calcareous plates but even true bony formations may be present. Similar deposits are found in the cornea, in the capsule of the lens, in intraocular tumours, etc. When a bulb containing these is incised, the passage of the knife causes a grating sound, and the calcareous parts can be recognised if pricked with a needle. Such tissues require to be decalcified.

The eye must be well hardened before being placed in the decalcifying fluid, in order to prevent alteration of the soft parts. The hardening is best performed in Müller's fluid, which itself has a slight decalcifying action. Indeed, when the deposit is not extensive, immersion in Muller's fluid for a month is sufficient to remove the lime salts. The action of this medium may 
be hastened and increased by the addition of a small quantity of nitric acid, and by changing the mixţure every eight days.

The following solution, recommended by Haug, is, in the author's opinion, the most suitable for the tissues of the eye :-

$\begin{array}{llllllr}\text { Nitric acid } \ldots & \ldots & \ldots & \ldots & \ldots & \ldots & \text { I } 5 \\ \text { Absolute alcohol } & \ldots & \ldots & \ldots & \ldots & \ldots & 300 \\ \text { Distilled water } \ldots & \ldots & \ldots & \ldots & \ldots & \ldots & \text { I 50 } \\ \text { Chloride of sodium } & \ldots & \ldots & \ldots & \ldots & \ldots & \text { I }\end{array}$

A large quantity of the fluid is employed, and it should be renewed several times.

Greeff has employed a 5 per cent. solution of trichlor-acetic acid for decalcification with very satisfactory results. If a large quantity of fluid is used, and this is changed several times, even large bony plates are decalcified in a few days. Thorough washing is necessary, as any acid left in the tissue spoils the stains.

The time required for the complete removal of the calcareous matter varies with the extent of the deposit and with the size of the pieces. When the bulb is incised, the seat of the deposit is noted, and the spot examined from time to time by pricking it with a needle or by making an incision over it. When decalcification is complete and the grating sound is no longer elicited, the tissue is at once removed from the fluid. Several days are required as a rule.

The pieces are now washed for I-2 days, and then hardened in alcohol gradually increased in strength.

If the condition is not detected till the tissue is imbedded, the celloidin must be redissolved in equal parts of absolute alcohol and ether, and decalcification then proceeded with.

If, however, the calcareous foci, or the bony plates are small, it is sufficient to place the imbedded tissue for a time in 70 per cent. alcohol containing I per cent. hydrochloric acid, and then to dehydrate and proceed with the cutting.

\section{Bleaching.}

For the minute examination of the posterior layers of the iris, the pigment epithelium of the retina, the ciliary body, etc., it is often neccssary to remove the pigment, so as to render the tissues transparent and admit of their being stained. This process is carried out when the Dilatator Pupillæ is being investigated.

Mr. John Griffith, of the Royal Westminster Ophthalmic Hospital, adopts the following method: -

I. The eye having been hardened in Müller's fluid in the usual manner is bisected, and portions of the ciliary region or other parts requiring investigation are left soaking in a stream of running water for 24 hours.

2. The tissue is next placed in the bleaching solution-euchlorine-for 48 hours, i.e., till bleached.

3. It is then washed in running water for another 24 hours.

4. It is further hardened in alcohol of gradually increasing concentration.

The bleaching solution is made as follows: One gramme of chlorate of potash is placed in a glass-stoppered bottle, and shaken up with $2 \mathrm{c} . \mathrm{cm}$. of strong hydrochloric acid. Distilled water is now added so as to make $300 \mathrm{c.cm}$., and the mixture is shaken from time to time. It should be kept in the dark, since exposure to light causes chlorine gas to be evolved, and renders the solution inert. (See "A Contribution to the Anatomy and Physiology of the Iris," Transactions of the Eighth Intern. Ophth. Congress, Edinburgh, 1894.) 
When, however, tissues are decolourised in bulk, shrinking and displacement of the parts are apt to take place.

A preferable method is, therefore, that of Leopold Miuller, by which the sections are bleached individually. ("Ueber Entfärbung des Pigmentes in mikroskopischen Schnitten und eine neue Untersuchungsmethode des accommod. und nicht accommod. Auges," Wiener klin. Wochenschr., Bd. VIII, S. 59, 1895.) The celloidin sections are placed in Io per cent. alcohol, next in pure water, and are then exposed in peroxide of hydrogen to sunlight for 48 hours, till they are sufficiently bleached. Unfortunately this renders them very brittle, although they stain well.

Chloride of lime or chlorine water may be employed instead of peroxide of hydrogen, but they possess the same disadvantage.

E. Fick (Centralblatt fïr Physiologie, Bd. IX, No. 19, 1895) recommends a saturated solution of bichromate of potash with the addition of one-third of its volume of dilute sulphuric acid. In a cold solution the bleaching is accomplished in about three-quarters of an hour; if carried out at a higher temperature in the course of a few minutes.

Grunert (Archiv für Augenheilkunde, Bd. XXXVI, S. 333) recommends the process of A. Alfieri. The individual sections are bleached. They are transferred from water to a solution of permanganate of potash ( 1 in 2000), in which they remain for at least 24 hours. If they are exposed to sunlight less time is required. As soon as they have acquired a brown colour they are placed in a solution of oxalic acid ( 1 in 300), in which they become fully bleached within a few seconds. This method appears to be the most satisfactory.

The duration of the immersion in the two solutions depends upon the quantity of pigment present in the tissue. After the sections have been thoroughly washed in water, they can be stained as desired. They are, however, very fragile, and must be carefully moved with the section-lifter and not with a needle. Such sections are more difficult to stain, and should remain longer than usual in the solutions. The most suitable stain is Heidenhain's Iron-hæmatoxylin. With this Grunert has obtained excellent results.

\section{Preservation of the Bulbs and Macroscopic Preparations.}

When the eyeball is kept too long in Müller's fluid, the tissues are rendered less susceptible to stains, the lens becoming hard, etc. The same remarks apply to most of the fixing media, and especially to formalin. After being fixed, the bulbs should, therefore, be preserved in strong ( 90 per cent.) alcohol, which is renewed from time to time, until it no longer becomes turbid. In this they are left unopened, or they may be divided previously.

There are several excellent methods of preserving the eyeball for macroscopic demonstration or for the museum.

\section{Gelatine Method of Priestley Smith.}

This is an admirable method. The eye is well hardened, and, having been frozen, is bisected. One half may be reserved for microscopic examination. The other half is treated as follows: it is placed, if necessary, in a 2 per cent. solution of chloral hydrate, in order to remove the colour imparted by Müller's fluid, the solution being changed every 2 or 3 days until it is no longer tinged.

It is then placed successively in glycerine solutions, 10 per cent., 25 per cent., and 50 per cent. remaining in each $2+$ hours or longer. These steps 
are neccssary in order to prevent shrinking of the tissues when the specimen is imbedded in the jelly.

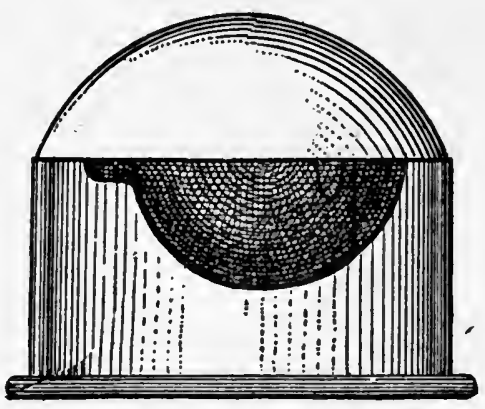

FIG. 4.-Priestley Smith's Jar as modified by Treacher Collins.

The half of the eyeball is placed in a specimen jar, which is partiy filled with melted jelly, the concavity of the eye being upwards. When every interstice is filled, the eye is turned over, care being taken to exclude air bubbles. The presence of these can be ascertained by holding the jar over a mirror. If the specimen tends to float in the jelly, it may be maintained in position by means of a pin passed through a strip of card laid across the mouth of the jar. When the jelly has become hard, the jar is filled, and after a time inverted over a sheet of opal glass. Openshaw leaves just sufficient jelly to cover the specimen, and "when the jelly has become sufficiently firm to support it, a disc of white enamel glass (cut to fit loosely the interior of the jar) is dropped flat upon the surface of the jelly. The jar is then filled with jelly. When the jelly is quite set, a cover of common glass is applied by means of 'black cement,' a mixture of gutta percha, 4 parts, and pitch, I part."

The jelly consists of :-

\begin{tabular}{|c|c|c|c|c|}
\hline Glycerine... & 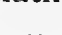 & 8 & 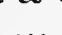 & . \\
\hline Water $\quad .$. & $\ldots$ & 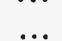 & $\ldots$ & $\ldots$ \\
\hline
\end{tabular}

The gelatine is allowed to swell up in the water, and is then melted by gently heating. The white of one egg is added, and the whole boiled thoroughly and filtered warm through flannel. Lastly the glycerine is added, and a trace of carbolic acid or thymol. The jars are procurable from Messrs. Osler, Broad Street, Birmingham. Treacher Collins in order "to show up more of the details of the specimens, and also to add to their general effectiveness, cements a plano-convex lens on the jars by means of Canada balsam."

Nettleship employs for imbedding-

$\begin{array}{lllllllr}\text { Glycerine } & \ldots & \ldots & \ldots & \ldots & \ldots & \ldots & 250 \\ \text { Gelatine } & \ldots & \ldots & \ldots & \ldots & \ldots & \ldots & 250 \\ \text { Creosote } & \ldots & \ldots & \ldots & \ldots & \ldots & \ldots & \text { I }\end{array}$

The interstices of the eyeball are filled with the mass, and the specimen is enclosed in an air-tight jar.

Instructive preparations can be simply made by placing a thick section of the eyeball on a disc of opal glass, pouring a little glycerine jelly over it, and, finally, laying gently on the top a plano-convex lens, taking care to exclude all air bubbles, much in the same way as one lays a cover-glass on a microscopic specimen. 


\section{DRY METHOD.}

The bulb is fixed and hardened in alcohol in the usual manner. It is then divided suitably, and the parts, having been thoroughly dehydrated, are soaked in oil of turpentine for at least eight days, till they become transparent. They are now removed from the turpentine and placed in a vessel partially protected from the air, so that the turpentine evaporates slowly. When the specimen is dry, it will keep for an indefinite length of time; it only requires to be protected from dust.

When examined with a lens, preferably a binocular lens or a binocular microscope, the ciliary body, the spaces of Fontana, and the zonule of Zinn, present pictures of great beauty.

Hyrtl's Method.-Hyrtl pierced the optic nerve, converting it into a tube along which the contents of the eye were expressed. The globe, now reduced to cornea and sclera, was then inflated and dried. The method is only of historic interest, since the specimen reveals nothing but the size of the organ.

\section{Preservation in Formalin.}

Formalin possesses the property of maintaining the transparency of the cornea. It is, therefore, suitable for preserving specimens exhibiting affections of this structure and of the anterior chamber, or those in which it is desired to examine newly formed vessels in the cornea.

Preparations showing the latter are easily produced. The cornea of a rabbit, if infected with pathogenic aspergillus spores, is soon invaded by new vessels, which run in from the limbus. The eye is then enucleated, and divided through the equator; or the cornea is excised in toto, stained with eosin, and imbedded in Canada balsam. Under a low power the delicate network of vessels is revealed (Straub, Achiv fiir Augenheilkunde, Bd. XXXVII, S. 2).

Formalin renders the lens opaque.

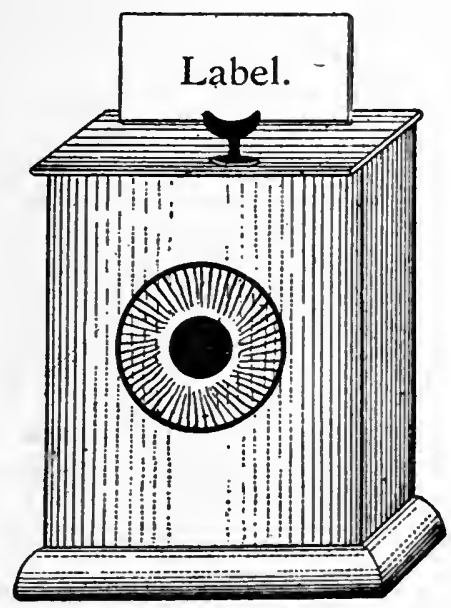

FIG. 5.-Jar for Museum Specimen.

It is suitable for preserving specimens of almost every kind. If, however, the tissues are intended for microscopic examination, they should not be left unduly long in formalin, because they become too hard for cutting with the microtome. 
For demonstration purposes the eyeball, after being hardened and divided, is enclosed in a jar with flat sides (see Fig. 5).

The preparation is first placed in distilled water for a few minutes, whether it has been hardened in alcohol or formalin. Some fine gelatine is dissolved in water at a gentle heat, and by means of this the preparation is fastened with its back to the posterior wall of the jar. As soon as the gelatine has become solid, the vessel is filled to the top with alcohol, or with a 3 or 4 per cent. solution of formalin. The upper margins of the jar are coated with gutta-percha cement, and the lid is warmed and applied, so as to exclude air A clasp for the label is fastened to the cover.

II.

\section{SPECIAL PART.}

\section{Cornea.}

\section{LAYERS OF THE CORNEA.}

The surface of the cornea is covered by transparent Stratified Pxvement Epithelium. The superficial cells are flattened. Those of the middle layers are rounded or polygonal, and possess protoplasmic processes connecting the surfaces of adjacent cells (prickle-cells). Those of the deepest layer, basal cells, are elongated and cylindrical. Between the epithelial cells there is a system of lymphatic spaces, but these, as a rule, are not visible. They become very apparent, however, when the corneal epithelium is swollen and œdematous. The prickle-cells are then pushed aside, so that their processes become evident, and between them, as well as between the other cells, the lymphatic spaces can be seen.

The second layer of the cornea is called Bowman's Membrane, and it must be considered as the uppermost layer of the substantia propria. It is composed of condensed fibrillæ of connective tissue, and therefore does not belong to the group of elastic membranes.

The substantia propria, forming by far the greater part of the cornea, consists of a connective tissue ground-substance with cellular elements and nerves. The ground-substance is arranged in lamellæ, which lie one above another. The lamellæ themselves are made up of small bundles of connective tissue fibrilla held together by fine but strong cement substance. A few oblique bundles unite neighbouring lamellæ. Between the lamellæ is the lymph-canalicular system discovered by von Recklinghausen. The canaliculi exhibit dilatations, the Lacunce. At fairly definite intervals cells are found in these lacunæ, and a knowledge of these is of the first importance to the pathologist, since they have played a prominent part in the investigations into the nature of inflammation. Two kinds of cells occur in the cornea.-I. The corneal corpuscles, discovered by Virchow, and by Cohnheim appropriately called fixed corneal cells to distinguish them from the second variety. They are flattened and star-shaped, with numerous long processes. They lie in the lacunæ, and send their processes along the canaliculi to join the processes of neighbouring cells. A lacuna contains usually only one cell, and this does not quite fill the space. 2. There are also found in the canalicular system, as von Recklinghausen has shown (Virchore's Archiv, Bd. XXIII, S. I 57), socalled migratory cells, although in small numbers under normal conditions. These are round cells which have found their way into the cornea from the marginal capillary loops, and are indistinguishable from the round 
cells found in other organs. They are smaller, and in the recent condition more highly refracting, than the fixed cells, and, unlike these, exhibit amoboid movements which enable them to change their shape and position.

The most postcrior layer of the cornea is the Membrane of Descemet. It is a strong, elastic, homogeneous layer, presenting in transverse sections bright highly refracting striæ. It is very resistant. When ulceration has destroyed the anterior layers of the cornea, the membrane of Descemet may for a considerable time alone prevent rupture; when finally it does yicld, or when it is pierced in injuries of the cornea, it behaves like an elastic structure, the margins of the opening retracting and becoming curled on themselves.

The posterior surface of Descemet's membranc is covered with a delicate but close mosaic of polygonal endothelial cells, which pass over on to the ligamentum pectinatum iridis and the anterior surface of the iris.

Cross sections through the normal human cornea.-Staining with hematoxylin. Differentiating. Counterstaining with eosin or orange G.

Tangential sections. - In these the epithelial covering is visible at the margins owing to the curvature of the cornea.

\section{Corneal Epithelium.}

Epithelial cells.-The form of these cells is best exhibited in teased preparations. The cornea of a calf or pig should be sclected, bccause in these animals the epithelial layer is more pronounced than in man. The cornea is removed and placed in a macerating solution, e.g., a Io per cent. salt solution, Müller's fluid diluted with two parts of water, or, best of all, 30 per cent. alcohol (Vossius). On the second day the upper layers can be removed in the form of a thin pellicle; on the third day the deeper layers can be detached by gentle rubbing with a cataract needle. The examination is made in water or glycerine, the mass resolving itself into its individual cells. These are very varied in shape. (Cf. Vossius, von Graefe's Archiv. Bd. XXVII, Heft. iii, S. 237.)

Karyokinetic figures can be demonstrated in the corneal epithelium of the calf, and in that of other animals after injury to the cornea.

Silvering of the Epithelial Cells.-Surface view. The surface of a frog's cornea is rubbed with a pencil of nitrate of silver till it becomes dull white. The head of the animal is then removed and exposed in a vessel containing water slightly acidulated with acetic or formic acid. The cornea becomes dark brown after $\frac{1}{4}$-I hour, the time depending on the intensity of the illumination. It is next excised and spread out on a slide, radial cuts being made through the margins if necessary, and then mounted in glycerine. In this way a positive silver image is obtained. The protoplasm of the cells varies in colour from light to dark brown. The cell boundaries stand out clearly, the intercellular substance being unstained. (Cf. Sattler, Archiv fïr mikroskop. Anatomie, Bd. XXI, I882.)

The corneal epithelium possesses a well-marked Intercellular Lymph System. This is very prominent when the cornea is odematous (glaucoma, panophthalmitis, iridocyclitis, haziness of the cornea), the prickle-cells becoming separated by the effusion of lymph so that their processes are easily recognised. Between the deeper cells drops of liquid may often be seen arranged in the form of a rosary.

Leber has suggested a method whereby this condition is artificially produced. He injects oil of turpentine into the superficial layers of the substantia propria, whence it finds its way into the spaces between the epithelial cells. For microscopic purposes tangential sections are made from the cornea, either while this is fresh, or after it has been hardened for a few days in Müller's 
fluid. The sections should include a very thin layer of the ground-substance, which serves to prevent the turpentine from oozing out. They are then carefully rinsed, and placed for a short time in a 1 per cent. solution of osmic acid. In this the turpentine acquires a dark colour, thus revealing its distribution between the cells. ( $C f$. Leber, ron Graefe's Archin', Bd. XXIV, Heft i, S. 265 ; Fuchs, Bd. XXVII, Heft iii, S. 66.)

\section{CORNEAL Fibrilla.}

Lamella of the substantia propria can be resolved into very delicate fibrillæ when the cement substance has been dissolved. Small pieces of hardened cornex arc placed for 24 hours or longer in a concentrated solution of picric acid, and then teased as finely as possible with two needles. Alcohol. Oil. Canada balsam. Staining is unnecessary, but can be carried out if desired.

\section{Corneal Cells and Lacuna.}

These can be readily demonstrated in the fresh condition, often, indeed, better than in silver preparations. The complete cornea of a small animal or a portion of a large cornea is removed with the utmost care, all crushing and stretching being avoided, and placed in a glass cell along with some aqueous fluid. A cover-glass is applied, and the margin of this is brushed with oil to prevent evaporation. Thus treated the preparation kecps for 24 hours. M. Schultze recommends the slide to be placed on a warm stage $\left(30^{\circ}-40^{\circ} \mathrm{C}\right.$.). In the frog's cornca the migratory cells become visible after Io or I 5 minutes, and if the stage is warm their movements are more active.

After about an hour the lymph-canalicular system and the fixed corneal corpuscles arc distinguishable. (Waldeyer, Graefe-Saemisch's Handbuch, Af. I, Bd. I.)

\section{Fixed Corneal Corpuscles.}

(a) Ranrier's Gold Chloride Methol.-Ranvier (Lehrbuch der hist. Technik) has employed chloride of gold to demonstrate the fixed corneal corpuscles. The result of the treatment is that the corpuscles with all their processes present delicate pictures tinted dull red, while the substantia propria of the cornea remains colourless. These are "positive images" as opposed to the "negative images" produced by the silver method in which the substantia propria is impregnated, while the lymphatic spaces and the cells are unstained.

I. The juice of a fresh lemon is expressed, and filtered through flannel. Small corneæ, removed from the animals immediately after death, are placed in this in toto. The cornea of a frog or of a small mammal, such as the guinea pig or rabbit, is left in the juice for about five minutes. Larger cornex remain longer.

2. The cornea is then washed for one minute in about $5 \mathrm{c.cm}$. of distilled water.

3. It is placed in $10 \mathrm{c.cm}$. of a I per cent. solution of chloride of gold, and kept in the dark for 15 minutes.

4. It is transferred by means of a glass lifter to $10 \mathrm{c.cm}$. of distilled water, and washed for a few minutes.

5. It is next placed in $50 \mathrm{c.cm}$. of water containing two drops of acetic acid, and exposed to the light. The reduction process lasts two or three days, and is controlled by examination under the microscope. The fixed corneal corpuscles, and sometimes also the nervous fibrillæ, are impregnated.

6 . When reduction is complete, the tissue is placed in 70 per cent. alcohol, and left in the dark for 24 hours. 
Thin lamellæ are detached from the posterior surface by means of a scalpel and needle, and mounted in dammar varnish ; or, the cornea having been imbedded in celloidin, tangential sections are made with the microtome. The corneal corpuscles, like the lymph spaces, are arranged most regularly towards the back of the cornea. The most beautiful pictures are therefore obtained from this region.

(b) Drasch's Method.-This also yields excellent preparations of the corneal corpuscles (Stöhr, Lelerbuch der Histologie). The cornea is removed from the animal, not immediately after death, but I2-24 hours later, the body being meanwhile kept in a cool place. Small pieces, about $6 \mathrm{~mm}$. square, are taken and placed in the dark for one hour in a mixture of -

Solution of gold chloride, I per cent. $\cdots 5 \mathrm{c.cm}$.

Distilled water $\quad \ldots \quad \ldots \quad \ldots \quad \ldots \quad 5 \mathrm{c} . \mathrm{cm}$.

During this period the mixture should be stirred from time to time with a glass rod. The pieces are then transferred by means of a glass section-lifter to $30 \mathrm{c.cm}$. of distilled water, and remain in this in the dark for 8-16 hours, after which they are placed in a mixture of-

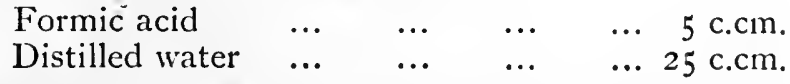

and exposed to daylight. When reduction is complete, the pieces are of a dark violet colour, and are then hardened for six days in alcolol gradually increased in strength. Tangential sections are made and mounted in dammar varnish.

\section{LyMPh-Canalicular System.}

(a) Silvering of the Cornea.-Negative images. Stricker's Method.

The cornea of a fresh eye, e.g., a frog's, is exposed for a moment to the vapour of boiling water. The epithelium can then be casily scraped away. The surface of the cornea is next cauterised with nitrate of silver. It is not, however, always necessary to remove the epithelium; the silver may be applied to the surface of the cornea while this is still intact.

The eye is washed in distilled water.

It is then placed in $50 \mathrm{c.cm}$. of distilled water containing 2 drops of glacial acetic acid, and exposed to sunlight for 24 hours, until it has become brown.

The cornea is removed and divided, and the pieces are hardened in alcohol gradually increased in strength. Tangential sections are made. As in the gold method, the most beautiful pictures are obtained from the posterior layers of the cornea, where the canaliculi and spaces are more regularly arranged. The ground-substance appears bright or dark brown; the lymphatic canals and their contents are colourless.

Thin cornex from small animals can be mounted as a whole, a few radiating incisions being made so that they lie flat. In the case of large cornere, lamella are removed from the posterior surface, or thick sections are cut.

(b) Punctuie Injections with Berlin Blue.

(c) Leber's Method. - The fresh cornea of a frog, or a part of the cornea of a larger animal, is placed in a $I$ per cent. solution of ferric sulphate. After a few minutes it is removed, and, the epithelium having been gently stripped from its surface, again returned to the liquid for 5 minutes. It is then washed, and placed in a $\mathrm{I}$ per cent. solution of ferrocyanide of potassium, in which it acquires a blue colour. It is once again washed in water, and examined in glycerine, or hardened in alcohol. The lymph spaces appear as colourless gaps in the field of the blue ground substance. (C f. 'cn Graefe's Archiv, Bd. XIV, Heft iii, S. 300.) 
(d) Altmann's Corrosion Methods. - These methods are based on the circumstance that fats hardened with osmic acid withstand the action of Eau de Javelle (solution of hypochlorite of potash) for a long time. They yield Corrosion Preparations. Olive oil is injected in the manner already described into the corneal spaces. Pieces of the cornea are then hardened in osmic acid, and cut with the freezing microtome. The sections are placed in a concentrated watery solution of hypochlorite of potash till the tissues are dissolved, and only the dark casts of the lymphatic spaces are left in the form of black strands. The sections must be carefully handled since they are very brittle. (Archiv. fiir mikroskop. Anatomie, Bd. XVI, S. 47 I. I879.)

Altmann's Oil-Impregnation Method is a similar process. The cornea should be as fresh as possible. If thin, it may be treated as a whole; if thick, it should be divided into two parts. The tissue is placed for eight days in a mixture of

$$
\begin{array}{cccccc}
\text { Olive oil } \ldots & \ldots & \ldots & \ldots & \ldots & 2 \\
\text { Absolute alcohol } & \ldots & \ldots & \ldots & \ldots & \text { I } \\
\text { Sulphuric ether } & \ldots & \ldots & \ldots & \ldots & \text { I }
\end{array}
$$

The pieces are then washed in running water for a few hours, hardened in osmic acid for 24 hours, and treated with Eau de Javelle diluted with an equal quantity of water, till all the tissue is dissolved.

\section{CORNEAL NERVES.}

(a) Cohnheim's Gold Chloride Method.-Cohnheim introduced the gold method, employing it for the demonstration of the corneal nerves.

I. A mixture consisting of :-

Solution of chloride of gold, I per cent... $\quad \ldots \quad 8 \mathrm{c.cm}$.

Formic acid $\quad \ldots \quad \ldots \quad$... $\quad \ldots \quad \ldots \quad 2$ c.cm.

is placed in a test tube, and heated over a flame till it boils up three times. It is then poured into a watch-glass and allowed to cool. Fresh pieces of the cornea are placed in this, and left in the dark for about half an hour.

2. They are washed for a few minutes in a watch-glass in distilled water.

3. The pieces are then exposed to daylight in a mixture of -
Formic acid... $\quad \ldots \quad \ldots \quad \ldots \quad \ldots \quad \ldots$ IO $\mathrm{c.cm}$

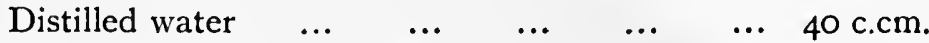

Here reduction goes on, and the pieces become gradually dark violet, the process lasting two or three days.

4. The pieces are next placed in about $30 \mathrm{c.cm}$. of 70 per cent. alcohol, and left in the dark for 24 hours.

5. They are transferred to the same quantity of 90 per cent. alcohol, and kept in the dark for several days to prevent further reduction.

Cross sections may be made. Tangential sections are, however, to be preferred. In these latter, on account of the curvature of the cornea, the epithelium and the subepithelial nervous plexus are well displayed at the margins.

N.B.-Steel instruments must not be brought into contact with gold solutions. All manipulations should be carried out by means of glass or wooden lifters.

(b) The Golgi-Cajal Method yields beautiful pictures.

(c) Ehrlich's Intra-Vitam Methylen Blue Method is also suitable.

\section{Elastic FibRES.}

These are present at the margin of the cornea. They may be stained with Orcein or by Weigert's Method. 
Descemet's Endothelium.-This can be stripped off in the form of a pellicle after maceration of the cornea in IO per cent. salt solution or in 30 per cent. alcohol. Staining and mounting.

\section{Cell Boundaries of Descemet's Endothelium.}

Ranvier employs silver nitrate to demonstrate these.

I. Pieces of the cornea are placed in $\frac{1}{2}$ per cent. solution of nitrate of silver till they begin to lose their transparency.

2. They are washed in distilled water.

3. They are transferred to a 2 per cent. solution of acetic acid, and exposed to sunlight till they become brown.

4. They are again washed in distilled water.

5. Examination in glycerine, or hardening in alcohol gradually increased in strength.

\section{INFLAMMATION OF THE CORNEA.}

The centre of a rabbit's cornea is punctured with an infected needle. After a few hours migratory leucocytes may be seen making their way from the marginal capillary loops towards the wound. The longer the examination is delayed, the more numerous are the cells found in the section. Hardening in corrosive sublimate. Staining with hæmatoxylin.

The immigration of leucocytes is still more active if a small cavity, made in the centre of a rabbit's cornea, is filled with a culture of virulent staphylococci, e.g., from an abscess. The eye is enucleated after 18-24 hours. Tangential sections are made, stained with Delafield's hæmatoxylin, and differentiated. The infiltrating migratory cells contain, in the case of the rabbit, in nearly every instance eosinophilous granules. Some of the cells are oval; others are in the form of elongated spindles. ( $C f$. O. Schaudigel, von Graefe's Archiv, Bd. XLIII, S. 392.)

\section{INCISED WOUNDS OF THE CORNEA.}

If the centre of a cornea has been perforated, and the tissue is examined at various intervals afterwards, it is possible to observe the peculiar inward growth of the epithelium, the apposition of the lamellæ, and the curling of the Descemet's membrane.

\section{Newly Formed Blood Vessels in the Cornea.}

Straub's Method.-The cornea is infected with aspergillus spores. When the new vessels appear on its surface, the cornea is removed, stained in eosin, and mounted in balsam.

\section{Iris and Choroid.}

The layers of the iris are best studied in meridional sections through the anterior half of the eye. Staining should be performed with carmine, since, especially in the case of a dark iris, the blue colour of hæmatoxylin does not offer sufficient contrast to the pigment. A layer of endothelium can be demonstrated on the anterior surface of the iris (Fuchs). A fresh eye is taken, and the sclera is divided behind the ciliary body. The anterior portion of the sclera and the cornea are then detached, so that the iris is fully exposed. The specimen is rinsed in water, and stained with drops of a I per cent. solution of nitrate of silver. Having been slightly hardened in weak alcohol, the iris is 
separated at its insertion. The posterior pigment layer is now brushed away, and after thorough dehydration, the iris is mounted in dammer with its anterior surface uppermost. (Fuchs, "Beiträge zur norm. Anatomie der menschlich. Iris," von Graefe's Archiv, Bd. XXXì, Heft iii.)

Special interest attaches to the posterior layers of the iris. These can only be studied in the eyes of albino animals and of embryos; otherwise the iris must be depigmented in the manner already described. The Dilatator Pupillæ and the double epithelial layer on the posterior surface should be examined. The aspect of the latter varies according as the pupil is dilated or contracted, just as the appearance of the epithelium lining the bladder is influenced by the degree to which the organ is distended (Grunert, Greeff).

The pupil is contracted by most hardening media, and it is not easy to fix it in the condition of mydriasis. To secure this, Heine recommends that the eye be fixed in Flemming's solution in the incubator at a temperature of $40^{\circ}$ C. (L. Heine, "Physiol.-anat. Untersuch. u. d. Accommodation des Vogelauges," von Graefe's Archiv. Bd. XI,V, Heft iii. ; Grunert," Der Dilatatos Pupillæ d. Menschen," Archiv für Auginheilkunde, Bd. XXXVI., S 319.)

Nerves. - The extremely delicate network is best demonstrated in the eyes of albino rabbits by the Ehrlich-Dogiel Methylen Blue Method. - The cye is enucleated immediately after death, and a small quantity of I/20 per cent. solution of methylen blue is injected into the anterior chamber by means of a hypodermic syringe. After 3-5 minutes the eyeball is bisected along its equator. The iris is then carefully detached from the limbus cornex, spread out on a slide, and divided into four segments. It is now advisable to pour a few drops of the staining solution over the specimen, and to place it in the incubator at $37^{\circ} \mathrm{C}$. for 10 or 15 minutes. The maximum effect is by this time usually obtained, and the staining process must be interrupted (Andogsky, "Zur Frage über die Ganglienzellen der Iris," Archiv für Augenheilkunde, Bd. XXXIV, S. 87).

Cross-Sections of the Choroid. Staining with carmine.

Teased Preparations. - The choroid is teased, and the pieces preserved in glycerine diluted with water. In this way may be exhibited the pigment epithelium, the branched pigment cells of the stroma, elastic fibres, pieces of the lamina vitrea, and portions of larger vessels and capillaries.

\section{Pigment Cells.}

The pigment cells can be beautifully demonstrated by excising a piece of hardened choroid, and mounting it unstained. Alcohol. Oil. Canada balsam. The inner surface with the pigment epithelium is placed uppermost. On focussing the microscope for the upper layer the delicate hexagonal cells of the pigment epithelium are seen, on focussing more deeply the branched pigment cells of the stroma in the intervascular spaces and the large blood vessels. Isolated hexagonal pigment cells are usually found at the margin, and one of these should be examined with the oil-immersion lens. The pigment consists of small rod-shaped crystals.

\section{Vessels of THE ChOROID.}

These are best studied from their outer aspect. A hardened eye is incised around its equator. The incision should involve the sclera only; this structure is then dissected off as far as the ora serrata in front and the optic nerve behind. The fibres of the supra-choroid layer should not be torn away, but carefully divided with scissors. In this way the venæ vorticosæ are exhibited. 
Sattler has investigated the finer structure of the choroid, and published a very full account of this. ("Ueber den feineren Bau der Choroidea," von Graefe's Archiv, Bd. XXII, S. I). Specially interesting is the view of the first endothelial layer which lies between the chorio-capillaris and the layer of medium-sized blood vessels. This layer can, according to Sattler, be demonstrated in a piece of choroid stained with hæmatoxylin, after removal of the outer vascular layers with their pigmented stroma, by placing it on a slide with the membrana vitrea lowermost. The microscope (high power) is now focussed for the inner surface of the membrana vitrea, which can be recognised by the remains of the retinal pigment cells adhering to it. When the tube is gradually raised the following structures come into view, the grating-like configuration on the outer aspect of the membrana vitrea, then the contours and the nuclei of the capillary vessels, next the pale oval nuclei of the cells forming the first endothelial layer (Sattler's membrane).

\section{Lens.}

Formalin of the usual strength should not be employed in the preparation of the lens, since it renders it much too hard.

In the form of a weak ( 2 per cent.) solution, however, formalin may be recommended. In this the lens remains for two to four days, and is then further hardened in alcohol, gradually increased in strength. The lens fibres swell up in sublimate solutions.

The lens must not remain too long in Müller's fluid, or it becomes quite hard and brittle.

When it is of no importance to maintain the shape of the lens, it may be hardened from the first in alcohol.

It should be observed that paraffin imbedding is not adapted for the lens.

Zenker's fluid is the best medium for hardening the lens. Imbedding in celloidin. In order to obtain good sections, we must divide the lens capsule. If the lens is still in the eyeball after imbedding we cut down on it till a slice has been removed from its anterior surface. The block is then placed in the alcohol-ether mixture, and the preparation is re-imbedded.

The terms employed in the description of the lens are similar to those applied to the globe itself. The lens is thus said to possess an equator, various meridians, an anterior and a posterior pole, and an axis. It is better to speak of equatorial and meridional sections, and to avoid loose expressions such as cross and longitudinal sections.

The following layers are distinguished :-

\section{The Lens Capsule.}

This is a homogeneous elastic membrane which envelopes the lens completely. It is thicker in front than behind, and thickest of all at the margin of the anterior surface. When lacerated, the capsule retracts like an elastic band, the margins of the wound curling with the outer surface inward. The capsule is very resistant to reagents, and persists unchanged for long periods in various pathological processes.

\section{The Endothelium of the lens Capsule.}

This is a single layer of flattened cells which lie beneath the anterior portion of the lens capsule, extending outwards towards the equator. When examined in the fresh state in a drop of aqueous, the cells are seen to be bright and finely granular. They exhibit a large nucleus and one or two 
nucleoli. The contours of the cells are polygonal, mostly hexagonal, so that a surface view presents the appearance of a delicate mosaic. Towards the equator the cells become more slender and elongated, and pass gradually into nucleated lens fibres. The equatorial transition zone is called the Lens Whorl. It is indistinct in old age.

The capsular endothelium is very liable to undergo changes. It is often found to be altered in the old, probably as a preliminary stage in the formation of a cataract, while the lens fibres are still unaffected. The changes are still more marked when the lens becomes cataractous as a result of experiments or injury. The cells over a considerable area are often degenerated, the protoplasm swelling up and becoming coarsely granular and vacuolated. The nucleus exhibits similar changes. These changes can be best demonstrated by tearing off shreds of the capsule with the adherent endothelium, and staining with carmine. (Hess, "Ueber Naphthalinveränderungen," Ophth Gesellschaft, I887; Schirmer, "Studie über Maturation der Cataract," von Grafe's Archiv', Bd. XXXIV, Heft i, etc.)

Karyomitosis can be demonstrated, especially in the equatorial region, after injuries. This is apparent after 20 hours, and most evident after 4-6 days. (Kiribucki, "Experimentelle Untersuchungen über Cataract," von Graefe's Archiv, Bd. L, Heft i.) The cells show a great tendency to proliferate and form plexuses of spindle-shaped elements (Capsular Cataract).

\section{The Lens Substance.}

This consists of fibres, Fibre Lentis. The fibres are ribbon-like and of almost the same width throughout their length. In cross-sections they are seen to be hexagonal. The peripheral fibres are broader and thicker than the central. Around each there is an extremely thin layer of cementsubstance, which appears as a thin black line if the section is immersed for a short time in a weak solution of nitrate of silver ( 1 in 800-1000).

The lens fibres abut against one another, in certain planes radiating from the axis. The edges of these planes form on the anterior and posterior surfaces the Lens Stars. In the new-born child each star has three rays; in the adult the figure is more complicated. The rays are rendered very prominent by immersing the lens, as soon as removed, in a solution of silver nitrate, $I$ in 500 . They then appear as black lines on a brown ground. In many animals the lens star is simpler than in man. (Friedenberg, "Ueber die Figur des Linsensternes," Archiv fïr Augenheilk., Bd. XXXI.)

A thin layer of liquid is often found between the capsule and its epithelium. In hardened preparations this Subcapsular Layer is coagulated in the form of minute granules, or appears as a fine network of fibrillæ. Morgagni's globules occur in this layer in old lenses.

There is a similar layer of nutrient fluid between the endothelium and the lens fibres, the Subendothelial Layer. (See also, Carl Rabl, Ueber den Bau und die Entwicklung der Linse. Leipzig, W. Engelmann, I900.)

\section{Zonule.}

The zonule, or suspensory ligament of the lens, does not, as was once supposed, consist of membranes, or lamella, enclosing the so-called Canal of Petit, but of a large number of fine radiating fibres (Fibre Zonulares). Most of the fibres spring from the intervals between the ciliary processes, and some of them can be followed backwards over the orbiculus almost as far as the ora serrata. The fibres which arise farthest back pass mainly to the 
anterior surface of the lens, while those which are inserted into the posterior surface of the lens have their origin in front towards the posterior chamber. The two sets of fibres cross each other near the ciliary processcs. There are also intermediate fibres between the anterior and posterior main bundles; these pass to the equator of the lens. The zonule is thus formed exclusively of fibres enclosing intercommunicating intervals which maintain a connection between the posterior chamber in front and the spaces in the vitreous behind.

\section{Demonstration of the Zonule.}

A survey of the zonule is obtained as follows: A hardened bulb is divided along the equator, and the vitreous removed by means of forceps and a brush. The cornea and sclera are detached close to the root of the iris in front. The iris is then excised. When the preparation is examined from the front by transmitted light and with the aid of a magnifying-glass, fibres can be seen stretching between the summits of the ciliary processes and the equator of the lens. From behind it is observed that the main body of the fibres passes back between the ciliary processes, leaving the summits of these free from attachments.

If the scissors are now passed from behind and made to divide the zonule close to the processes, the lens can be removed surrounded by a ring of fibres. These are rigid as a result of the hardening, and enclose an annular prismoidal space, the base of which corresponds to the equator and to the margins of the two surfaces of the lens.

Meridional Sections should be made first, and they should be fairly thick. The fibres are seen to occupy a triangular area between the lens and the ciliary processes. They are arranged more closely at the anterior and posterior ooundaries, but intermediate fibres are also visible. Further, in such sections the crossing of the fibres is demonstrated.

The structure of the zonule is, however, best recognised in Cross-Sections through the fibres and the ciliary processes. Numerous fine points are visible between the processes, and in front of and behind these. The points are the cross sections of the fibres.

\section{Corpus Vitreum.}

The demonstration of the structure of the vitreous body presents special technical difficulties.

A. The following method (Lenhosseck, Ogawa, Archiv für Augenheilk., Bd. I,V, S. 52) has proved valuable.

To avoid rapid and too extensive shrinking of the vitreous, the eyeball before it is opened, is placed for -

I. Eight days in Müller's fluid to which there has been added half its volume of Io per cent. formalin.

2. Six weeks in pure Müller's fluid (Elschnig).

3. One day in running water.

4. Two or three weeks in alcohol gradually increased in strength.

5. The eyeball is now opened, while it lies in the exsiccator, by removing the cornea, or by making a section with a sharp knife parallel to the equator.

6. Imbedding in celloidin. The tissue should be placed in very thin celloidin, and this should be allowed to become thick by slow evaporation. This is a most important precaution, since the shrinking takes place mainly in the celloidin. 
7. The mounted block is kept in 80 per cent. alcohol, until sections are made.

\section{Staining.}

I. Delafield's hæmatoxylin is used to demonstrate the framework of the vitreous, ordinary hæmatoxylin-eosin to demonstrate the cells.

2. Washing in water.

3. Alcohol. Xylol. Balsam.

In sections stained with hæmatoxylin, after $24-48$ hours, all the tissues of the vitreous are over-stained with the exception of the fibrilla.

Good preparations of the vitreous may also be obtained by injecting Zenker's fluid into the centre of the tissue, and afterwards employing van Gieson's stain.

\section{Retina.}

The human retina is a perfectly transparent membrane about $\frac{1}{3} \mathrm{~mm}$. in thickness. It is very instructive to cut into a fresh eye and to allow some vitreous to escape; the retina is then found detached and floating freely in the vitreous. It has, therefore, no substantial connection with the tissues behind, and is kept applied to the choroid only by the normal tension of the vitreous. In its fully developed condition the pigment epithelium is firmly adherent to the choroid and has no attachment to the retina proper. From a developmental point of view, however, the pigment epithelium belongs to the retina.

The retina is firmly united with the choroid at two places only: first, at the papilla; and, secondly, around the ora serrata. This connection is evident not only in a fresh eye which has been opened, but also in pathological conditions, exudations, etc.

Boll discovered, in 1876 , that during life the retina possessed a purplish-red tint, and that this was due to colouring-matter contained in the outer segments of the rods. The pigment at once becomes pale when exposed to daylight. Hence it is seldom seen in eyes removed from the dead body.

Visual Purple. - This is very evident in fishes, like the bream, which possess a white chalky tapetum. If the fish is kept in the dark for some time before being lilled, and the eye is then removed and divided along its equator, the retina appears as a rosc-red membrane, which soon becomes pale and cloudy in daylight. The colour is maintained longer if the posterior half of the eyeball is at once transferred to a weak solution of formalin. In other animals with dark choroids the reddish tinge is less apparent.

Macula Lutea.-Further, the area corresponding to the highest acuity of vision and its neighbourhood (macula lutea) present a yellow appearance due to a pigment which is diffused through all the layers of the retina. This colour persists for a considerable time after death.

This is best demonstrated in an eye removed from the dead body. The bulb is divided along the equater, and the portion of retina around the papilla removed and placed on a slide under a cover glass. Even with the naked eye, and still more clearly under a low power of the microscope, the Fovea Centralis is recognisable as a bright depression devoid of blood vessels and surrounded by an intensely yellow ring.

Coloured Globules are found in the retinæ of many birds and reptiles. They lie at the junction between the outer and inner segments of the cones, lending to the retina the appearance of a delicate variegated mosaic. To obtain a view of these, a fresh piece of retina should be removed from the eye of a pigeon or fowl, transferred to a slide, and examined under a high power. 


\section{Cross-Sections of the Retina.}

The eye is hardened in toto in warm alcohol, sublimate, Flemming's fluid, formalin, or Müller's fluid. It is then laid open, and a small portion of the retina, a few millimeters in diameter, is removed and imbedded in paraffin. Celloidin sections are too thick. Staining with hæmatoxylin.eosin.

Three rows of nuclei are seen clearly in a section so prepared. The outc: most row, the outer nuclear layer, contains six or seven layers of nuclei; the intermediate row, the iuner nuclear layer, is only about half as thick; the innermost row, the layer of ganglion cells, contains throughout the greater part of the retina only a single layer of nuclei. These three rows of nuclei correspond to three layers of nerve cells (Neurons), the relationship between which has been established by the researches of Ramón y Cajal.

The following layers can be distinguished in a cross-section of the retina :--

I. Pigment epithelium.

II. Layers of rods and cones.

III. Membrana limitans externa.

IV. Outer nuclear layer.

V. Outer plexiform layer.

VI. Inner nuclear layer.

VII. Inner plexiform layer,

VIII. Layer of ganglion cells.

IX. Layer of nerve fibres.

$\mathrm{X}$. Membrana limitans interna.

\section{Pigment Epithelium.}

This is a single layer of polygonal, usually hexagonal cells, which, whon viewed from the surface, appcar as a delicate mosaic. (For the method of demonstrating these sec above.) The elements are separated from each other by a delicate layer of coleurless cement substance (Neurokeratin). The individual cells are best studied in teased preparations, which have been hardened in I per cent. osmic acid. Each cell consists of an outer nonpigmented zone, a basal zone, and processes. The outer zone contains the oval nucleus. With an oil immersion lens, the pigment present in the basal zone and processes can be recognised in the form of minute crystalline rods. In the human retina the processes are short; in that of the frog and the bird they are very long. When the retina of a frog, which has been kept in the light for some time before being killed, is examined, the processes are found to be full of pigment particles, and exterided so as to surround the rods and cones and almost to reach the external limiting membrane. On the other hand, when the frog has been kept in the dark, the processes and pigment crystals are found to be retracted towards the basal zone.

\section{LAYER OF RODS AND CONES.}

This layer exhibits many variations in the different vertebrata, and lends to each retina its characteristic appearance. The rods and cones are not complete cells. Each is prolonged through the limitans externa to become connected with one of the nuclei of the outer nuclear layer, and ends finally; the rod as a small knob, the cone as a flat dendron, in the outer plexiform laycr. They are casily isolated.

The rods and cones are too closely packed together in sections to admit of their being seen in their entirety. Morcover, they often become distorted in the hardening process. 
When Weigert's stain for the medullary sheaths is employed, and differentiation is not carried too far, the inner segments of numerous rods and cones will be found to be coloured and to stand out clearly.

\section{Isolation of the Visual Cells.}

The retinal elements can be isolated in several ways.

I. Fresh Preparations. - The eye is removed from the animal immediately after death, and divided along the equator. A small portion of the transparent retina is excised and teased on a slide in a drop of vitreous fluid. The tissue is protected by a cover-glass rested on small pieces of wax or on a paper ring surrounding the piece of retina. The various elements, rods, cones, etc., are then found to be isolated. In optical cross section the former appear as small, the latter as larger, circles.

2. The best method for completely isolating the visual cells is the Osmic Acill Method introduced by $M$. Schultze. A small eye, e.g., a frog's, is excised and placed at once in a $I$ per cent. solution of osmic acid for I $2-24$ hours. Thereafter it is macerated for I-2 days in several changes of distilled water. A larger eye, e.g., a human eye, shouid be divided along the equator; the posterior hemisphere is treated in the osmic acid, and is then macerated for at least two days. Only absolutely fresh material can be employed. Small pieces of the retina are removed by means of forceps and placed on a slide in a drop of glycerine. If permanent preparations are desired the cover-glass must be cemented (See "Mounting in Glycerine"). Examination under a high power shows the various retinal elements isolated. Complete visual cells may be be seen. The remainder of the hardened retina may be stored, and will keep well for years in the solution recommended by Merkel (von Graefe's Archiv., Bd. XX). The solution consists of equal parts of absolute alcohol, glycerine, and water.

3. G. Stort and Engelmann employ the method suggested by Altmann. The bulb is hardened in a $3-3.5$ per cent. solution of nitric acid for six hours, washed for a short time in running water, and then divided through the equator. Small pieces of the retina are placed on a slide in a minute quantity of water or diluted glycerine, so that they adhere to the glass, and are hacked with a sharp razor. (Altmann, Archiv für Anatomie und Physiologie, S. 219 , I881; Genderen Stort, von Graefe's Archiv für Ophthalmologie, Bd. XXXIII, Heft iii, S. 230.

\section{Membrana Limitans Externa.}

In cross sections of the retina the external limiting membrane appears as a sharp line, separating the layer of rods and cones from the outer nuclear layer. Specimens treated with iodised serum (tincture of iodine I, pericardial or amniotic fluid IOO) or by Golgi's method show that the membrane is formed by the apposition of the outer ends of the sustentacular fibres of Müller. The membrane is fenestrated, the round apertures corresponding to the rods and cones. The surface view has, therefore, the appearance of a grating. The larger apertures correspond to the cones, the smaller to the rods.

\section{OUter Nuclear I.AYer.}

The outer nuclei vary very considerably in size in different animals, being largest in amphibians and reptiles, and very small, on the other hand, in fishes and mammals. They are the nuclei of the visual cells. The peculiar 
arrangement of the chromatin in these nuclei, different in different animals, produces the ribbed appearance which they often present in the human retina. This is best demonstrated by hardening in Flemming's solution and staining with safranin. It can, however, be seen in sections stained with hæmatoxylin (oil-immersion lens).

\section{OUter Plexiform Layer.}

This was formerly called the outer molecular layer, since in cross-sections of the retina it has a finely granular appearance. The granules are transverse sections of fibrils which here form a dense reticulum. This altered conception of the anatomical structure is due to the application of Golgi's method in the examination of the retina. The outer plexiform layer contains the endings of the visual cells and the rich arborisations of the bipolar cells of the next layer.

\section{INNER NUCLEAR LAYER.}

Three sets of cells can be distinguished in this layer. Most externally situated is the layer of "horizontal" cells. These are particularly well seen in cross-sections of the retina of the fish, when stained with hrmatoxylin. Next to these is the large mass of nuclei belonging to the "bipolar" cells. The bipolar cells are spindle-shaped, one process passing into the outer plexiform layer, the other into the inner plexiform layer. They serve to connect the visual cells with the large ganglion cells of Layer VIII. The innermost nuclei belong to the flattened branched cells, called "spongioblasts" by W. Müller, and "amacrine cells" by Ramón y Cajal.

\section{InNer Plexiform Layer.}

This resembles the outer plexiform layer. It consists of a dense reticulum of fibrils derived from the cells in the adjacent layers. In birds it presents horizontal markings, due to plexuses lying one orer the other.

\section{Layer of Ganglion Cells.}

This consists of a single layer of cells unless in the region of the macula lutea, where there are several layers. The presence, then, of more than one stratum of ganglion cells is an indication that the section belongs to the neighbourhood of the macula.

The morphology of the ganglion cells and their branched processes is demonstrated most clearly by Golgi's method. Surface views of the retina prepared by Ehrlich's process are also of astonishing beauty. The finer structure of the ganglion cells in their normal state as well as in pathological conditions is of great interest, and should be investigated by means of Nissl's stain or one of its modifications.

The ganglion cells are separated from one another by the fibres of Müller and by small oval neuroglia cells.

\section{LAyER OF Nerve Fibres.}

The distribution of the nerve fibres in this layer has been investigated very fully by Michel in surface preparations hardened in Müller's fluid (Ucber die Ausstrahlungsweise der Opticusfasern in der menschliclen Retina. Wiesbaden, J. F. Bergmann, 1875). The structure of the individual fibres can also be clearly distinguished in pieces of the retina treated with methylen blue. The axis-cylinder consists of fine fibrillæ united by a small amount of interfibrillar 
substance. (Dogiel, "Ueber die nervösen Elcmente in der Netzhaut des Mcnschen," Archiv für mikrosk. Anatomie, Bd. XXXVIII.)

\section{IO. Memirana Limitans Interna.}

This is formed by the expanded bascs of Müller's supporting fibres.

There are still certain portions of the retina which possess histological peculiarities, and so call for further examination. These are the ora serrata and the macula lutea.

\section{Ora Serrata.}

The retina does not cease at the ora scrrata, but becomes somewhat suddenly reduced to a single layer of cylindrical epithelial cells, which are prolonged forward over the orbiculus and ciliary processes, and, becoming flatter, cover the posterior surface of the iris. At the margin of the pupil this layer of cells, representing the retina proper, is reflected to become continuous with the prolongation forward of the pigment epithelium. These two layers form the Pars Ciliaris and Pars Iridica Retina.

\section{Macula Lutea.}

The macula lies about $4 \mathrm{~mm}$. to the temporal side of the optic papilla and a little distance below the horizontal meridian. It is usually elliptical in shape, with its longer axis placed horizontally. The yellow collour of the macula and the thickening of the ganglion cell layer in its vicinity have already been referred to. In the centre of the macula the retina is greatly thinned, all the laycrs, with exception of that formed by the visual cells, being absent or very much reduced. In this way a depression with sloping sides is formed-the Foner Centralis.

The structural relations of the various retinal elements are best displayed by means of Golgi's method. The retina is extremely difficult to handle, but the beauty of a successful preparation repays the trouble expended. The tissue must be fresh. The eye of a large animal should be selected. Cajal's roll method followed by double impregnation, ctc. If several rolls are taken and exposed to the reagents for different periods, some are likely to be successful.

\section{Comparative Anatomy.}

The structure of the retina is suprisingly uniform in all vertebrates. The layers are always the same unless in the l'etromyzon and in a few members with rudimentary eyes. The main differences are found in the form and number of the rods and cones, due to the peculiarity of each animal's vision.

The retina of the mammal resembles most closely that of the fish, the only difference being that in the latter there are fewer elements, and, as a consequence, a simpler structure, In birds and amplibians the retina is distinguished by having the outer nuclear layer thinner than the inner. The opposite is usually the case.

\section{Optic Nerve.}

The method of dividing the optic nerve, and of incising the dura along its outer aspect so as to afford a guide in the localisation of the sections, has already been described. Müller's fluid is the most generally useful hardening medium, permitting the employment of most stains except those for tubercle bacilli. When it is desired to demonstrate recent degenerative processes 
Marchi's fluid should be chosen, while the distribution of the neuroglia is displayed by the methods of Golgi and Weigert.

Imbedding in paraffin cannot be recommended, the high temperature producing shrinking of the connective tissue.

The course of the optic nerve is divisible into the following segments :-

The optic radiation.

The optic tract.

The chiasma.

The intracranial portion of the nerve.

The intracanalicular portion.

The intraorbital portion-

(a) Before the entrance of the central blood-vessels.

(b) After the entrance of the central blood-vessels.

The intraocular portion-

(a) The medullated scleral portion.

(b) The lamina cribrosa.

(c) The papilla.

Each of thesc parts exhibits histological peculiaritics which require to be specially examined.

The intraocular portion is studied in longitudinal sections stained by van Gicson's method which displays admirably the distribution of the connective tissue. Some of the sections should be treated by IVeigert's method to show the medullary sheaths. These cease at the level of the lamina cribrosa.

A few millimetres behind the bulb transverse sections should begin to be made These also are stained by van Gieson's method. The dural, arachnoidal, and pial sheaths can be distinguished surrounding the stem of the nerve. The pial sheath gives off septa which pass into the nerve and divide it into compartments, these being again subdivided into smaller spaces by secondary septa. This frame-work carries the nutrient blood vesseis, the central vessels being contained in a stout bundle of connective tissue in the middle of the nerve. The connective tissue exhibits a few spindle-shaped slender nuclei. The medullated fibres are surrounded by the penetrating septa, and between the fibres oval nuclei belonging to neuroglia cells may be distinguished.

Between the pial sheath and the peripheral nerve bundles there is a narrow zone, which displays a fine meshwork of neuroglia fibrils, and is devoid of nerve fibres. This is the neuroglia mantle of Fuchs, and was at one time mistaken for an atrophic condition (peripheral atrophy).

Retrobulbar fatty tissue, muscular fibres, and ciliary nerves and vessels, are seen around the section of the nerve.

The entrance of the central vessels is met with farther back. At this level the cross-section of the nerve has a reniform outline. The vessels are accompanied by a thick offshoot of connective tissue.

Behind the entrance of the central vessels the connective tissue stroma is much more scanty.

The nerve is embraced by the periosteum in its intracanalicular portion.

Beyond the optic foramen the dura leaves the nerve.

At the chiasma horizontal sections stained with hrmatoxylin and eosin or by van Gieson's method are instructive. The nerve fibres are here no longer divided into bundles by septa. Only a few delicate strands of connective tissue are found projecting into the peripheral parts of the chiasma. The nerve fibres are, however, to some extent divided into groups by rows of neuroglia cells. In sections stained so as to exhibit the medullary sheaths the decussation of the nerve bundles can be clearly seen. 
The anatomical relations of the nerve fibres are different in the lower animals, and, as a rule, simple. The arrangement found in fishes, although varied, is the simplest. The complete decussation can usually be recognised with the unaided eye. In the pike the right nerve crosses over the left, union taking place only between the pial sheaths; in the herring the right nerve passes through a slit in the left; in the carp both nerves split into two portions which cross like two clasped fingers of the right and left hands.

In birds and reptiles thi: decussating portions of the nerves are separated into a smaller or larger number of leaves, which intercross like the clasped fingers of the two hands. Vertical sections through the middle of the chiasma have thus a zig-zagged outline. This is well seen in the frog.

\section{Comparative Anatomy.}

This is very interesting. The greatest variations are found among the fishes. In the optic nerve of the petromyzon there is an axial column of cells continuous with the cells in the retina. The nerve fibres are grouped around this column. The nerve of the pike is a compact cylinder of fibres, the blood vessels running parallel with these. In most of the bony fishes branched trabecula of connective tissue penetrate the nerve stem, but do not reach the opposite side. The nerve thus acquires a ribbon-shaped structure. The simplest case of this kind is seen in the sturgeon, whose optic nerve is S-shaped in cross-section. In the sole, salmon, whiting, etc., there are several folds. The carp's nerve is in the form of branched compound processes. The division of the fibres into distinct bundles begins to appear in the eel and the cobitis fossilis.

In the larval stage of the amphibians a strand of neuroglia cells is present on the dorsal aspect of the devcloping optic nerve. These are remains of the cpithelial optic stalk; at a later stage they occupy a more central position in the nerve. In fully developed specimens of salamandra maculata the optic nerve consists of parallel rows of neuroglia cells separating isolated bundles of nerve fibres.

In the turtle the nerve fibres are arranged so as to form a trench which is occupied by a process of connective tissue carrying the blood vessels. The neuroglia cells are distributed throughout the sections, but are most closely packed in the centre of the nerve.

Neuroglia septa are present in the reptiles. The cells forming these are arranged in longitudinal rows, and communicate with each other by means of their numerous processes.

In the serpents processes derived from the pial sheath separate the fibres of the optic nerve into distinct bundles. In the centre of each bundle there is a row of neuroglia cells surrounded by the nerve fibres.

The nerve is ribbon-shaped in most birds.

In mammals connective tissue septa are always present. The higher an animal stands in the class, the more numerous are the septa, and the more complete the separation of the nerve fibres into distinct bundles.

In the optic tract trabeculæ are absent, there being only a thin (30 $\mu$ in thickness) covering over the fibres. These latter are still medullated.

In the newly-born child the fibres in the orbital portion of the nerve are, as a rule, destitute of medullary sheaths. These are not fully developed till the ninth or tenth week.

\section{Demonstration of Elastic Tissue.}

The method of Unna or Weigert is adapted for this purpose. The sheaths 
of the nerve contain an abundance of this tissue. The lamina cribrosa is composed mainly of elastic fibres.

\section{Neuroglia.}

Golgi's Method.--The dural sheath should be removed, and a portion of the optic nerve, two or three millimetres in length, placed for $12-24$ hours in the osmio-bichromate mixture, and for the same length of time in the silver solution. This procedure is usually successful. It is best to take the optic nerve and chiasma from a newly killed animal, e.g., a pigeon.

Weigert's Method. - There is an extraordinary increase of neuroglia in the optic nerve when it is atrophied.

\section{IsOlation OF THE NeRVE Fibres.}

The nerve bundles are composed of groups of nerve fibres. Each nerve fibre again consists of an axis cylinder surrounded by a thin sheath of myelin. Varicosites are often found on the nerve fibres. These are probably produced artifically in the removal of the sheaths. In the optic nerve the fibres do not possess a neurilemma or sheath of Schwann, the nucleated membrane which surrounds the myelin sheath in most nerve fibres; the myelin is in direct contact with the neuroglia. The calibre of the fibres varie.s greatly, some having a diameter of $10 \mu$, while others are infinitely slender.

It is not easy to obtain isolated portions of the nerve fibres of any considerable length, since the myelin sheath crumbles very readily and the axis cylinders are easily torn. The best preparations arc obtained by macerating pieces of fresh nerve in a weak $\left(\frac{1}{30}-\frac{1}{40}\right.$ per cent.) solution of chromic acid, or in a Io per cent. salt solution; or by hardening the pieces in osmic acid, macerating in water, and then teasing them. Medullated nerve fibres are well demonstrated in thick sections treated by Golgi's method; for nonmedullated fibres the methylen blue method of Ehrlich is most suitable.

\section{CORPORA AMYLACEA.}

Homogeneous spherical bodies, $15-25 \mu$ in diameter, are often found inside the bundles of the optic nerve. They occur also in other parts of the nervous system, and are called corpora amylacea. They are usually present in large numbers in atrophied nerves, but they are found not uncommonly in normal nerves. Their favourite seat is the chiasma and its neighbourhood or the optic tract. They are always present in certain animals, e.g., the cat and the dog. Iodine stains the corpora amylacea yellow; iodine and sulphuric acid colour them a beautiful violet. They are stained deep blue by hrmatoxylin, and yellowish or red by van Gieson's mixture.

Recent degenerative processes are studied in specimens treated by Marchi's method. Suitable tissue is obtained by dividing the optic nerve, or enucleating one eye.

Atrophic nerves exhibit an increase in their supporting tisssue (sclerosis). This is well shown in cross-sections stained by van Gieson's method. Weigert's stain for the medullary sheaths displays the changes in the nerves fibres.

In cases of neuritis retrobulbaris centralis and where there has been amblyopia due to tobacco or alcohol, the papillo-macular bundle is found to be atrophied. 
APPENDIX.

\title{
THE EXAMINATION OF THE SECRETIONS AND BACTERIA OF THE EYE.
}

\author{
BY \\ PROFESSOR STOCK.

\section{I.-On Procuring the Secretion.}

(A) Conjunctiva.-It is important to examine the secretion at the right moment. The organisms which cause the inflammation are most readily found while the disease is still advancing. When a conjunctivitis is subsiding, it is quite possible that, although the secretion is plentiful, the organisms are no longer present. Indeed, the secretion may be germ free, or contain only parasitic bacteria.

A flake of mucus should be removed from the lower conjunctival sac by means of a sterilised platinum loop, or, in case of need, by means of a clean thin match. The specimen should include mucus, since the tears alone contain too few organisms. If there is no secretion in the conjunctival sac, there is almost certain to be some at the inner canthus. Specimens from this spot are, however, apt to be contaminated by parasites from the skin.

The mucus should be spread on a clean slide in a very thin and uniform layer.

The preparation must now be fixed. This is accomplished by passing the slide through the flame of a spirit lamp, so as to raise it to a temperature which can just be borne by the back of the hand. The specimen is now ready to be stained.

(B) Cornea.-When it is desired to examine a corneal ulcer for bacteria, the specimen should be taken from the advancing margin, and be removed by means of a bent platinum wire, or, in practised hands, by means of a Graefe knife. In any case care must be taken that intact cornea is not injured, and so infected with septic matter.

(C) Contents of the Eyeball.-Some of the contents are removed by means of a hypodermic syringe. If cultures are to be made, the spot where the needle is inserted should be touched with the galvano-cautery. If the eyeball has been enucleated, it is better to incise the tunics, and remove a specimen with the platinum loop.

\section{2.-STAINING.}

\section{Löfler's Methylen Blue Solution.}

Concentrated alcoholic solution of methylen blue $\quad \ldots \quad 30$

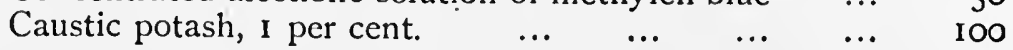

The preparation, after being fixed by heat, is immersed in this for 20-30 seconds.

Washing in water.

2. Gram's Stain.

(a) Anilin-water Gentian-violet Solution.

$\begin{array}{lllll}5 \text { per cent. aqueous solution of gentian-violet } & \ldots & \ldots & 88\end{array}$

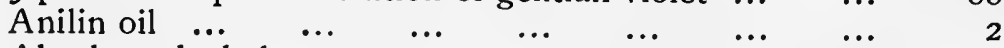

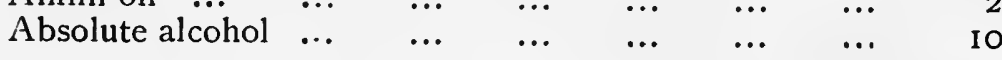


The mixture should be well shaken for a quarter of an hour, and then filtered. It keeps for about two months.

In this the preparation is stained for 25 scconds.

(b) Washing in water.

(c) Treatment with Lugol's solution (iodine I, iodide of potassium 2, water 300 ) for 15 seconds.

(d) Differentiation in absolute alcohol, till the blue colour is no longer given off ; in the case of thin preparations for $1-2$ minutes.

(e) Washing in water.

$(f)$ Staining in a 5 per cent. aqueous solution of safranin for five seconds.

Gram-positive germs are blue, gram-ncgative red.

Weak carbol-fuchsin (I : 20) may be used instead of safranin.

3. Tubercle Bacilli. For the demonstration of these the following is the best method:-

(a) Carbol-fuchsin.

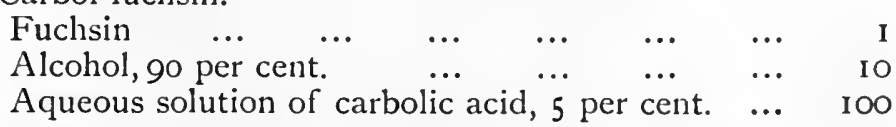

The cover-glass is heated over the flame of a spirit lamp till steam begins to rise.

(b) Washing in water.

(c) Treatment with 2 per cent. hydrochloric acid anilin-water for two to three seconds.

(d) Differentiation in absolute alcohol till red clouds are no longer given off.

(e) Washing in water.

$(f)$ Staining in Löffler's methylen blue for ten seconds.

(g) Washing, alcohol, oil, balsam.

4. Giemsa's Stain. This is very useful for staining scrapings of epithelium The everted conjunctiva is gently stroked with the edge of a cover-glass, and the material thus obtained is spread over a second glass. After the preparations have dried in the air, they are fixed for ten minutes in equal parts of absolute alcohol and ether, and then stained for half an hour in Giemsa's fluid. The stock solution should be procured from Grübler. One drop of this is added to I c.cm. water.

5. Capsules. When it is desired to stain capsules, the simplest method is to treat the preparation in a saturated solution of methyl-violet for three to four seconds, to mount it in water, and to examine it under water.

N.B.-Gram's method is the most useful for our purpose. There are so few germs in question that it is almost always possible to make a diagnosis by this method alone.

\section{Description of the Commoner Micro-organisms.}

\section{Gram-Positive.}

(a) Xerosis Bacilli. Pseudodiphtheria bacilli. These are short rods, and are present in every conjunctival sac, sometimes in enormous numbers in the secretion at the canthi. If the preparation is too thick, we may find in parts red-stained rods which appear smaller than the Xerosis bacilli. Such they are, nevertheless, and the stain has not reached them properly owing to the thickness of the preparation. A germ stained blue by Gram's method appears larger than the same germ stained red by safranin. 
(b) Diphtheria Bacilli. It is frequently impossible to distinguish these from the Xerosis bacillus. When the organisms are arranged in pallisade form, they are probably diphtheria bacilli.

(c) Staphylococci. Microscopic examination does not enablc us to distinguish the pathogenic Aureus from the non-pathogenic Albus.

(d) Pneumococci. These are oval-shaped cocci, often arranged in pairs. They frequently vary in size. (Serpiginous ulceration of the cornea, pneumococcus conjunctivitis in children, suppuration of the tear-sac).

(c) Streptococci. These form chains containing as many as twenty cocci. (Membranous conjunctivitis, suppuration of the tear-sac).

\section{GRAM-NEGative.}

(a) Diplobacilli. These lie in pairs with their narrower ends touching. (Chronic conjunctivitis. Corneal ulcer).

(b) Bacterium Coli. Sometimes found in cases of acute catarrh in new-born children.

(c) Koch-Wecks' Bacilli. Very small slender rods. They set up an acute contagious conjunctivitis.

(d) Influenza Bacilli. These occur as small rods which are thicker than the Koch-Weeks' bacilli. They cause conjunctivitis, and are also found in suppurative affections of the tear-sac.

(e) Bacillus Pyocyaneus. This is smaller than the bacterium coli. It sometimes causes severe ulceration of the cornea.

$(f)$ Gonococci. These are Gram-negative, and thus easily distinguished from staphylococci. The methylen blue stain does not allow us to distinguish between them. They usually occur in pairs, and are frequently found in the interior of the cells.

$(g)$ Micrococcus Catarrhalis. This is rarely met with, so that its presence is not likely to lead to a false diagnosis.

(h) Bacillus Pnenmonice Friedlaender. This is sometimes found in pus from the tear sac. It possesses a distinct capsule.

The reaction given by the Bacillus subtilis is not a constant one. Sometimes it is Gram-positive, at other times Gram-negative. This bacillus has becn found in cases of violent panophthalmitis.

\section{Staining of Gram-positive Micro-organisms in Sections.}

Celloidin sections.

Staining for 24 hours in filtered alum-carmine.

Staining on the slide for 25 seconds with anilin-water gentian-violet.

Washing in water, the section being kept on the slide by means of a needle or glass rod.

Treatment with Lugol's solution for 13 seconds.

Drying with filter paper.

A piece of dry filter paper is now laid on the specimen, and anilin oil is poured over it. This prevents shrinking and folding of the section. Further differentiation is carried out in anilin oil till blue clouds are no longer given off.

Xylol, changed 4 or 5 times. Balsam.

\section{Staining of Gram-negative Micro-organisms in Sections.}

Celloidin sections.

Staining by the method of Nicolle. 
The sections are left for $\frac{1}{2}-\mathrm{I}$ minute in the following solution:

Thionin, saturated solution in 50 per cent. alcohol $\quad \ldots \quad$ IO

$\begin{array}{llll}\text { Carbolic acid, I per cent. aqueous solution } & \ldots & \ldots & 100\end{array}$

Washing in water.

Differentiation for a short time in absolute alcohol. Oleum origani. Balsam.

\section{Staining of Spirochæta Pallida (Greeff and Flemming).}

\section{I.-IN FILMS.}

All crusts are removed from the surface of the ulcer; and the superficial laycrs of tissue are scraped away with a sharp spoon. When the bleeding has stopped, a slide is drawn over the raw surface. The film is then fixed in a mixture of alcohol and ether, and stained for twenty-four hours in Giemsa's solution (one drop of the stock solution to I c.cm. water.)

Leishman's method also gives good results. The stain is procured from Griibler, and dissolved in methyl-alcohol (0.15: 100). This is poured over the air-dried specimen. After one minute, the slide is placed in a vessel containing the same staining fluid diluted with three parts of water, and left there for twenty-four hours.

\section{2.-In Sections.}

Lev'aditi's Impregnation Method.-The pieces of tissue may be hardened in formalin, alcohol, or sublimate. A small piece is left for eight days in a $\mathbf{I}^{\cdot} 5$ per cent. solution of silver nitrate, at a temperature of $38^{\circ} \mathrm{C}$. It is then well washed in water, and next placed for 24 hours at the temperature of the room in the following solution:

$$
\begin{array}{lllllll}
\text { Pyrogallol } & \ldots & \ldots & \ldots & \ldots & \ldots & 4 \\
\text { Formalin... } & \ldots & \ldots & \ldots & \ldots & \cdots & 5 \\
\text { Distilled water } & \ldots & \ldots & \ldots & \ldots & \ldots & 100
\end{array}
$$

It is then washed, and imbedded in celloidin or paraffin.

3. Burri's Chinese Ink Method.-This is simple and effective, and exhibits the organisms unstained. After the crusts have been removed from a fresh pustule by mcans of cotton wool moistened with physiological salt solution, a Bier's suction glass is placed over the raw area and a loopful of the serum thus extracted is transferred to a clean slide, and rubbed up with a loopful of sterile water, and a loopful of Chinese ink. Since the ink may contain bacteria, it should be sterilised for several days in succession, and allowed to settle for several days.

4. The living and motile spirochæta is readily demonstrated, if a drop of serum is placed on a slide and examined in the dark field. The serum may be obtained in the manner just described, or by abrading the skin.

\section{Trachoma Corpuscles.}

\section{Greeff's Modification of Giensa's Methiod.}

In recent times Giemsa's method has been much employed to demonstrate the Chlamydozoa or trachoma corpuscles. The conjunctival secretion is taken with a platinum loop, and smeared on a slide in as thin a layer as possible.

The conjunctival epithelium is obtained by scraping the surface with the edge of a cover glass, and spreading out what is removed in the same manner as a blood preparation; or a specially constructed platino-iridium instrument 
(Fig. 6) may be used to remove the epithelium, and spread it out in a very thin layer on cover glasses. It is not advisable to spread the specimen by drawing one cover glass over another, nor to compress it by hard rubbing.

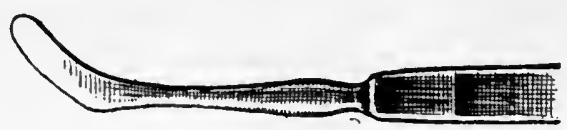

FIG. 6. Platino-iridium Scarificator.

The film is dried in the air, and fixed by immersion in absolute alcohol for 20-30 minutes. The cover-glass is then floated on the freshly prepared staining solution, film-side downwards, and cxposed to the action of the stain for $6-9$ hours.

The staining solution consists of :-

I. 'Twelve parts of Giemsa's eosin solution $(25 \mathrm{c} . \mathrm{cm}$. of a I per cent. solution of French eosin in $500 \mathrm{c} . \mathrm{cm}$. of distilled water, i.e., I to 20,000 eosin).

2. Three parts of a solution of azur I (I to I,000).

3. Three parts of azur II ( 0.8 to I,000).

These three solutions should be thoroughly mixed by vigorous shaking, filtered, and preferably raised to a tempcrature of $37^{\circ} \mathrm{C}$.

The scctions, after being treated with the stain for 5-9 hours at the above temperature, are rinsed in distilled water, dried well with blotting paper, and, without being heated over a flame, mounted in cedar oil. If the staining is carried out at a temperature of $56^{\circ} \mathrm{C}$., three hours suffice.

Hartmann recommends a wet fixation method, the cover-glasses being at once immersed in an alcoholic solution of corrosive sublimate for I-2 minutes; and then for a time in 50 per cent. alcohol.

Heidenhain's Iron-Hæmatoxylin Method may be employed instead of Giemsa's to demonstrate these corpuscles.

\section{Differentiation.}

The corpuscles stand out more clearly if the preparations are differentiated in an acid. The smears, after being treated with Giemsa's stain, are placed in absolute alcohol till they assume a blue colour, and are then, if necessary, exposed to a I per cent. solution of acetic acid (Lindner, Flemming).

\section{Demonstration in Sections.}

A fold of the conjunctiva is hardened in alcohol, and imbedded in paraffin. The paraffin is removed, and staining is carried out by Giemsa's or Heidenhain's method (4-5 hours). Washing in alcohol for 4-5 minutes. Mounting in cedar oil.

The corpuscles have hitherto been found in cases of trachoma and ophthalmia neonatorum. 




UPRDrus DEPA. MAY 241958

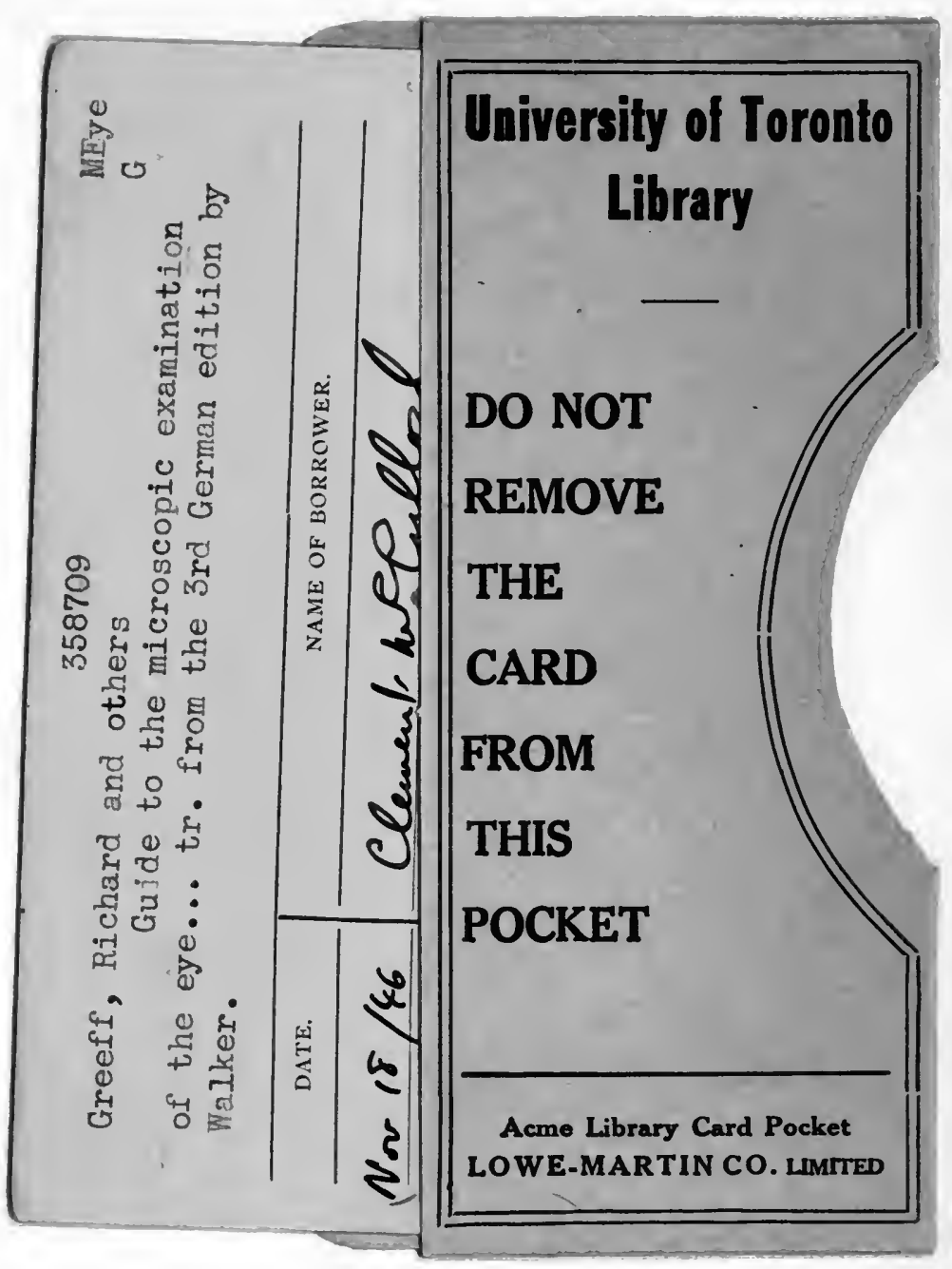


